\title{
VARIAÇÃO DA RESISTÊNCIA ELÉTRICA EM MADEIRAS VISANDO O GRUPAMENTO DE ESPÉCIES
}

\author{
Inês Cristina Martins Galina \\ Engenheira Florestal
}

Orientador: Prof. Dr. Ivaldo Pontes Jankowsky

Dissertação apresentada à Escola
Superior de Agricultura "Luiz de
Queiroz", da Universidade de São Paulo,
para obtenção do título de Mestre em
Ciências, Área de Concentração:
Ciência e Tecnologia de Madeiras

PIRACICABA

Estado de São Paulo - Brasil

Fevereiro - 1997 
Dados Internacionais de Catalogação na Publicação (CIP) DIVISÃo DE BIBLIOTECA E DOCUMENTAÇÃO - Campus "Luiz de Queiroz"/USP

\author{
Galina, Inês Cristina Martins \\ Variaçāo da resistência elétrica em madeiras visando o grupamento de espécies / \\ Inês Cristina Martins Galina. - - Piracicaba, 1997. \\ 93 p. : il. \\ Dissertação (mestrado) - - Escola Superior de Agricultura Luiz de Queiroz, 1999. \\ Bibliografia.
}

1. Física da madeira 2. Medidor elétrico de umidade 3. Resistência elétrica 4. Secagem da madeira 5. Tecnologia de madeira 6 . Teor de umidade 1 . Titulo

CDD 674.132 


\title{
VARIAÇÃO DA RESISTÊNCIA ELÉTRICA EM MADEIRAS VISANDO O GRUPAMENTO DE ESPÉCIES
}

\author{
INÊS CRISTINA MARTINS GALINA
}

Aprovado em: 09.05 .1997

Comissão julgadora:

Prof. Dr. Ivaldo Pontes Jankowsky

ESALQ/USP

Prof. Dr. José Otávio Brito ESALQ/USP

Prof. Dr. Ivan Tomaselli UFPR

Prof. Dr. IVALDO PONTES JANKOWSKY Orientador 
Aos meus pais Antonio e Nair, por

tudo que me possibilitaram, com tanto

amor, respeito, e compreensão

e a todos os meus amigos que sempre me deram força e apoio, nas horas difíceis 


\section{Agradecimentos}

- Ao Prof. Dr. Ivaldo Pontes Jankowsky, pela orientação, compreensão e paciência no decorrer deste trabalho;

- Ao Prof. José Luiz Stape pelo auxílio na análise estatística e interpretação dos resultados;

- Ao Laboratório de Anatomia e Identificação de Madeiras do IPT (Instituto de Pesquisas Tecnológicas), especialmente ao Dr João Peres Chimelo e Geraldo José Zenid, pela identificação das madeiras utilizadas;

- A todos os funcionários da Serraria da ESALQ/USP pelo apoio na preparação dos corpos de prova;

- A empresa Vector Engenharia de Automação Ltda pelo desenvolvimento do equipamento para execução do trabalho;

- A Indusparquet Ind. e Com. de Madeiras Ltda e a Ind. Madeireira Uliana Ltda pelo fornecimento de algumas madeiras nativas;

- A Companhia Melhoramentos de São Paulo Arbor pelo fornecimento das madeiras de coníferas;

- A CAF pelo fornecimento da madeira de Eucalipto

- A CAPES (Coordenadoria de Apoio à Pesquisa do Estado de São Paulo) pela concessão da bolsa de estudos;

- A FINEP pelo suporte financeiro no projeto "Desenvolvimento de controles computadorizados para secadores de madeira";

- A Lauro Piedade pela confecção dos desenhos; 
- A todos os meus colegas do curso de Ciência e Tecnologia da Madeira, que sempre me apoiaram e incentivaram,

- As pessoas que de uma forma ou outra colaboraram para a realização deste trabalho e tiveram seus nomes aqui omitidos;

Para todos os meus mais sinceros agradecimentos. 


\section{SUMÁRIO}

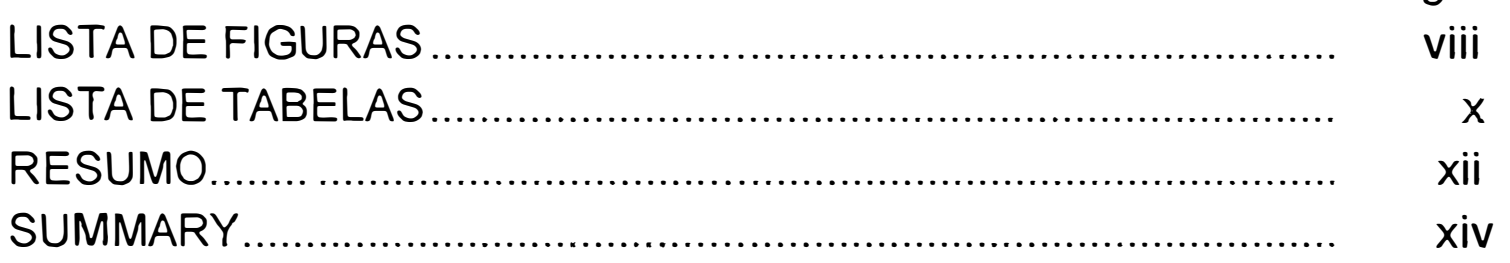

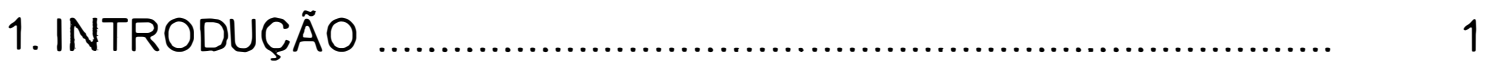

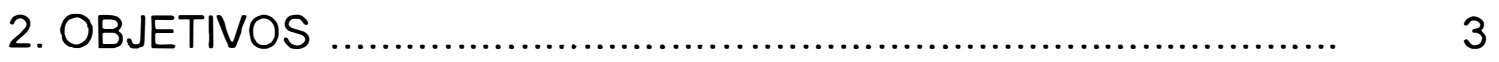

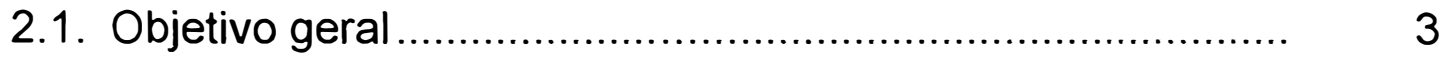

2.2. Objetivos específicos .............................................. 3

3. REVISÃO BIBLIOGRÁFICA ….............................................

3.1. Fluxo de água na madeira............................................... 5

3.2. Determinação do teor de umidade da madeira.................... 8

3.3. Medidores de umidade do tipo resistência ......................... 10

3.4. O processo de secagem convencional .............................. 14

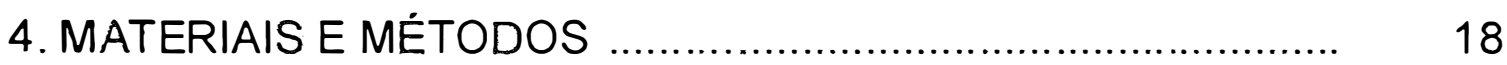

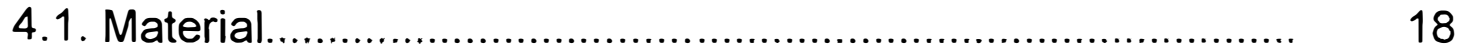

4.2. Preparação dos corpos de prova ......................................... 20

4.3. Estimativa da massa seca ............................................... 21

4.4. Determinação da densidade básica.................................. 22

4.5. Equipamento para medição da resistência elétrica ............ 22

4.6. Condução do experimento ............................................... 26

4.7. Análise estatística ........................................................ 27

5. RESULTADOS E DISCUSSÃO _............................................ 29

5.1. Relação entre a resistência elétrica e umidade ................... 29 
5.2. Interação entre a resistência elétrica e a densidade básica

5.3. Grupamento de espécies

6. CONCLUSÕES

58

ANEXO: Gráficos

60

REFERÊNCIAS BIBLIOGRÁFICAS 


\section{LISTA DE FIGURAS}

\section{FIGURAS}

1. Esquema mostrando a forma de retirada das amostras para medição da resistência elétrica, para determinação da umidade inicial e da densidade básica

2. Equipamento utilizado para medição da resistência elétrica.......

3. llustração da forma e do isolamento dos sensores, e dimensão em relação a espessura da amostra.

4. Disposição dos sensores nos corpos de prova, sentido paralelo e perpendicular a direção da grã.

5. Esquema da sequência experimental.

6. Correlação entre a resistência elétrica ( $R$ ) e o teor de umidade ( U ) para madeira de Jatobá.

7. Correlação entre a resistência elétrica $(R)$ e o teor de umidade ( U ) para madeira de Eucalyptus grandis.

8. Correlação entre a resistência elétrica ( $R$ ) e o teor de umidade ( U ) para madeira de Marfim

9. Correlação entre a resistência elétrica ( $R$ ) e o teor de umidade (U ) para madeira de Imbuia

10.Gradientes de umidade para madeiras com diferentes permeabilidades 
11. Relação entre a densidade básica e a resistência elétrica, no sentido perpendicular, calculada a $5 \%$ de umidade ...................

12. Relação entre a densidade básica e a resistência elétrica, no sentido perpendicular, calculada a $15 \%$ de umidade

13. Dendrograma da análise de Cluster 


\section{LISTA DE TABELAS}

TABELA

Página

1. Relação das espécies utilizadas.

2. Valores de resistência elétrica máximo e mínimo, e respectivos teores de umidade mínimo e máximo, medidos no sentido perpendicular à grã .

3. Valores de resistência elétrica máximo e mínimo, e respectivos teores de umidade mínimo e máximo, medidos no sentido paralelo à grã.

4. Resultado da análise de regressão, para os dois sentidos de medição.

5. Teste $t$ aplicado ao parâmetro $A$ da equação que relaciona a resistência elétrica com o teor de umidade, comparando os dois sentidos de medição.

6. Teste $t$ aplicado ao parâmetro $B$ da equação que relaciona a resistência elétrica com o teor de umidade, comparando os dois sentidos de medição

7. Resistência elétrica calculada para teores de umidade de $5 \%$ e $15 \%$.

8. Grupamento de espécies pela análise de Cluster, para os níveis 0,$0 ; 0,2 ; 0,3 ; 0,4 ; 0,5$.

9. Parâmetros $A$ e $B$ da equação que relaciona o teor de umidade com a resistência elétrica para os grupos formados após a análise de Cluster. 
10. Variação do desvio absoluto máximo para os grupos formados nos níveis 0,0 a 0,5 da distância Euclidiana.

11. Variação do desvio absoluto mínimo para os grupos formados nos níveis 0,0 a 0,5 da distância Euclidiana

52

12. Variação da soma dos quadrados dos desvios para os grupos formados nos níveis 0,0 a 0,5 da distância Euclidiana

53

13. Variação do quadrado médio dos desvios para os grupos formados nos níveis 0,0 a 0,5 da distância Euclidiana

14. Variação do coeficiente de determinação para os grupos formados nos níveis 0,0 a 0,5 da distância Euclidiana 


\title{
VARIAÇÃO DA RESISTÊNCIA ELÉTRICA EM MADEIRAS VISANDO O GRUPAMENTO DAS ESPÉCIES
}

\author{
Autor: Inês Cristina Martins Galina \\ Orientador: Prof. Dr. Ivaldo Pontes Jankowsky
}

\section{RESUMO}

Neste estudo foi analisada a variação da resistência elétrica em função do teor de umidade da madeira, com o objetivo de identificar e agrupar espécies com padrões similares de resposta.

Foi medida a resistência elétrica nos sentidos paralelo e perpendicular à grã, sendo que a estimativa mais precisa do teor de umidade foi obtida no sentido perpendicular.

Foram pesquisadas 27 espécies, entre coníferas e folhosas, com densidades que variaram de 0,335 a $0,928 \mathrm{~g} / \mathrm{cm}^{3}$. Nenhuma correlação foi obtida entre a densidade básica e a resistência elétrica da madeira 
confirmando, que o grupamento por densidade para correção da espécie não é o mais adequado.

A análise dos resultados mostrou que a medição da resistência elétrica para determinação do teor de umidade é válida para a faixa de 4 a $40 \%$.

O grupamento de espécies baseado na equação que relaciona a resistência elétrica com o teor de umidade $(\ln R=A+B U)$ é adequada, porém o número de grupos ou escalas de correção para espécie, irá depender da capacidade do medidor e da precisão desejada nas leituras do teor de umidade. 


\title{
VARIATION OF ELECTRICAL RESISTANCE IN WOOD SEEKING SPECIES GROUPING
}

\author{
Author: Inês Cristina Martins Galina \\ Adviser: Prof. Dr. Ivaldo Pontes Jankowsky
}

SUMMARY

The variation of the relationship between electrical resistance of wood and its moisture content was analysed to identify and to group species with similar relationship pattern.

Electrical resistance was measured in both perpendicular and parallel to grain direction. The more precise estimate of moisture content based on electrical resistance was obtained in the perpendicular to grain direction.

A total of 27 species including softwoods and hardwoods, with specific gravity ranging from 0.335 to $0.928 \mathrm{~g} / \mathrm{cm}^{3}$, were studied. The 
results showed a high relationship between wood electrical resistance and its moisture content in the range from 4 to $40 \% \mathrm{MC}$.

Although the wide range of specific gravity no relationship was found between this property and electrical resistance, confirming that species grouping based on specific gravity is not adequate to measure wood moisture content through its electrical resistance.

The grouping of species based on the equation which relates electrical resistance to moisture content ( $\ln R=a+b M C$, where $R$ is the electrical resistance and $\mathrm{MC}$ is the wood moisture content) is adequate. However, the number of groups will depend on the moisture meter capacity or the desired precision for measurements. 


\section{INTRODUÇÃO}

A secagem da madeira através de secadores permite grande redução no tempo, além de minimizar defeitos que ocorrem durante o processo.

A operação é baseada em um programa, onde a temperatura e a umidade relativa do ar no interior do secador são ajustadas de acordo com o teor de umidade da madeira. Dessa forma, é fundamental que esse teor seja determinado de maneira mais precisa e exata possivel.

O controle do processo é o aspecto que mais precisa de aprimoramento, pois é durante a secagem que deverão ser tomados os cuidados para se evitar grande ocorrência de defeitos, (Jankowsky, 1993)'.

Entre os métodos utilizados para a determinação do teor de umidade da madeira, o gravimétrico e o elétrico são os mais empregados, sendo o segundo método mais prático e eficiente, principalmente em secadores de grande porte.

O medidor elétrico permite a colocação de pontos de medição (sensores) em amostras distribuídas em locais estratégicos dentro do secador, visualizando-se desse modo o perfil da variação do teor de umidade da madeira em toda a carga, com leitura direta e imediata. Outra grande vantagem reside em não precisar abrir o secador para as medições, mantendo-se a estabilidade das condições climáticas internas.

A importância desse método fica mais evidente quando o objetivo é a automação no controle do processo, que requer um fluxo contínuo de informações referentes aos parâmetros e as variáveis do processo, (Wengert \& Denig, 1995).

1 Jankowsky, I. P. Curso de atualização em secagem de madeira. Piracicaba. 1993. 10p. 
Entre os medidores elétricos, o mais utilizado é o tipo resistência, que tem por princípio a relação existente entre a resistência elétrica e o teor de umidade da madeira. Uma das desvantagens é que a maioria dos medidores elétricos disponiveis no mercado são calibrados para coniferas, de composição química e estrutura anatômica muito mais simples que as folhosas tropicais, podendo ser uma fonte de erro na leitura da umidade.

As diferenças entre espécies se referem à localização, quantidade e movimentação da água de forma distinta, além de variaçōes na relação entre resistência elétrica e teor de umidade, (James, 1975).

No Brasil grande parte das madeiras comercializadas são folhosas provenientes da região tropical, para as quais os medidores elétricos tornam-se menos eficientes e precisos.

O grupamento de espécies de acordo com a resistência elétrica e o teor de umidade permitirá melhorar a precisão dos medidores elétricos do tipo resistência, bem como aprimorar o controle do processo através de sistemas automatizados. 


\section{OBJETIVOS}

\subsection{Objetivo Geral}

O presente trabalho visa primordialmente determinar padrões de variação da resistência elétrica da madeira em função do teor de umidade, para diferentes espécies utilizadas no mercado madeireiro, visando aprimorar o monitoramento da umidade durante o processo de secagem.

\subsection{Objetivos Especificos}

Entre os objetivos específicos, buscou-se, para as espécies estudadas:

- avaliar a variação da resistência elétrica em função do teor de umidade, identificando os padrões de comportamento;

- grupar as espécies que apresentam comportamentos similares;

- estudar a relação entre a resistência elétrica e a densidade básica da madeira;

- verificar o sentido de medição da resistência elétrica (perpendicular ou paralelo a direção das fibras) que permite melhor precisão na estimativa do teor de umidade da madeira. 


\section{REVISÃO DE LITERATURA}

O processo de secagem é considerado de extrema importância, pois quando bem conduzido, problemas e defeitos podem ser sanados ou minimizados, auxiliando os processamentos posteriores.

A secagem de madeiras consiste em fornecer energia (calor) para a madeira, de forma a promover a vaporização da água na superfície, e ao mesmo tempo, remover essa água que é vaporizada. Simultaneamente, deve ocorrer a movimentação da água presente nas partes internas até a superfície, mantendo um equilíbrio entre a quantidade de água que é evaporada e a que chega até a superfície.

Assim, controlar o processo implica em ajustar as condições internas do secador (temperatura e umidade relativa do ar), de acordo com o teor de umidade da madeira. A compatibilização das condições do meio de secagem com as caracteristícas da madeira é expressa pelo programa de secagem.

De acordo com Wengert \& Denig (1995) o futuro do desenvolvimento da secagem de madeiras em secadores será caracterizado pela utilização de controles computadorizados. O desenvolvimento de aplicativos (softwares) sofisticados, destinados a controlar o processo de secagem, resultarão em aumento de produtividade, (Jankowsky, 1996).

Para que se possa atingir esse nível tecnológico é necessário o conhecimento do fluxo de água na madeira e, principalmente, aprimorar métodos para a determinação do teor de umidade da madeira de forma contínua e com precisão. 


\subsection{Fluxo de água na madeira}

A madeira apresenta uma série de características, tais como a estrutura anatômica e as propriedades físicas e mecânicas, as quais tem profunda influência no processo de secagem, e indicam maior ou menor facilidade com que a água se move no seu interior, (Ponce \& Watai, 1985 e Simpson \& Baah, 1989).

Panshin \& De Zeeuw (1970), relatam que a madeira é uma substância higroscópica; ela tem afinidade por água em ambas as formas, a líquida e vapor. Essa habilidade da madeira para ganhar ou perder água é dependente da temperatura e umidade do meio atmosférico. Como consequência, a quantidade de umidade na madeira altera com as mudanças nas condições do meio circundante. Para utilizar a madeira como matéria prima é essencial conhecer o teor de umidade, e entender onde a umidade está localizada e como ela se move através da madeira.

A água na madeira pode existir em duas formas básicas: água higroscópica ou de adesão, localizada nas paredes das células, e a água capilar ou livre encontrada nas cavidades das células na forma líquida ou vapor, (Kollmann \& Côté, 1968; Skaar, 1972 e 1988 e Siau, 1971 e 1984).

Porém, a água encontrada na forma de vapor, nos seus capilares, pode ser quantitativamente desprezada, pela baixa densidade do vapor de água em relação à água higroscópica e capilar, (Galvão \& Jankowsky, 1985).

Com relação a quantidade de água, Skaar (1972) define o teor de umidade máximo da madeira, como a umidade na árvore no momento em que ela foi abatida. Esse autor afirma ainda, que estudos do teor de umidade máximo da madeira mostram consideráveis variações entre espécies de árvores, entre cerne e alburno na mesma árvore, e ainda entre troncos cortados de diferentes alturas da árvore. Existem também as variações de estação do ano e as variações entre árvores da mesma espécie.

Panshin \& De Zeeuw (1970) definem o teor de umidade como a quantidade total de água existente numa peça de madeira, expressa como uma porcentagem da massa seca em estufa. 
Ponce \& Watai (1985) relatam que a umidade da madeira recém cortada varia muito de acordo com a espécie, sendo que em algumas a umidade inicial situa-se em torno de $30 \%$, enquanto que outras chega a $200 \%$ ou mais.

Peck (1953) citado por Skaar (1972) mostra as variações encontradas na umidade máxima, a qual vai de $30 \%$ em cerne de Douglas-fir à $249 \%$ em alburno de Western red cedar. O alburno geralmente contém muito mais umidade (média de $149 \%$ ) do que o cerne (média de $55,4 \%$ ) no caso de coníferas; já em madeiras de folhosas, essa diferença não é muito grande, tendo o alburno em torno de $81,4 \%$ em média e $82,7 \%$ para o cerne.

Do mesmo modo com que a quantidade e a localização da água na madeira é diferente para coniferas e folhosas, o mesmo ocorre com a translocação.

A movimentação de líquidos nas madeiras se dá, obviamente, por meio dos elementos estruturais que desempenham a função de condução : os vasos nas angiospermas e os traqueídes axiais $e$ transversais nas gimnospermas, e os raios em ambas, (Burger \& Richter, 1991).

Quando a madeira seca, a água sai primeiro da cavidade da célula, tomando-se uma célula em particular, visto que as "forças de atração" dessa água são apreciavelmente menores do que aquelas "forças de atração" da água na parede da célula. O teor de umidade no qual a parede da célula está completamente saturada, mas a cavidade da célula está vazia de água liquida tem sido designado como o Ponto de Saturação das Fibras (PSF), segundo Tiemann (1906) citado por Skaar (1972).

Kollmann \& Côté (1968) afirmam que o movimento de água livre, acima do PSF, é causado por forças capilares e, abaixo do PSF a água aderida na forma de vapor move-se através das paredes das células devido ao gradiente de umidade estabelecido através das mesmas. Esse movimento é um fenômeno de difusão. O movimento da água abaixo do PSF ocorre também como difusão de vapor d'água na estrutura vazia, devido a um gradiente de pressão de vapor.

Segundo Kollmann \& Cótê (1968), o tecido das coníferas é mais simples do ponto de vista da variedade dos tipos de células. Além do parênquima nos raios, canais de resina e fibras longitudinais, somente um 
outro tipo de célula pode ser encontrada, o traqueide. Os longitudinais podem compor até $95 \%$ do volume total da madeira de algumas espécies.

Quanto ao fluxo longitudinal em coníferas, Siau (1971) informa que cerca de $93 \%$ do volume da madeira é constituido por traqueides axiais (dispostos longitudinalmente), e tendo estes um centro oco e geralmente vazio, os fluídos podem entrar no lume diretamente pelas extremidades afiladas $e$ fluir livremente na madeira através do comprimento dos traqueídes e passar para o lume dos traqueídes adjacentes através das pontoações areoladas onde as extremidades dos mesmos se sobrepõem. Cita também trabalho de Wardrop e Davies (1961) os quais concluíram que o cerne é menos permeável do que o alburno, e o lenho inicial também é menos permeável do que o lenho tardio, isto foi atribuído a maior fração de pontoações aspiradas em cerne e lenho inicial.

O fluxo de água nas folhosas mostra caminhos diferentes dos encontrados nas coniferas.

Nas folhosas os vasos podem perfazer de $5 \%$ a $60 \%$ do volume da madeira, e normalmente constituem o caminho longitudinal do fluxo de menor resistência. São elementos com extremidades abertas, a penetração de fluídos ao longo da grã de algumas madeiras de folhosas, é muito mais rápida e extensa do que para dentro (através dos raios) e das fibras que circundam os vasos, (Siau, 1971).

Pela baixa resistência ao fluxo das placas de perfuração nas extremidades dos vasos, eles se comportam como um tubo capilar aberto e comprido.

Tratando várias espécies de folhosas Behr et al (1969), citado por Siau (1971), afirmam não ter encontrado diferença significativa entre a penetração de água em fibras de lenho inicial e tardio, ao contrário dos resultados encontrados para coníferas. Nesse mesmo experimento, foi concluído que os raios das folhosas geralmente tem menor contribuição para o fluxo global que os de coniferas, apesar da média mais alta da fração volumétrica dos raios.

Hayashi e Nishimoto (1965) citados por Siau (1971) encontraram que a taxa de fluxo de água através do alburno foi maior do que através do cerne, e que essa taxa através de madeiras com anéis porosos também foi maior do que 
em madeiras com poros difusos. $E$ a presença de tiloses reduziu significativamente a permeabilidade da madeira.

Siau (1984) afirma ainda que o fluxo em folhosas é muito mais complexo e variável do que em madeira de coniferas.

\subsection{Determinação do teor de umidade da madeira}

Para a determinação do teor de umidade da madeira Kollmann \& Côté (1968), Skaar (1972 e 1988), Johnston (1970) e Huy (1985) apontam alguns métodos distintos, entre eles : estufa ou gravimétrico, destilação, titulação e medidores elétricos do tipo resistência e do tipo dielétrico.

Entre os métodos citados acima, o de titulação, e também de destilação, são utilizados apenas em procedimentos laboratoriais. Nas indústrias que secam madeira, os outros dois são mais práticos e usuais.

Pode-se dizer que o gravimétrico é de fácil execução, utilizando equipamentos simples, como uma estufa e uma balança de precisão.

Este método implica na pesagem da amostra úmida e sua secagem em estufa à $103^{\circ} \mathrm{C}( \pm 2)$ até alcançar massa constante. O teor de umidade é costumeiramente expresso como uma porcentagem da massa total, (Johnston, 1970). Ou pode ser expresso pela relação entre a massa da água e a massa da madeira seca à $103^{\circ} \mathrm{C}$, em porcentagem, (Galvão \& Jankowsky, 1985).

É considerado menos preciso para as madeiras com altos teores de resinas, óleos, gorduras ou materiais voláteis. Outra desvantagem está no fato da destruição da amostra e no longo periodo necessário para o conhecimento da umidade.

Dean (1970) lembra ainda que, quando o teor de umidade é determinado por esse método, amostras representativas das peças testadas devem ser preferencialmente escolhidas.

O método elétrico faz uso de propriedades elétricas da madeira, as quais dependem consideravelmente do teor de umidade. $O$ desenvolvimento dessa técnica tornou possivel a medição da umidade de forma ão destrutiva e rápida. Foi Stamm, em 1927, que demonstrou a possibilidade de medir a resistência a corrente contínua para estimar o teor de umidade da madeira. 
A partir disso, surgiu o medidor de umidade do tipo resistência, utilizado nos dias atuais, (Chen et al., 1994).

Segundo Kollmann \& Côté (1968), estes medidores, muito usados nas indústrias de madeira, estão disponíveis no mercado americano desde 1930.

Existem dois tipos principais de medidores elétricos, cada um operando de acordo com um princípio diferente. O mais simples e mais antigo é o medidor tipo resistência, que mede a resistência elétrica a corrente contínua (DC). O outro, é do tipo dielétrico, que trabalha com corrente alternada (AC).

O princípio utilizado no medidor de umidade do tipo resistência, é exatamente a resistência da madeira à passagem da corrente elétrica entre dois sensores (Moraes, 1988). A madeira age como um elemento de resistência em um circuito elétrico do medidor de umidade, (James, 1958).

Os medidores elétricos do tipo dielétricos são divididos em capacitância e perda de carga. O primeiro mede a constante dielétrica, e o segundo, um efeito combinado da constante dielétrica e a perda de carga. Esses medidores tem suas leituras afetadas pela densidade, temperatura, orientação da grã e a frequência da corrente, (Skaar, 1988).

Estudando a precisão de diferentes medidores, Milota (1996) e Milota \& Gupta (1996), afirmam que existem diferenças de leitura, nos medidores elétricos tipo capacitância, mesmo para espécies já calibradas anteriormente, devido a diferença de densidade básica utilizada pelo fabricante e a do experimento.

Quarles \& Milota (1991), que trabalharam com medidor de umidade de alta frequência e medidor de frequência dupla, encontraram que o modelo de regressão foi melhorado significativamente com a adição da variável densidade básica, principalmente para o medidor de alta frequência em linha.

Desenvolvendo novo trabalho com medidor de umidade tipo capacitância, para espécies com diferentes massas específicas, Milota (1994), buscou demonstrar que o peso específico realmente influencia as leituras do medidor de umidade. Utilizando a leitura do medidor elétrico versus teor de umidade, para 8 espécies diferentes, em uma regressão linear, o $r^{2}$ encontrado foi de 0,62 . Quando são usados valores de peso específico na regressão o $r^{2}$ aumentou para 0,89 . 


\subsection{Medidores de umidade do tipo resistência}

A madeira da mesma forma que outros materiais orgânicos e higroscópicos, é um condutor elétrico cuja resistência medida entre um par de eletrodos varia sensivelmente em função do teor de umidade, (Jankowsky \& Brienza, 1980).

Segundo Kyte (1970), os medidores elétricos consistem basicamente de um sistema de eletrodos, um amplificador para converter a corrente elétrica medida, e um sistema de leitura, usualmente um ohmímetro com uma escala adequadamente calibrada.

As propriedades elétricas da madeira são medidas em resistividade ou resistência, ou também pelo seu reciproco, a condutividade.

Muitos medidores tem uma leitura direta, relata James (1988), calibrados em porcentagem para uma espécie e com tabelas de correção para outras espécies. Simpson (1994), trabalhando com espécies tropicais, também afirma que o fator de correção para espécie é fundamental, seja na forma de tabela ou embutido no circuito do aparelho.

Ainda James (1964), comenta que os medidores fabricados nos Estados Unidos são comumente, mas não obrigatoriamente, calibrados para Douglas-fir (Pseudotsuga menziesii).

Moraes (1988), declara que os aparelhos utilizados em seu estudo, foram desenvolvidos em países que utilizam outras espécies de madeira, que não as tropicais brasileiras, e portanto, novas curvas de calibração precisam ser desenvolvidas.

Vermaas (1982c), reportou que os medidores de umidade são calibrados empiricamente em termos de resistência, pois são medidas entre sensores a uma distância e profundidade pré determinadas, com o teor de umidade uniforme no perfil e em temperatura única $\left(20^{\circ} \mathrm{C}\right)$.

Com relação a resistência em função da umidade, James (1958) relata que do $\mathrm{PSF}$ até a umidade próxima de $0 \%$, a resistência aumenta em um milhão de vezes. $E$ do PSF até a completa saturação das estruturas a resistência muda menos de 50 vezes.

Quando a madeira está bem seca ela é um excelente isolante, ou seja, um péssimo condutor. Nesse ponto a resistência elétrica é máxima, 
diminuindo com o aumento do teor de umidade (Kollmann \& Côté, 1968), variando de uns poucos quiloohms em madeira úmida a vários gigaohms em peças secas (Bittner \& Vanicek, 1992).

Em dois estudos diferentes, James (1958 e 1964) encontrou valores distintos de resistência para coníferas e folhosas. Em coniferas, o maior valor foi de 57.600 Mohm ( $7 \%$ de umidade) e o menor foi de 0,42 Mohm (25\%). Para - Eucalyptus saligna à $5 \%$ de umidade a resistência foi em torno de 120.000 Mohm e a $26 \%$ foi de 0,12 Mohm.

Vermaas (1982b), trabalhando com $P$. pinaster e $P$. radiata, descobriu que em baixos teores de umidade a correlação entre $\circ \log R$ e $\circ$ inverso da temperatura é curvilinear e não linear, como mencionam a maioria dos trabalhos publicados.

Lin (1965), em seu estudo para explicar o fenômeno de condução elétrica na madeira usou uma teoria modificada da condução eletrolítica em cristais iônicos, sendo que a madeira pode ser classificada como um polímero sólido. De acordo com esse modelo, o número de cargas conduzidas na madeira é o maior fator que afeta o mecanismo de condução, na faixa de umidade de $0 \%$ a $20 \%$. Em teores de umidade mais altos, o grau de dissociação de íons absorvidos é suficientemente alto de modo que a mobilidade dos íons pode tornar-se o maior fator.

Segundo Panshin \& De Zeeuw (1970), a madeira seca pode alcançar resistividades na ordem de $3 \times 10^{17}$ a $3 \times 10^{18}$ ohm-cm em temperatura ambiente. Em teores de $16 \%$ e próximo ao PSF ela diminui para $10^{8}$ e $10^{5}$ a $10^{6} \mathrm{ohm}-\mathrm{cm}$, respectivamente, na mesma temperatura.

Com relação ao teor de umidade James (1975 e 1988), encontrou que do PSF até $0 \%$, existe uma correlação muito grande entre o logaritmo da condutância e o logaritmo do teor de umidade. Acima do PSF até a completa saturação, essa correlação é extremamente pequena.

Desenvolvendo trabalho com madeiras brasileiras Jankowsky \& Galina (1996), obtiveram melhores resultados na leitura da umidade (inclusive acima do PSF), quando se utiliza uma combinação de duas equações diferentes, para teores acima e abaixo do PSF. 
De acordo com James (1958) e Dean (1970), os instrumentos são calibrados numa faixa entre $4 \%$ e $120 \%$, mas a leitura confiável está entre $7 \%$ e $25 \%$. Acima de $25 \%$ a precisão é muito reduzida, (Chen et al., 1994).

Segundo Galvão \& Jankowsky (1985) a resistência elétrica da madeira é inversamente proporcional ao seu teor de água, sendo que, de $30 \%$ até $0 \%$ de umidade, a resistência aumenta cerca de 1 milhão de vezes. Mallque et al. (1991), citando Kellog (1981) e Kollmann (1959), confirma que os valores de condutividade encontrados entre $6 \%$ e o PSF são da ordem de $10^{-10}$ a $10^{-4}$ $(\Omega-\mathrm{cm})^{-1}$.

Skaar (1988), afirma que com o aumento do teor de umidade, a resistividade é reduzida em cinco vezes para cada aumento percentual, numa faixa de $0 \%$ a $7 \%$. A partir de $7 \%$ a resistividade diminui a uma taxa de quatro a duas vezes para cada aumento percentual.

Os pesquisadores tem mostrado que as propriedades elétricas da madeira são afetadas por outros fatores, além do teor de umidade, também importantes, (James, 1994).

Outro fator que afeta a resistividade é a temperatura da madeira James (1968); James (1975 e 1988), citando Davidson (1958) e Vermaas (1982a), relatam que a resistência elétrica da madeira diminui com o aumento da temperatura. Em metais o efeito é oposto, sendo que quanto maior a temperatura, maior a resistência.

Clarck \& Williams (1933), citados por Salamon (1964), e Vermaas (1982a e 1982c), explicam que a variação da condutividade com a temperatura um resultado de íns livres e adsorvidos, sugerindo que o processo de condução é preferivelmente iônico do que eletrônico.

Os pesquisadores Pfaff \& Garrahan (1986), também desenvolveram tabelas de correção para temperaturas de $-29^{\circ} \mathrm{C}$ até $+49^{\circ} \mathrm{C}$, pois a umidade lida no medidor necessita dessa correção.

Baseado na equação de correção da temperatura desenvolvida por Pfaff e Garrahan (1986), Samueisson (1992) utilizou em seu trabalho a equação :

$$
U k=\frac{U+0,567-0,0260+0,000051(x)^{2}}{0,881(1,0056)^{x}}
$$


onde :

$U k=$ teor de umidade corrigido pela temperatura (\%);

$U$ = teor de umidade lido (\%);

$t=$ temperatura da madeira $\left({ }^{\circ} \mathrm{C}\right)$;

$x=t+2,8\left({ }^{\circ} \mathrm{C}\right)$.

Devido a influência da temperatura Skaar (1988), alerta para o fato de quando estimar a umidade através dos medidores elétricos, a temperatura da madeira deve ser conhecida, assim como o fator de correção da mesma.

Visualizando um outro aspecto, James (1958) encontrou que a resistência através da grã é levemente maior do que a medida ao longo da grã.

Kollmann \& Côté (1968), também notaram que a resistividade é afetada pela direção da grã. Eles encontraram que a resistividade ao longo da grã é metade da perpendicular, e na direção radial a resistividade é igual a $10 \%$ menos, do que na tangencial.

Stamm (1930), reporta que a condutividade longitudinal de 8 madeiras americanas foi 1,9 a 3,2 vezes maior do que na tangencial, (Skaar,1988).

Concordando com as afirmações anteriores Concha (1975), afirma que a corrente elétrica circula paralela à fibra, e portanto os sensores devem ser colocados na mesma direção. Afirma ainda que a diferença nas leituras (paralela e perpendicular) é mínima abaixo de 10\% de umidade, e aumenta com teores mais altos.

Os preservativos e a própria constituição química da madeira, em menor escala, também interferem nas propriedades elétricas. Vermaas (1983) citado por Skaar (1988), notou que as madeiras com mais altos teores de lignina tenderam a ter maiores condutividades.

Skaar (1988), afirma que extrativos não solúveis em água são tidos como redutores da condutividade da madeira, devido a serem péssimos condutores. Para os solúveis em água o efeito é oposto, pois podem conter complexos que incluem eletrólitos, aumentando a condutividade.

Neste sentido foi notado entre pesquisadores, que espécies de madeiras com alto teor de extrativos, que crescem em climas tropicais, 
mostraram maior diferença na determinação da umidade (método elétrico), do que espécies que crescem em climas temperados, (Skaar, 1988).

Estudos tentando correlacionar a densidade com a resistividade e/ou condutividade da madeira, tem apresentado resultados não consistentes para uma afirmação definitiva. Venkateswaran (1972) citado por Skaar (1988), atribui isso ao fato que os fatores citados anteriormente, como temperatura e composição química da madeira, são mais importantes.

Reforçando esta afirmativa, Vermaas (1982a), cita Keylwerth \& Noack (1956), que declararam que nenhuma correlação específica entre densidade e resistência foi encontrada. Ainda na mesma publicação Venkateswaran (1973) comenta que, em geral, nesse ponto nota-se uma diminuição da resistência com o aumento da densidade.

Num experimento utilizando 6 espécies da Amazônia Peruana, Mallque et al. (1991) concluiram que a resistividade elétrica, medida no sentido longitudinal, está diretamente relacionada com a densidade básica das espécies.

Um outro grupo de variáveis, extrínsecas a madeira, que afetam a resistência ou resistividade da madeira podem ser apontados, tais como tipos e configurações de eletrodos, pressão de contato, forma e dimensão da amostra, efeitos eletrolíticos em eletrodos, e a magnitude e duração da voltagem aplicada, (Vermaas, 1975, Skaar, 1988).

James (1986), explica que a configuração dos eletrodos influenciam a leitura do teor de umidade, devido ao gradiente de umidade existente na espessura da peça.

O tempo também é um fator que afeta os valores de leitura. Simpson (1994), encontrou melhores resultados ( $95 \%$ de confiança) nas leituras de umidade para medidores elétricos do tipo resistência, quando a leitura foi feita até 20 segundos após a instalação dos sensores, ou a aplicação da corrente.

\subsection{O processo de secagem convencional}

A secagem convencional de madeira (utiliza temperaturas que variam entre 40 e $90^{\circ} \mathrm{C}$ ), é um processo que envolve alterações contínuas nas condições climáticas internas do secador, de modo a otimizar o tempo 
dispendido na secagem e minimizar a incidência de defeitos decorrentes do processo, (Jankowsky, 1989 e Dreiner \& Welling, 1992).

Dreiner \& Welling (1992) afirmam que a secagem feita em secadores é controlada de acordo com um conjunto de valores definidos pelo programa de secagem, o qual apresenta valores de temperatura e umidade relativa que devem ser utilizados dentro do secador, em sequência, de modo que a alteração dos parâmetros deve ser compatível com a umidade da madeira, obtendo-se a maior velocidade com a menor porcentagem de defeitos.

De acordo com Galvão \& Jankowsky (1988), a umidade da madeira deve ser usada como referência para mudanças nas condições do secador, porque é a sua variação que determina o aparecimento de tensões internas nas peças, as quais são responsáveis por diversos defeitos de secagem.

Zeleniuc (1992) pesquisou duas maneiras de controle automático, usando tempo de secagem e teor de umidade como parâmetros para abastecer - sistema controlador do processo. Verificou que a segunda alternativa apresentou melhores resultados sobre as condições finais da umidade, com menor tempo.

O controle da umidade da madeira durante a secagem, pode ser feito através da colocação ou não de amostras de controle no meio da carga.

A umidade da madeira também pode ser monitorada sem a colocação de amostras de controle individuais, através dos métodos de célula de carga ou TDAL, os quais utilizam a carga no todo.

O método de célula de carga (load cell) é derivado do gravimétrico, porém é empregado na carga inteira. Este método também pode ser aplicado para amostras individuais, da mesma maneira que são colocados os sensores no método elétrico.

Este método é baseado na variação da massa de toda a carga da estufa ou de pequenas amostras; como é semelhante ao gravimétrico, necessita de preparação prévia da carga e de um pequeno laboratório, e pode ocorrer erros nas determinações do teor de umidade inicial nas espécies com altos teores de extrativos ou resinas.

O ponto positivo do método da célula de carga, reside no equilíbrio do ambiente interno da estufa, uma vez que não é preciso abrir a porta durante a secagem para fazer as pesagens. 
Como desvantagens pode-se citar o desconhecimento do perfil de umidade durante a secagem, necessitando de que a carga seja homogênea quanto a densidade e umidade inicial (para não afetar os cálculos do teor de umidade), além de exigir um alto investimento inicial em equipamentos, (Jankowsky, 1994 - comunicação pessoal).

Outra forma de se determinar o teor de umidade, sem amostras de controle, é o método baseado na diferença de temperatura do ar que entra e o que saí da carga. Esse método é conhecido como Temperature Drop Across the Load ou TDAL.

Segundo estatísticas americanas a madeira de Southern pine é quase totalmente seca em alta temperatura atualmente, e este é o método mais empregado para monitorar a perda de umidade durante a secagem, (Oliveira \& Wengert, 1984).

Como trabalha com a carga toda, não é possivel medir a variação no perfil e sua precisão reduz grandemente com a diminuição da umidade, devido as pequenas diferenças das temperaturas, de entrada e saída, nas fases finais da secagem.

Sendo que cada espécie reage de maneira diferente, alguns parâmetros devem ser fixados, para que os resultados sejam confiáveis, como a velocidade do ar, a temperatura de bulbo seco, a espécie, a densidade da madeira, e a largura da pilha.

Por outro lado, a condução do processo de secagem por meio de amostras de controle, apresenta os melhores resultados, principalmente, porque permite visualizar diferenças de umidade no perfil da carga.

A determinação da umidade pelo método gravimétrico, empregado em amostras individuais, limita não só a colocação das amostras na carga, como também não permite a automatização do controle do processo de secagem. Além disso, necessita a retirada das amostras para pesagem, não alimentando automaticamente o sistema.

O monitoramento automático do processo de secagem requer leituras frequentes de temperatura de bulbo seco e úmido, da umidade relativa do ar, e do teor de umidade da madeira. Nessas condições, a determinação da umidade da madeira deve ser feita através de medidor elétrico, (Santini, 1996). 
Segundo Little $(1991)^{2}$ praticamente qualquer aspecto da secagem pode ser controlado pelo computador. Existem formas de medir as muitas variáveis do processo, tomar decisões e alterar condições como, temperatura e umidade internas do secador. O uso do computador torna o controle mais preciso, requer menor atenção do operador e permite a alteração das condições internas baseado no teor de umidade médio das peças, medido por medidor elétrico, consequentemente com menor gasto de tempo e energia.

$\mathrm{Na}$ Universidade de Tennessee, Little et al. (1986) incrementaram a estufa experimental com um computador para controlar o sistema. Ao final do experimento, os pesquisadores notaram que as condições internas do secador mantiveram-se muito mais estáveis do que no sistema convencional, proporcionando uma economia no tempo da secagem e redução da mão de obra.

Jankowsky (1989) relata que esse controle pode ser feito de forma manual, semi automática ou totalmente automática. Quanto maior a automatização do processo, mais otimizado ele se torna, porém aumenta a necessidade de equipamentos mais sofisticados.

Wengert \& Denig (1995), afirmam que a utilização de sistemas controlados por computadores monitoram melhor o processo de secagem, caracterizando o futuro da secagem de madeiras.

2 Little, R.L. The use of microcomputer controls in hardwood drying. 1991. p. 82 a 85 Trabalho não publicado 


\section{MATERIAIS E MÉTODOS}

\subsection{Material}

Foram utilizadas 27 diferentes madeiras (listadas na Tabela 1), incluindo espécies provenientes de florestas naturais, e outras de reflorestamento. Das espécies reflorestadas foram utilizadas coníferas dos gêneros Pinus, Araucaria, Cryptomeria e Cunninghamia, e folhosas do gênero Eucalyptus. Entre as espécies nativas foram utilizadas madeiras tradicionais do mercado e outras menos conhecidas.

Todo o material foi adquirido na forma de tábuas, com dimensões variáveis, trabalhando-se com um mínimo de cinco e um máximo de 10 tábuas por espécie, dependendo da disponibilidade de material.

As folhosas tropicais foram cedidas por indústrias madeireiras ou compradas no mercado local, tomando-se o cuidado de coletar as tábuas de forma aleatória no estoque de cada fornecedor. A identificação desse material foi feita no Laboratório de Anatomia e Identificação de Madeiras da Divisão de Produtos Florestais do IPT.

O material proveniente de florestas plantadas foi fornecido por empresas reflorestadoras, a identificação das espécies foi feita apenas com base nos registros das próprias empresas. Desse material foi coletada uma tábua por tora, diretamente na serraria. 
Tabela 1 : Relação das espécies utilizadas.

\begin{tabular}{ll}
\hline Nome vulgar & Nome cientifico \\
\hline Angelim pedra & Folhosas nativas \\
Breu & Hymenolobium excelsum Ducke \\
Cedro & Protium sp \\
Cedrorana & Cedrela fissilis Vell. \\
Cerejeira & Cedrelinga catenaeformis Ducke \\
Cumaru & Amburana spp \\
Faveira vermelha & Dipteryx odorata (Aubl.) Willd \\
Freijó & Dimorphandra sp \\
Goiabão & Cordia goeldiana Huber \\
Guajará & Planchonella pachycarpa \\
Imbuia & Pouteria sp \\
Ipê & Ocotea porosa (Nees et Mort.) L. Barroso \\
Jatobá & Tabebuia sp \\
Louro vermelho & Hymenaea sp \\
Marfim & Nectandra rubra Mez \\
Marupá & Balfourodendron riedelianum Engler \\
Muiracatiara & Simarouba amara Aubl. \\
Pau amarelo & Astronium lecointei Ducke \\
Quarubarana & Euxylophora paraensis Huber \\
\hline & Erisma uncinatum Warm. \\
\hline Eucalipto & Folhosas exóticas \\
Eucalipto & Eucalyptus cloeziana F. Muell. \\
Eucalipto & Eucalyptus grandis Hill ex Maiden \\
Eucalipto & Eucalyptus nesophylla Blakely \\
\hline Pinheiro do Paraná & Eucalyptus phaeotricha \\
Criptomeria & Coniferas \\
Cunninghamia & Pinustomeria japonica D. Don \\
\hline & \\
\hline & \\
\hline & \\
\hline
\end{tabular}




\subsection{Preparação dos corpos de prova}

As tábuas foram inicialmente uniformizadas quanto a espessura $(1,5$ $\mathrm{cm})$ e a largura $(15 \mathrm{~cm})$, para o posterior corte das amostras conforme esquema da Figura 1.

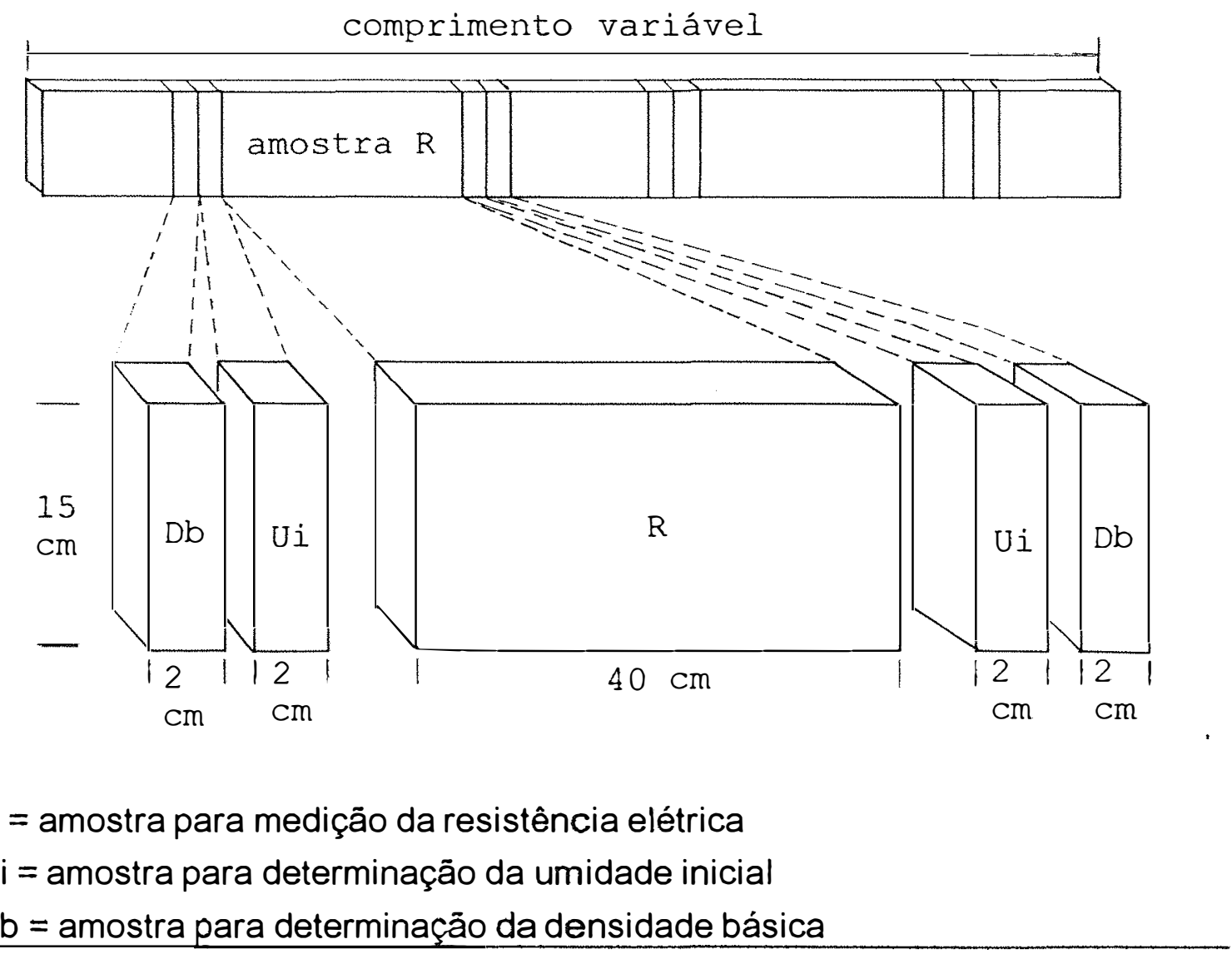

Figura 1 : Esquema mostrando a forma de retirada das amostras para medição da resistência elétrica, para determinação da umidade inicial e da densidade básica.

Logo após o corte, as amostras $\mathrm{R}$ e Ui foram pesadas, visando determinação da massa inicial úmida $\left(m_{\iota}\right)$. Em sequência, as amostras $R$ receberam uma camada de produto impermeabilizante nos topos, visando 
restringir a saída de água pelas extremidades e o consequente aparecimento de um gradiente de umidade no sentido do comprimento.

De cada espécie foram selecionadas 10 amostras para a medição da resistência elétrica, totalizando 270 corpos de prova.

\subsection{Estimativa da massa seca}

As amostras Ui foram submetidas a secagem a $103^{\circ} \mathrm{C}( \pm 2)$ até massa constante, obtendo-se assim a massa seca $\left(m_{s}\right)$.

Com base nos valores de massa úmida e seca obtidos, tem-se a umidade inicial ( $\left.U_{i}\right)$ base seca, de acordo com a equação 1.

$$
U i=\left(\frac{m_{u}-m_{s}}{m_{s}}\right) \times 100
$$

onde:

$m_{u} \Rightarrow$ massa úmida da amostra lateral, $\mathrm{g}$

$m_{s} \Rightarrow$ massa seca da amostra lateral, $\mathrm{g}$

$U i \Rightarrow$ umidade inicial estimada da amostra lateral, \%

Uma vez que as amostras $\mathrm{R}$ e Ui são pareadas, considerou-se que a umidade inicial da amostra $\mathrm{R}$ é igual a média das umidades iniciais das amostras Ui correspondentes. Essa metodologia é tradicionalmente usada na preparação de amostras de controle (Rasmussen, 1961).

A partir dos valores de $m_{u}$ e Ui de cada uma das amostras $R$, foi estimada a respectiva massa seca $\left(m_{s e}\right)$, de acordo com a equação 2.

$$
m_{s e}=\frac{m_{u} \times 100}{U i+100}
$$

onde : 
$m_{s e} \Rightarrow$ massa seca estimada do corpo de prova, $g$

$m_{u} \Rightarrow$ massa úmida do corpo de prova, $\mathrm{g}$

$U i \Rightarrow$ umidade inicial (média das amostras laterais), \%

A massa seca estimada permite o acompanhamento da perda de umidade dos corpos de prova e o encerramento do experimento.

Com o objetivo de minimizar diferenças nos teores de umidade, as amostras $R$ e Ui foram processadas concomitantemente.

\subsection{Determinação da densidade básica}

A densidade básica, usando as amostras $\mathrm{Db}$, foi determinada segundo o método da balança hidrostática, conforme a norma ABCP (M 14/70).

O método consta da imersão das amostras em água até completa saturação, determinação das massas imersa em água $\left(m_{i}\right)$, e úmida $\left(m_{u}\right)$, secagem a $103^{\circ} \mathrm{C}( \pm 2)$ e determinação da massa seca $\left(m_{s}\right)$. O cálculo da densidade básica é feito de acordo com a equação 3 .

$$
D b=\frac{m_{s}}{m_{u}-m_{i}}
$$

onde :

$D b \Rightarrow$ densidade básica, $\mathrm{g} / \mathrm{cm}^{3}$

$m_{s} \Rightarrow$ massa seca, $\mathrm{g}$

$m_{u} \Rightarrow$ massa úmida, $\mathrm{g}$

$m_{i} \Rightarrow$ massa imersa em água, $\mathrm{g}$

\subsection{Equipamento para medição da resistência elétrica}

O equipamento usado na medição da resistência elétrica foi especialmente desenvolvido pela empresa Vector Eng. de Automação Ltda. 
Consta de um multímetro especial (com capacidade para medir a resistência elétrica em uma faixa bastante ampla), microprocessado, e acoplado a um computador do tipo PC. O software, também especialmente desenvolvido, executa a análise e transformação do sinal emitido pelo multímetro e permite o interfaceamento com o monitor para visualização e registro dos resultados.

O equipamento (ilustrado na Figura 2) trabalhou com voltagem constante de 12 volts em corrente contínua. A configuração final do conjunto permitiu medições de resistência elétrica da madeira muito mais estáveis $\theta$ precisas em comparação a um multímetro comum.

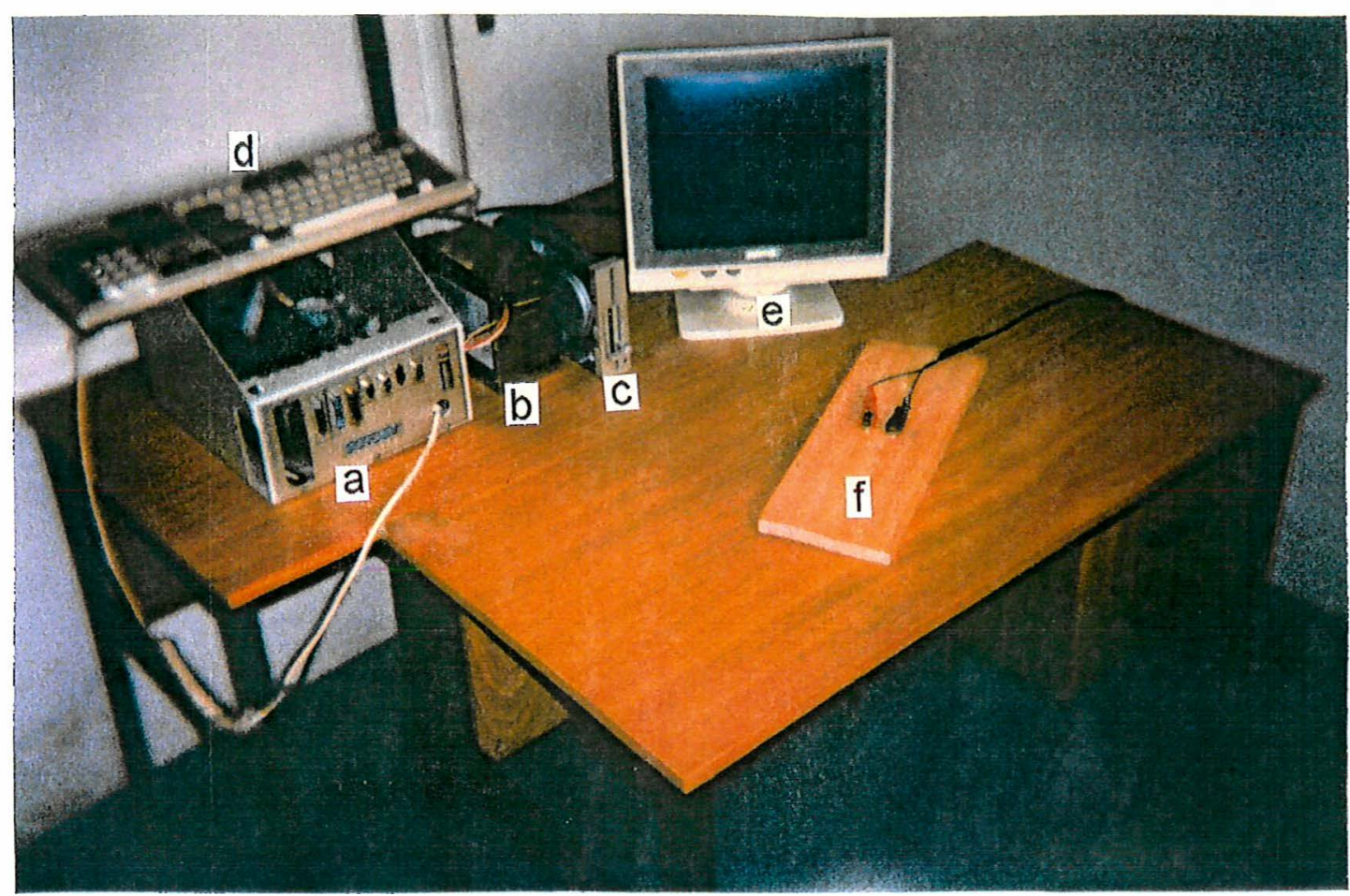

Figura 2 : Equipamento utilizado para medição da resistência elétrica

$$
\begin{aligned}
& a=\text { CPU e multimetro } \\
& b=\text { fonte de energia } \\
& c=\text { drive }
\end{aligned}
$$$$
d=\text { teclado }
$$$$
e=\text { monitor }
$$$$
f=\text { corpo de prova }
$$ 
Como o aparelho não inverte o sentido da corrente elétrica, as leituras foram feitas entre cinco e 10 segundos após a aplicação da corrente, período em que a leitura permanece estável.

O software do sistema incluiu uma compensação para a variação da temperatura ambiente. Essa compensação tem como base a equação para correção da umidade em função da temperatura apresentada por Samuelsson (1992), padronizando as leituras para $20^{\circ} \mathrm{C}$ de temperatura. A compensação da temperatura foi feita de acordo com a equação 4 .

$$
U k=\frac{U+0,567-0,0260+0,000051(x)^{2}}{0,881(1,0056)^{x}}
$$

onde :

Uk $\Rightarrow$ teor de umidade corrigido pela temperatura, \%

$U \Rightarrow$ teor de umidade lido, \%

$t \quad \Rightarrow$ temperatura da madeira, ${ }^{\circ} \mathrm{C}$

$x \quad \Rightarrow t+2,8,{ }^{\circ} \mathrm{C}$

Para propiciar a passagem da corrente elétrica no interior das amostras foram usados sensores de aço inox. Para assegurar que a resistência elétrica estava sendo medida no centro da amostra (em relação a espessura), foi aplicada uma camada de tinta epóxi na parte intermediária do sensor, deixando apenas a extremidade livre para a passagem da corrente elétrica. A Figura 3 ilustra o sensor utilizado. 

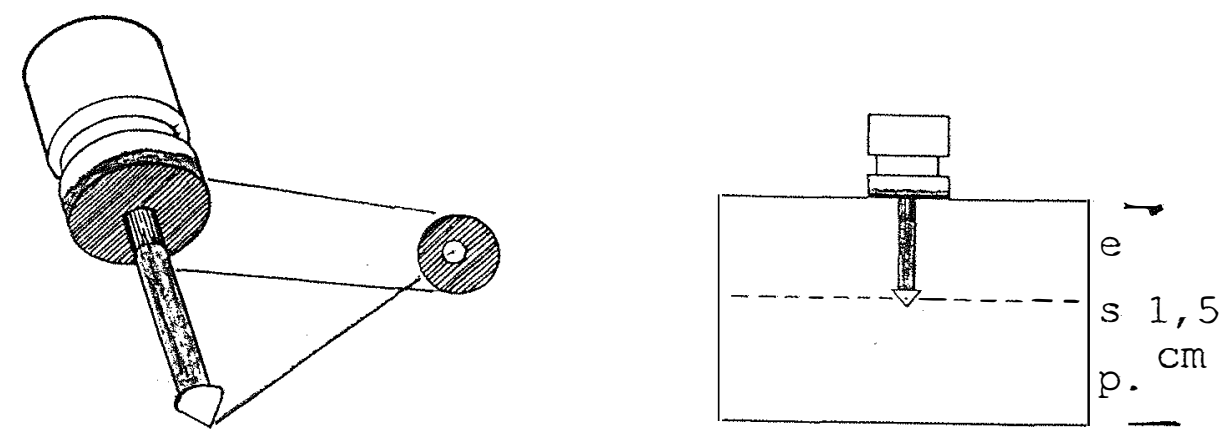

Figura 3 : llustração da forma e do isolamento do sensor, e dimensão em relação a espessura da amostra

Os sensores foram cravados nas amostras mantendo $3,0 \mathrm{~cm}$ de distância entre eles, acompanhando os sentidos paralelo e perpendicular em relação a grã. O posicionamento dos sensores é visualizado na Figura 4.

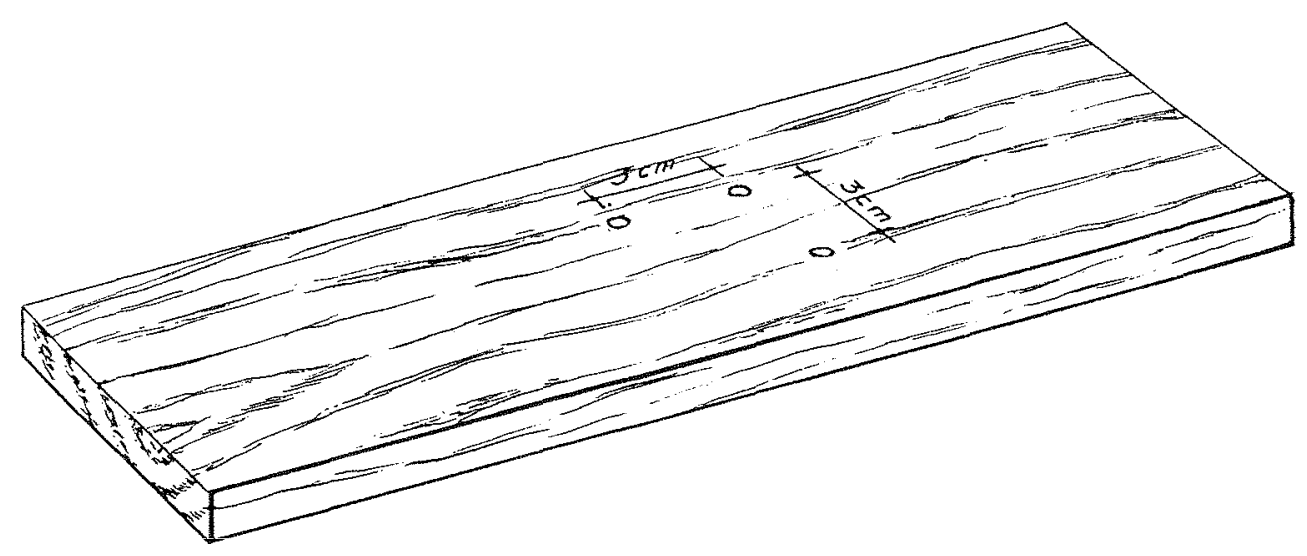

Figura 4 : Disposição dos sensores nos corpos de prova, sentido paralelo e perpendicular a direção da grã 
A conexão dos sensores com o multímetro foi feita com cabos isolados em silicone e conectores do tipo jacaré.

\subsection{Condução do experimento}

O esquema básico da condução do ensaio é apresentado na Figura 5. Após a preparação inicial (corte, pesagem, impermeabilização e colocação dos sensores), as amostras foram submetidas a um ciclo de secagens e medições, até que o teor de umidade fosse igual ou inferior a $8 \%$, esse valor foi determinado em função da sensibilidade do aparelho à leitura da resistência, abaixo de $8 \%$ a resistência é muito alta para a maioria das espécies.

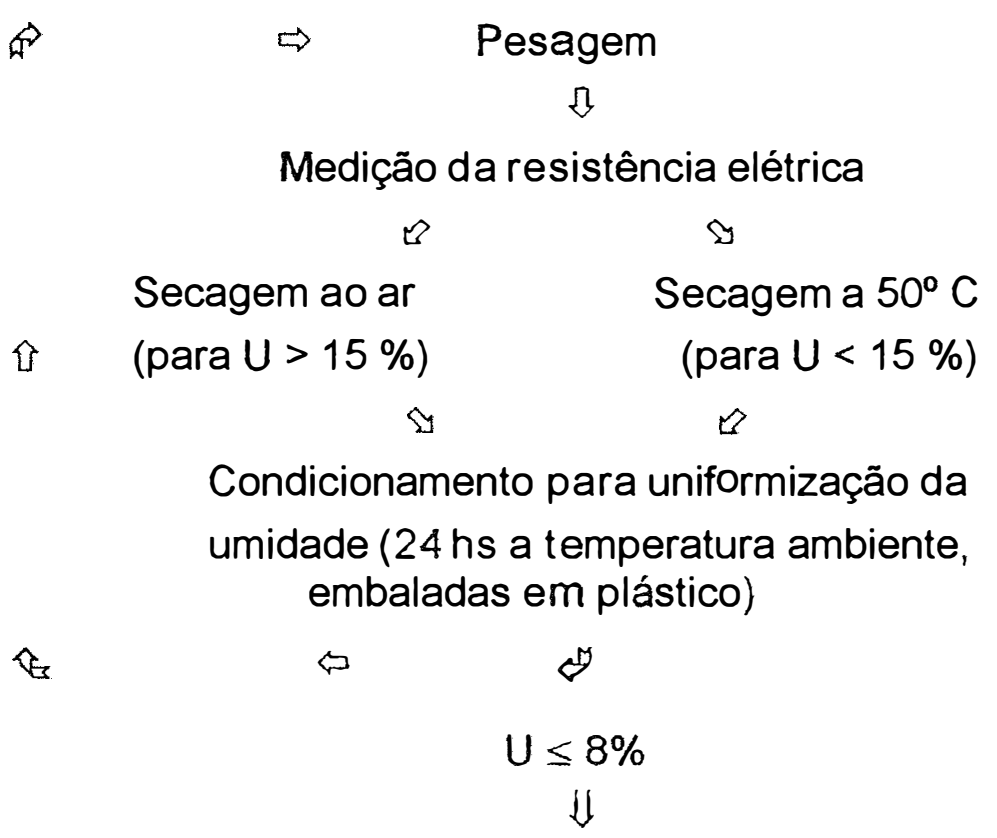

Secagem a $103^{\circ} \mathrm{C}( \pm 2)$

até massa constante

Figura 5: Esquema da sequência experimental 
Esse ciclo consistiu de :

- pesagem das amostras, para determinação da massa úmida corrente;

- medição da resistência elétrica, nos sentidos paralelo e perpendicular a grã;

- secagem ao ar se a umidade era superior a $15 \%$, substituido pela secagem a $50^{\circ} \mathrm{C}$, em estufa de laboratório sem circulação forçada de ar quando a umidade era inferior a $15 \%$. O periodo de secagem variou de 24 a 72 horas ao ar e de 2 a 5 horas em estufa, dependendo da facilidade de secagem da espécie em questão e do teor de umidade em si;

- condicionamento por 24 horas, embalada em plástico, visando eliminar o gradiente de umidade no sentido da espesura.

Atingido um teor de umidade igual ou inferior a $8 \%$, os sensores foram retirados e as amostras foram secas a $103^{\circ} \mathrm{C}( \pm 2)$ até massa constante (massa seca real).

Os sensores também foram pesados para corrigir os valores de massa úmida corrente, os quais permitiram calcular o teor de umidade das amostras ao longo do ensaio, usando a equação 5.

$$
U c=\left(\frac{m_{u c}-m_{s}}{m_{s}}\right) * 100
$$

onde :

$U_{c} \Rightarrow$ umidade corrente do ensaio, \%

$m_{u c} \Rightarrow$ massa úmida corrente (corrigida), $\mathrm{g}$

$m_{s} \Rightarrow$ massa seca real, $\mathrm{g}$

\subsection{Análise estatística}

Aos resultados de umidade e resistência elétrica por espécie, nos sentidos paralelo e perpendicular, foi aplicada análise de regressão simples. 
Dos modelos previamente avaliados, foi escolhido o modelo logarítmico, com equação geral do tipo :

$$
\ln y=A+B x
$$

onde :

y $\quad \Rightarrow$ variável dependente

$\mathrm{x} \quad \Rightarrow$ variável independente

$\mathrm{A}$ e $\mathrm{B} \Rightarrow$ parâmetros da equação obtidos da análise de regressão

Os parâmetros A e B para os sentidos paralelo e perpendicular foram comparados entre si através do teste $t$, visando verificar a diferença no sentido de medição.

O grupamento de espécies foi obtido com o auxílio da análise de Cluster. Este tipo de análise permite identificar grupos de espécies com comportamento similar quanto a correlação entre o teor de umidade e a resistência elétrica.

Como a análise de Cluster grupa as espécies em niveis adimensionais (distância Euclidiana), a escolha do nível final para grupamento teve como base a variação no coeficiente de determinação $\left(r^{2}\right)$ e na soma do quadrado dos desvios (SQD). 


\section{RESULTADOS E DISCUSSÕES}

5.1. Relação entre resistência elétrica e umidade

Os valores mínimo e máximo da resistência elétrica para as 27 espécies estudadas, com os respectivos teores de umidade, são apresentados na Tabela 2, para as medições no sentido perpendicular, e na Tabela 3 para o sentido paralelo à grã.

Os resultados da análise de regressão simples correlacionando o teor de umidade $(U)$ com a resistência elétrica $(R)$, nos dois sentidos estruturais, podem ser avaliados na Tabela 4.

Dentre os modelos previamente estudados o modelo logarítmico com a equação geral In $R=A+B(U)$, foi o que possibilitou o melhor ajuste dos dados experimentais. Esse ajuste já era esperado, pois diversos autores, dentre eles Samuelsson (1992), Vermaas (1982) e James (1964), já haviam confirmado que os modelos logarítmico e exponencial são os mais adequados para expressar essa relação.

Os gráficos individuais de cada espécie, mostrando a dispersão dos pontos experimentais, podem ser examinados no Anexo. As Figuras 6 a 9 ilustram a variação e as diferenças observadas entre as espécies.

A dispersão dos valores da resistência elétrica em função do teor de umidade variou entre as espécies. A Figura 6, para a madeira de Jatobá, ilustra uma situação de dispersão reduzida, com um bom ajuste dos resultados experimentais ao modelo. Já a Figura 9 ilustra a situação inversa, onde a madeira de Imbuia apresentou a maior amplitude de dispersão do experimento. 
Tabela 2 : Valores de resistência elétrica máximo e minímo, e respectivos teores de umidade mínimo (Umin) e máximo (Umax), medidos no sentido perpendicular à gră.

\begin{tabular}{|c|c|c|c|c|}
\hline Espécie & $\overline{R \min \left(x 10^{3} \mathrm{k} \Omega\right)}$ & $U \max (\%)$ & $\operatorname{Rmax}\left(x 10^{6} \mathrm{k} \Omega\right)$ & $\operatorname{Umin}(\%)$ \\
\hline Angelim pedra & 1,34 & 24,43 & 16,84 & 8,42 \\
\hline Breu & 1,47 & 22,61 & 71,01 & 6,88 \\
\hline Cedro & 1,40 & 25,17 & 12,60 & 11,00 \\
\hline Cedrorana & 1,54 & 24,77 & 5,10 & 9,92 \\
\hline Cerejeira & 1,52 & 24,41 & 113,79 & 8,37 \\
\hline Cryptomeria & 1,50 & 22,16 & 8,91 & 10,60 \\
\hline Cumaru & 1,39 & 36,28 & 11,14 & 7,94 \\
\hline Cunninghamia & 1,95 & 40,34 & 42,11 & 9,57 \\
\hline E. cloeziana & 1,74 & 30,56 & 17,65 & 5,61 \\
\hline E. grandis & 1,52 & 29,65 & 7,40 & 8,52 \\
\hline E. nesophylla & 1,49 & 30,88 & 23,83 & 7,45 \\
\hline E. phaeotrycha & 1,47 & 32,00 & 15,89 & 9,16 \\
\hline Faveira vermelha & 1,46 & 12,02 & 20,09 & 3,59 \\
\hline Freijó & 1,45 & 21,88 & 71,00 & 7,82 \\
\hline Goiabão & 1,43 & 19,62 & 23,42 & 5,63 \\
\hline Guajará & 1,44 & 25,43 & 28,97 & 6,64 \\
\hline Imbuia & 1,54 & 25,64 & 77,53 & 5,62 \\
\hline Ipê & 1,54 & 20,22 & 10,89 & 8,95 \\
\hline Jatobá & 1,39 & 20,54 & 52,23 & 6,59 \\
\hline Louro vermelho & 1,52 & 31,24 & 39,82 & 7,96 \\
\hline Marfim & 1,40 & 31,83 & 20,38 & 7,83 \\
\hline Marupá & 1,50 & 20,90 & 53,83 & 7,60 \\
\hline Muiracatiara & 1,52 & 26,69 & 24,67 & 9,42 \\
\hline Pau amarelo & 15,04 & 15,90 & 31,13 & 6,55 \\
\hline Pinheiro do Paraná & 2,14 & 24,26 & 48,39 & 8,75 \\
\hline Pinus patula & 1,49 & 29,72 & 26,71 & 9,21 \\
\hline Quarubarana & 1,59 & 22,35 & 16,56 & 8,69 \\
\hline
\end{tabular}


Tabela 3 : Valores de resistência elétrica máximo e minímo, e respectivos teores de umidade mínimo (Umin) e máximo (Umax), medidos no sentido paralelo à grã.

\begin{tabular}{|c|c|c|c|c|}
\hline Espécie & $\operatorname{Rmin}\left(x 10^{3} \mathrm{k} \Omega\right)$ & $\overline{U m a x}(\%)$ & $R \max \left(x 10^{6} \mathrm{k} \Omega\right)$ & $\operatorname{Umin}(\%)$ \\
\hline Angelim pedra & 1,34 & 24,43 & 22,11 & 8,42 \\
\hline Breu & 1,45 & 22,61 & 36,00 & 6,88 \\
\hline Cedro & 1,40 & 25,17 & 7,53 & 10,98 \\
\hline Cedrorana & 1,54 & 24,77 & 3,58 & 9,92 \\
\hline Cerejeira & 1,52 & 24,41 & 76,70 & 8,37 \\
\hline Cryptomeria & 1,50 & 22,16 & 12,19 & 10,60 \\
\hline Cumaru & 1,54 & 36,28 & 91,90 & 7,94 \\
\hline Cunninghamia & 1,77 & 40,34 & 23,86 & 9,57 \\
\hline E. cloeziana & 1,84 & 30,56 & 14,40 & 5,61 \\
\hline E. grandis & 1,52 & 29,65 & 7,40 & 8,52 \\
\hline E. nesophylla & 1,59 & 30,88 & 35,79 & 7,45 \\
\hline E. phaeotrycha & 1,47 & 32,00 & 20,79 & 9,16 \\
\hline Faveira vermelha & 1,46 & 12,02 & 17,47 & 3,59 \\
\hline Freijó & 1,43 & 21,88 & 65,71 & 7,82 \\
\hline Goiabão & 1,43 & 19,62 & 159,07 & 5,63 \\
\hline Guajará & 1,46 & 25,43 & 48,43 & 6,64 \\
\hline Imbuia & 1,54 & 25,64 & 40,10 & 5,53 \\
\hline Ipê & 1,54 & 20,22 & 8,40 & 8,95 \\
\hline Jatobá & 1,39 & 20,54 & 33,47 & 6,59 \\
\hline Louro vermelho & 1,52 & 31,24 & 18,68 & 7,96 \\
\hline Marfim & 1,54 & 31,83 & 20,38 & 7,83 \\
\hline Marupá & 1,50 & 20,90 & 46,60 & 7,60 \\
\hline Muiracatiara & 1,66 & 26,69 & 18,88 & 9,42 \\
\hline Pau amarelo & 12,52 & 15,90 & 33,47 & 6,55 \\
\hline Pinheiro do Paraná & 2,04 & 24,26 & 38,66 & 8,75 \\
\hline Pinus patula & 1,49 & 29,72 & 20,09 & 9,21 \\
\hline Quarubarana & 1,59 & 22,35 & 15,52 & 8,69 \\
\hline
\end{tabular}


Tabela 4: Resultado da análise de regressão, para os dois sentidos de medição.

\begin{tabular}{|c|c|c|c|c|c|c|c|}
\hline \multirow[t]{2}{*}{ Espécie } & \multicolumn{3}{|c|}{ Perpendicular } & \multicolumn{3}{|c|}{ Paralelo } & \multirow[t]{2}{*}{$\mathrm{N}$} \\
\hline & $A$ & $\mathrm{~B}$ & $r^{2}$ & $\bar{A}$ & $B$ & $r^{2}$ & \\
\hline Angelim pedra & 15,5832 & $-0,7434$ & 0,9121 & $\overline{15,4724}$ & $-0,7353$ & 0,8687 & 79 \\
\hline Breu & 11,8255 & $-0,5761$ & $\mid 0,8638$ & 12,0577 & $-0,5825$ & 0,8862 & 83 \\
\hline Cedro & 15,4507 & $-0,6432$ & $|0,9315|$ & 14,9956 & $-0,6291$ & 0,9234 & 72 \\
\hline Cedrorana & 12,7430 & $-0,5685$ & $|0,8684|$ & 12,2101 & $-0,5473$ & 0,8387 & 77 \\
\hline Cerejeira & 17,6672 & $-0,8811$ & $|0,8705|$ & 17,4403 & $-0,8799$ & 0,8746 & 40 \\
\hline Cryptomeria & 15,3350 & $-0,7337$ & $|0,8961|$ & 14,7856 & $-0,7163$ & 0,8121 & 57 \\
\hline Cumaru & 9,2395 & $-0,3568$ & $\mid 0,6029$ & 9,2971 & $-0,3598$ & 0,5539 & 70 \\
\hline Cunninghamia & 13,5666 & $-0,5156$ & $|0,7944|$ & 13,1868 & $-0,5092$ & 0,7486 & 57 \\
\hline E. cloeziana & 11,4150 & $-0,5150$ & $|0,8712|$ & 11,4509 & $\mid-0,5174$ & 0,8667 & 71 \\
\hline E. grandis & 11,4590 & $-0,4744$ & $\mid 0,8920$ & 11,4055 & $-0,4808$ & 0,8874 & $\overline{149}$ \\
\hline E. nesophylla & 11,8547 & $-0,4794$ & 0,8478 & 12,1318 & $-0,4973$ & 0,8419 & $\overline{113}$ \\
\hline E. phaeotrycha & 11,3918 & $-0,4753$ & 0,8233 & 11,1135 & $-0,4669$ & 0,8142 & 110 \\
\hline Faveira vermelha & 13,8274 & $-1,2033$ & 0,9346 & 13,5867 & $-1,1924$ & 0,9157 & 65 \\
\hline Freijó & 14,1493 & $-0,6959$ & 0,9358 & 14,2500 & $-0,6973$ & 0,9364 & 102 \\
\hline Goiabão & 12,3331 & $-0,6906$ & 0,8723 & 12,1684 & $\mid-0,6874$ & 0,8693 & 126 \\
\hline Guajará & 9,9033 & $-0,4117$ & 0,7014 & 9,8290 & $-0,4154$ & 0,6623 & 69 \\
\hline Imbuia & 13,2702 & $-0,6695$ & 0,7997 & 11,0704 & $-0,5858$ & 0,6414 & 112 \\
\hline Ipê & 14,9287 & $-0,7835$ & 0,8419 & 14,7493 & $-0,7797$ & 0,8651 & 60 \\
\hline Jatobá & 13,3480 & $-0,7542$ & $\mid 0,8679$ & 13,2628 & $-0,7571$ & 0,8461 & 93 \\
\hline Louro vermelho & 12,9745 & $-0,5870$ & $\mid 0,8486$ & 12,7645 & $-0,5806$ & 0,8347 & 105 \\
\hline Marfim & 13,1950 & $-0,5341$ & $\mid 0,8979$ & 13,2016 & $-0,5407$ & 0,8807 & 118 \\
\hline Marupá & 16,4187 & $-0,8406$ & 0,9650 & 15,7063 & $-0,7917$ & 0,9464 & 47 \\
\hline Muiracatiara & 14,9686 & $-0,6053$ & 0,9332 & 14,4047 & $-0,5822$ & 0,9069 & 104 \\
\hline Pau amarelo & 13,9681 & $-0,6475$ & 0,9415 & 13,7740 & $-0,6397$ & 0,9074 & 85 \\
\hline Pinheiro do Paraná & 16,8104 & $-0,7332$ & 0,9566 & 16,3049 & $-0,7108$ & 0,9549 & 83 \\
\hline Pinus patula & 16,1403 & $-0,6912$ & 0,8598 & 15,7487 & $\mid-0,6688$ & 0,8688 & 56 \\
\hline Quarubarana & 15,7063 & $-0,8413$ & 0,9098 & 15,2948 & $-0,8205$ & 0,9077 & 99 \\
\hline
\end{tabular}

$A$ e $B=$ parâmetros da equação $(\ln R=A+B U)$

$r^{2}=$ coeficiente de determinação

$\mathrm{N}=$ número de leituras feitas 


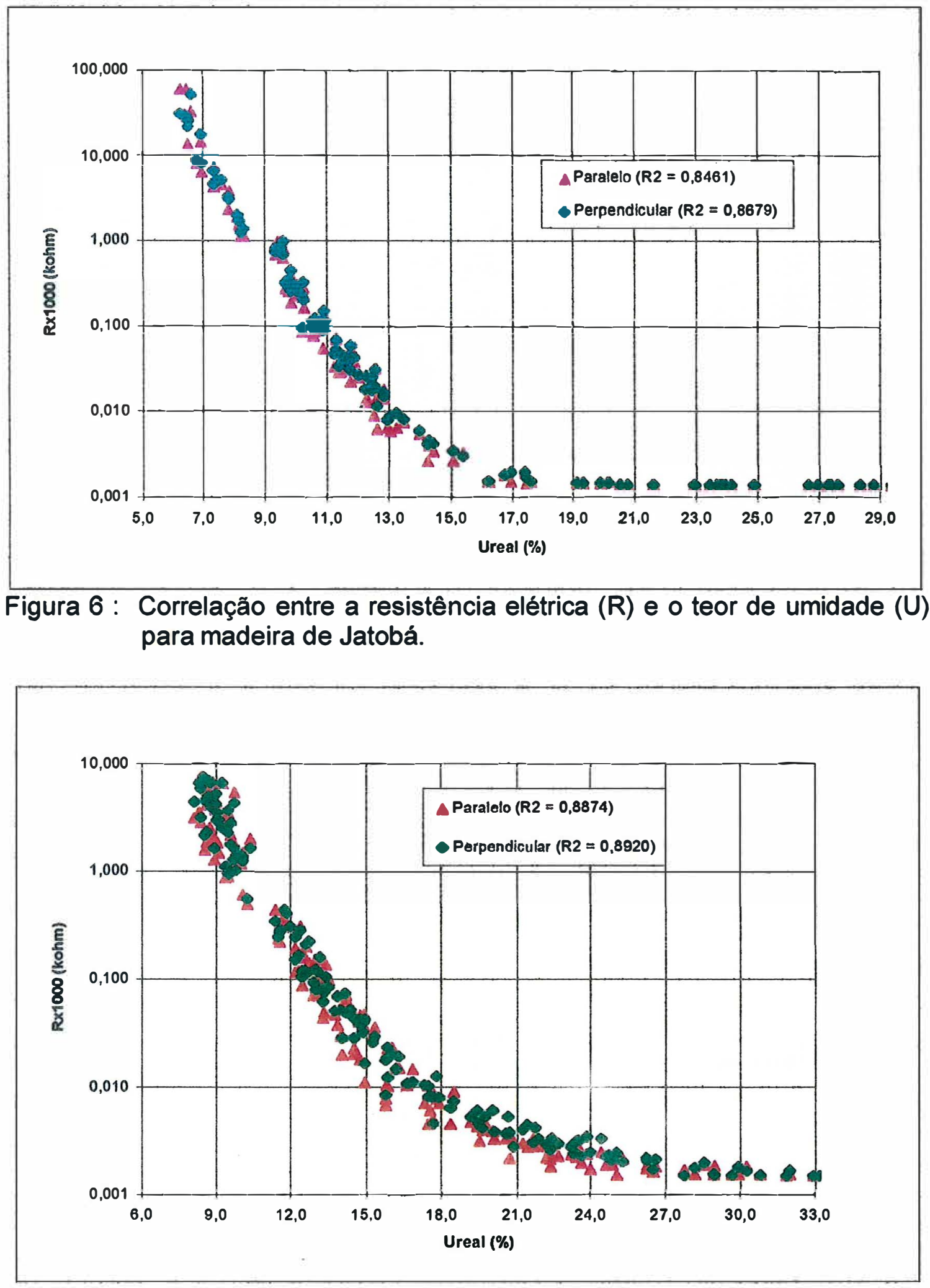

Figura 7 : Correlação entre a resistência elétrica $(R)$ e o teor de umidade (U) para madeira de Eucalyptus grandis. 


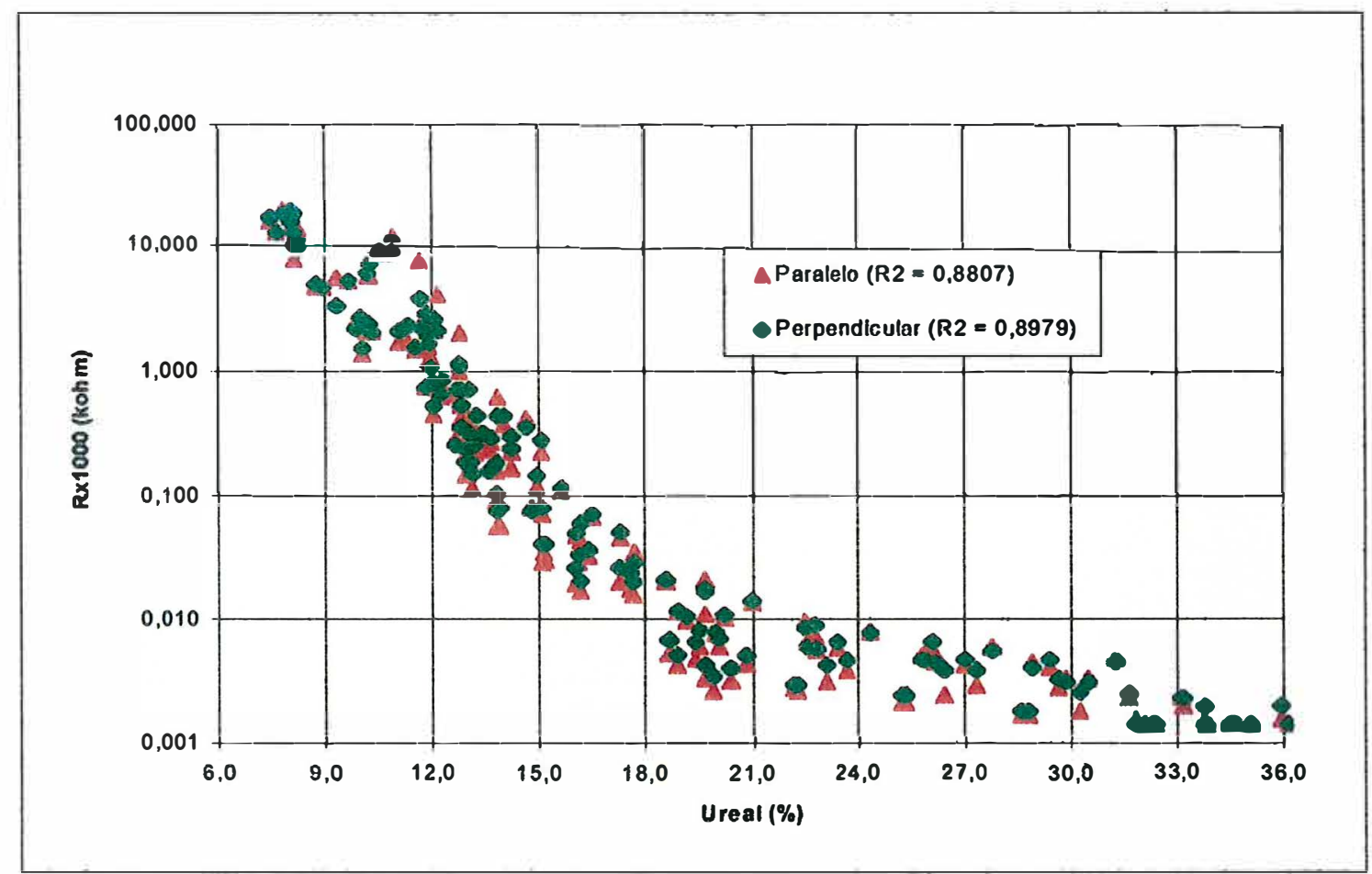

Figura 8: Correlação entre a resistência elétrica $(R)$ e o teor de umidade (U) para madeira de Marfim.

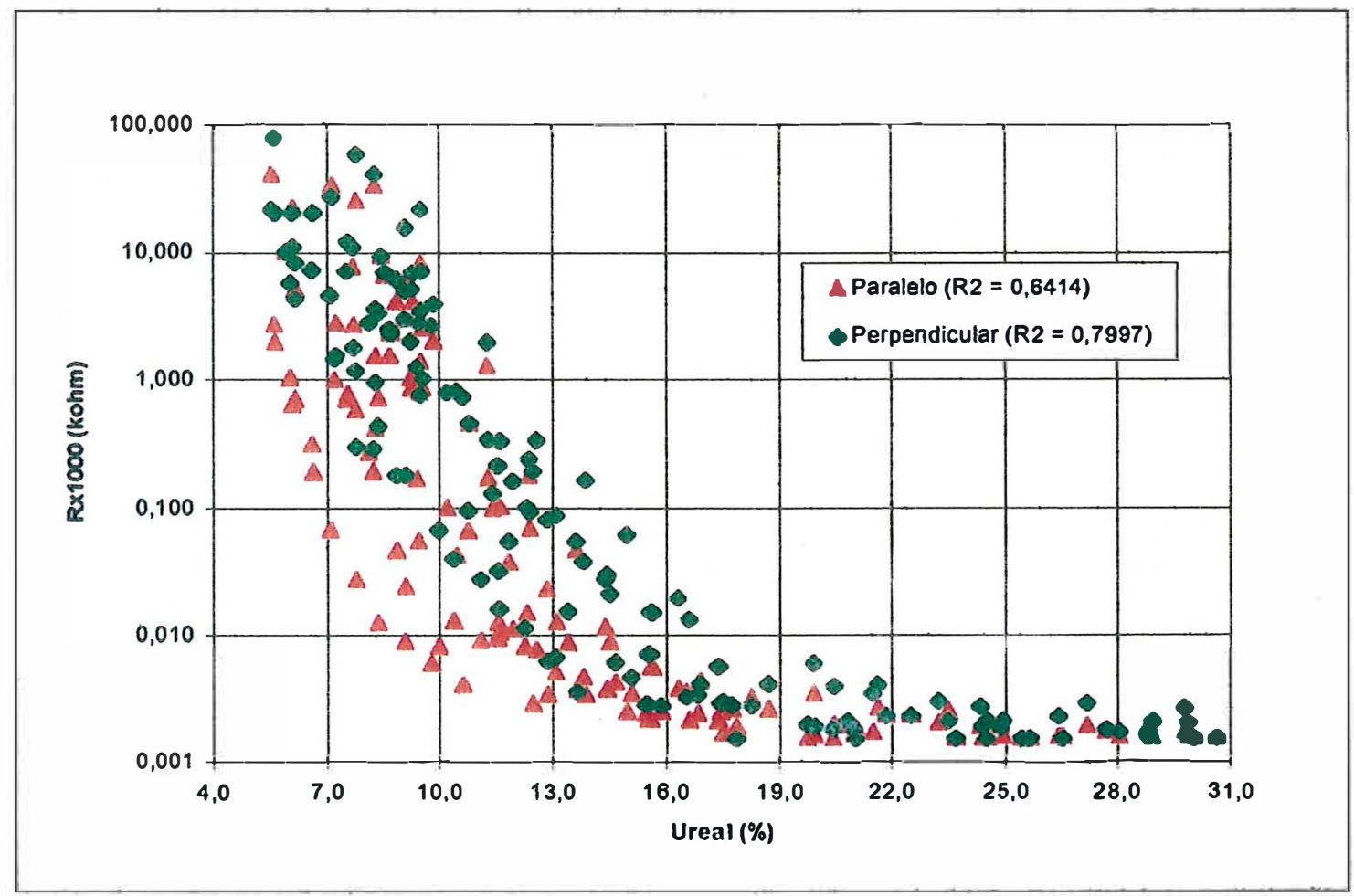

Figura 9: Correlação entre a resistência elétrica (R) e o teor de umidade (U) para madeira de Imbuia. 
Dispersões intermediárias são ilustradas nas Figuras 7 e 8 . Esta amplitude da dispersão representa o comportamento da maioria das espécies desse estudo, conforme pode ser comprovado pelo exame dos gráficos apresentados nos Anexos.

Tanto a dispersão dos valores experimentais em relação a curva média, como as diferenças de comportamento observadas entre as espécies, podem ser resultantes da posição dos sensores ou das variações químicas e anatômicas da madeira.

O fluxo da água no interior da madeira, principalmente acima do PSF (ponto de saturação das fibras), é dependente da estrutura anatômica da madeira. Durante a secagem forma-se um gradiente de umidade no sentido da espessura da peça de madeira, predominando um gradiente de forma parabólica, como pode ser observado na Figura 10-B, (Galvão \& Jankowsky, 1985).

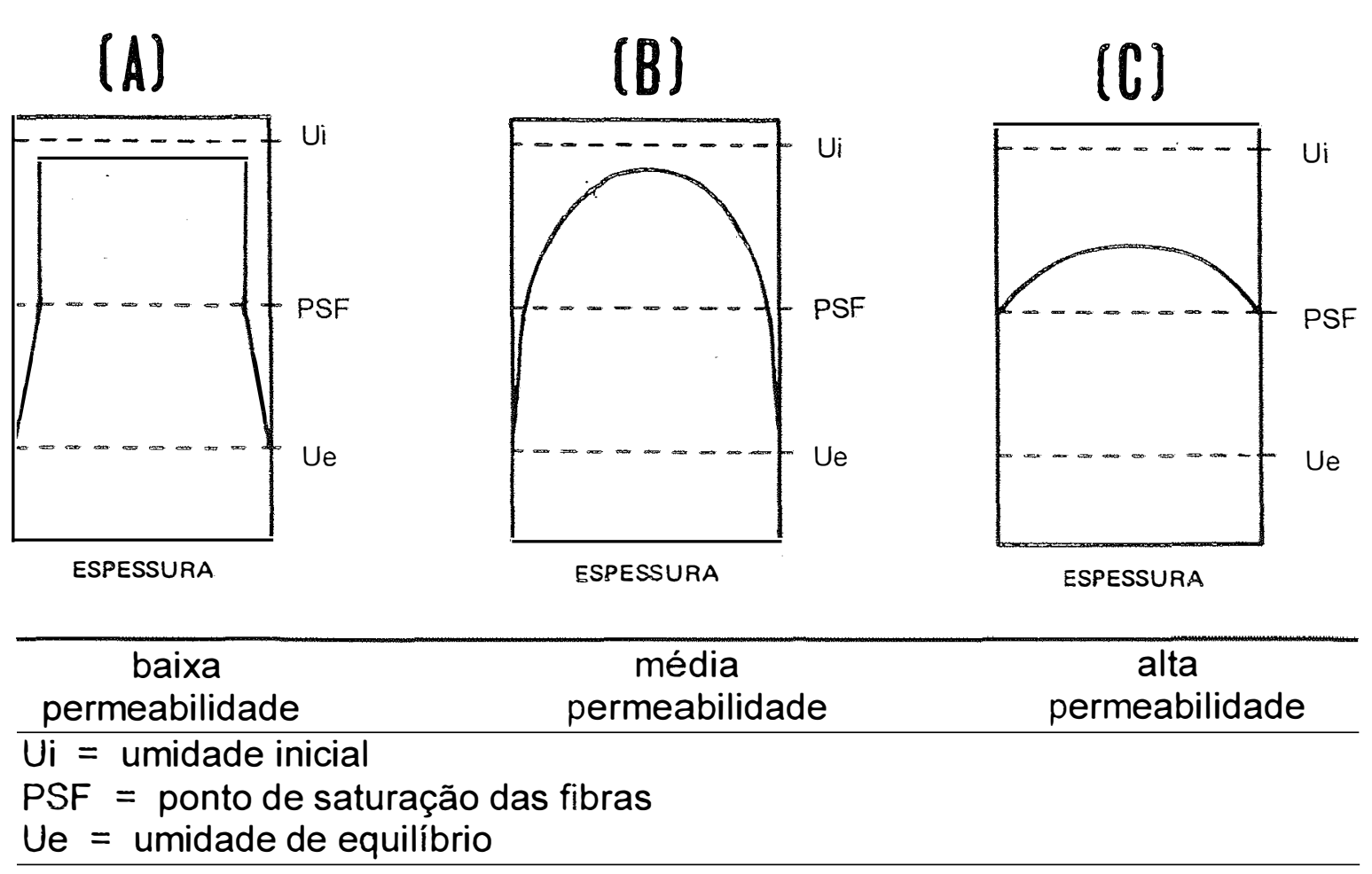

Figura 10: Gradientes de umidade para madeiras com diferentes permeabilidades. 
Para amenizar o efeito do gradiente de umidade é recomendado colocar os sensores a uma profundidade entre $1 / 4$ e 1/3 da espessura (Skaar,1972), porém neste estudo os sensores tiveram sua ponta colocada no centro da espessura da peça, visto que a metodologia adotada previa um periodo de condicionamento para minimizar esse efeito.

Os sensores foram colocados e fixados no centro do corpo de prova, fazendo a leitura em um único ponto da peça, mas a determinação da umidade foi feita pelo método gravimétrico, o qual expressa a umidade média da peça. Por isso, essas duas formas de medir a umidade podem apresentar grandes diferenças, principalmente para amostras que desenvolvem acentuado gradiente de umidade, como mostrado na Figura 10-A.

Outra hipótese provável para explicar a dispersão está relacionada com a composição química das madeiras. Cada espécie apresenta uma composição química própria, com íons de maior e menor mobilidade, que irá influenciar a resistência a passagem da corrente elétrica.

O Eucalyptus grandis e o Eucalyptus cloeziana, apresentam dispersão pequena, mostrando homogeneidade do material. Como são espécies que passaram por intenso melhoramento genético, provavelmente de árvores provenientes de uma mesma floresta, devem apresentar grande semelhança na estrutura anatômica e composição quimica. Para as espécies Eucalyptus nesophylla e Eucalyptus phaeotricha, a amplitude de dispersão já se mostrou maior, provavelmente pela menor intervenção na variabilidade do material.

Para espécies provenientes de reflorestamentos a explicação acima pode ser plausivel, mas para as madeiras nativas, o que pode melhor explicar a amplitude de dispersão é a procedência da madeira. Como a madeira foi adquirida de maneira aleatória, pode ter ocorrido casos em que os corpos de prova foram confeccionados a partir de árvores procedentes de sítios diferentes.

As madeiras oriundas de regiões geográficas distintas podem ter sua composição quimica alterada, por efeito do sítio, causando respostas variadas de resistência elétrica ao mesmo teor de umidade. 
Um exemplo típico da hipótese mencionada é o Cumaru, em que a forma de dispersão dos pontos no gráfico dá a impressão de existirem duas curvas distintas. A Imbuia também apresenta uma larga faixa de variação na dispersão dos pontos, sem dar a impressão de duas curvas.

No entanto, algumas espécies nativas como o Breu, o Freijó, o Goiabão, o Jatobá e o Marupá, apresentaram uma amplitude de dispersão muito pequena. Nesses casos, apesar da madeira ter sido adquirida de forma casualizada, existe a probabilidade das amostras terem sido feitas a partir de árvores muito próximas, ou até mesmo ser de uma única árvore.

Esses resultados comprovam que determinar o teor de umidade da madeira a partir da sua resistência elétrica deve levar em consideração as caracteristícas próprias de cada espécie de madeira, de forma a se obter respostas confiáveis.

Um outro aspecto a ser destacado é o teor de umidade a partir do qual a resistência elétrica passa a ser constante. A diminuição da sensibilidade do aparelho para leituras de resistência elétrica em faixas mais úmidas, também pode ser verificado nas Figuras 6 a 9 .

Pelo fato do medidor ter sido construído para medições em faixas de menor umidade (portanto, de maior resistência), para todas as espécies estudadas a resistência mínima é da ordem de $1,5 \times 10^{3} \mathrm{kohm}$. A exceção foi a madeira de Pau amarelo (resistência mínima de $15,0 \times 10^{3} \mathrm{kohm}$ no sentido perpendicular), cujo resultado foi decorrente da madeira já estar parcialmente seca (umidade máxima de 15,9\%) no início do ensaio.

Observou-se que o início de estabilização da curva (perda de sensibilidade do aparelho) ocorreu a teores de umidade entre 19,0 e 40,0 \%. Essa diferença entre espécies pode ter ocorrido em função de diferenças no PSF ou pela impermeabilidade ao fluxo de água capilar.

Essa perda de sensibilidade por parte dos aparelhos é bastante divulgado em trabalhos publicados por Vermaas(1982b), Panshin e De Zeeuw(1970) e James(1958 e 1964). Este último pesquisador afirma que encontrou uma correlação muito alta entre o logaritmo da condutância e o do 
teor de umidade, para umidades entre $0 \%$ e o PSF, porém acima do PSF até a completa saturação, a correlação é extremamente pobre.

O PSF é uma caracteristíca que varia entre espécies. Embora se considere $28 \%$ como um valor médio aplicado genericamente a todas as espécies, o valor real pode variar de 25 a $32 \%$ (Siau, 1988), existindo citações de que madeiras tropicais, com alto conteúdo de extrativos, podem ter um PSF abaixo dessa faixa (Kolmann \& Côté, 1968).

Uma vez que a resistência elétrica tende a ser constante com a umidade acima do PSF, consequentemente $\circ$ medidor elétrico não tem sensibilidade para baixos valores de resistência.

Apesar de predominar o gradiente de umidade ilustrado pela Figura 10-B (média permeabilidade), as madeiras impermeáveis (Figura 10-A) podem apresentar um alto gradiente de umidade. Nesses casos, a leitura feita pelo medidor elétrico indica um teor de umidade maior que o determinado pelo método gravimétrico, como mostrou a Faveira vermelha.

Para melhorar a exatidão das determinações do teor de umidade da madeira baseado na sua resistência elétrica, é necessário que o aparelho seja manufaturado de forma a medir também baixos valores de resistência, além de levar em consideração a formação de gradientes de umidade, que pode variar a sua forma em diferentes espécies de madeira.

Outro aspecto importante a ser discutido é o sentido de medição da resistência elétrica. As referências encontradas na literatura normalmente apontam valores maiores de resistência no sentido perpendicular, do que no paralelo.

Essas diferenças podem ser pequenas, como afirma James (1958), ou mais acentuadas segundo Kollmann \& Côté (1968), que afirmam que a resistividade paralela a grã é metade da obtida perpendicularmente.

Contudo, a literatura não menciona qual o melhor sentido de leitura de resistência elétrica, ou seja, qual o sentido estrutural que resultará em melhor exatidão na determinação da umidade. 
Complementando as informaçōes da Tabela 4 (análise de regressão), as Tabelas 5 e 6 apresentam os resultados do teste $t$, aplicados aos parâmetros $A$ e $B$, comparando os sentidos perpendicular e paralelo a grã. 
Tabela 5 : Teste $t$ aplicado ao parâmetro $A$ da equação que relaciona a resistência elétrica com o teor de umidade, comparando os sentidos de medição.

\begin{tabular}{|c|c|c|c|c|c|c|}
\hline \multirow{3}{*}{ Espécie } & \multicolumn{6}{|c|}{ Sentido de medição } \\
\hline & \multirow{2}{*}{$\frac{\text { Paralelo }}{\mathrm{A}}$} & \multicolumn{5}{|c|}{ Perpendicular } \\
\hline & & A & $s A$ & t calc & Sig. & $\bar{N}$ \\
\hline Angelim pedra & 15,4724 & 15,5832 & 0,3561 & 0,31 & n.s. & 79 \\
\hline Breu & 12,0577 & 11,8255 & 0,3593 & $-0,65$ & n.s. & 83 \\
\hline Cedro & 14,9956 & 15,4507 & 0,3366 & 1,35 & n.s. & 72 \\
\hline Cedrorana & 12,2101 & 12,7430 & 0,3690 & 1,44 & n.s. & 77 \\
\hline Cerejeira & 17,4403 & 17,6672 & 0,7365 & 0,31 & n.s. & 40 \\
\hline Cryptomeria & 14,7856 & 15,3350 & 0,5018 & 1,09 & n.s. & 57 \\
\hline Cumaru & 9,2971 & 9,2395 & 0,4846 & $-0,12$ & n.s. & 70 \\
\hline Cunninghamia & 13,1868 & 13,5666 & 0,5519 & 0,69 & n.s. & 57 \\
\hline E. cloeziana & 11,4509 & 11,4150 & 0,3176 & $-0,11$ & n.s. & 71 \\
\hline E. grandis & 11,4055 & 11,4590 & 0,2209 & 0,24 & n.s. & 149 \\
\hline E. nesophylla & 12,1318 & 11,8547 & 0,2906 & $-0,95$ & n.s. & 113 \\
\hline E. phaeotrycha & 11,1135 & 11,3918 & 0,3093 & 0,90 & n.s. & 110 \\
\hline Faveira vermelha & 13,5867 & 13,8274 & 0,3015 & 0,80 & n.s. & 65 \\
\hline Freijó & 14,2500 & 14,1493 & 0,2666 & $-0,38$ & n.s. & 102 \\
\hline Goiabão & 12,1684 & 12,3331 & 0,3116 & 0,53 & n.s. & 126 \\
\hline Guajará & 9,8290 & 9,9033 & 0,5383 & 0,14 & n.s. & 69 \\
\hline IImbuia & 11,0704 & 13,2702 & 0,3929 & 5,60 & ** & 112 \\
\hline İpê & 14,7493 & 14,9287 & 0,5462 & 0,33 & n.s. & 60 \\
\hline Jatobá & 13,2628 & 13,3480 & 0,3751 & 0,23 & n.s. & 93 \\
\hline Louro vermelho & 12,7645 & 12,9745 & 0,3916 & 0,54 & n.s. & 105 \\
\hline Marfim & 13,2016 & 13,1950 & 0,2614 & $-0,03$ & n.s. & 118 \\
\hline Marupá & 15,7063 & 16,4187 & 0,3362 & 2,12 & * & 47 \\
\hline Muiracatiara & 14,4047 & 14,9686 & 0,2460 & 2,29 & * & 104 \\
\hline Pau amarelo & 13,7740 & 13,9681 & 0,2212 & 0,88 & n.s. & 85 \\
\hline Pinheiro do Paraná & 16,3049 & 16,8104 & 0,2426 & 2,08 & ${ }^{*}$ & 83 \\
\hline Pinus patula & 15,7487 & 16,1403 & 0,5392 & 0,73 & n.s. & 56 \\
\hline Quarubarana & 15,2948 & 15,7063 & 0,3436 & 1,20 & n.s. & 99 \\
\hline
\end{tabular}

$A=$ parâmetro $A$ da equação

sA = desvio padrão

$\mathrm{t}=$ teste $\mathrm{t}$, para comparar valores

$\star *=$ significativo a $1 \%$

* $=$ significativo a $5 \%$

n.s. = não significativo

$N=$ número de leituras feitas 
Tabela 6 : Teste $\mathrm{t}$ aplicado ao parâmetro $\mathrm{B}$ da equação que relaciona a resistência elétrica com o teor de umidade, comparando os sentidos de medição.

\begin{tabular}{|c|c|c|c|c|c|c|}
\hline \multirow{3}{*}{ Espécie } & \multicolumn{6}{|c|}{ Sentido de medição } \\
\hline & \multirow{2}{*}{$\frac{\text { Paralelo }}{\text { B }}$} & \multicolumn{5}{|c|}{ Perpendicular } \\
\hline & & $B$ & $\mathrm{sB}$ & t calc & Sig. & $\bar{N}$ \\
\hline Angelim pedra & 0,7353 & 0,7434 & 0,0263 & 0,31 & n.s. & 79 \\
\hline Breu & 0,5825 & 0,5761 & 0,0254 & $-0,25$ & n.s. & 83 \\
\hline Cedro & 0,6291 & 0,6432 & 0,0208 & 0,68 & n.s. & 72 \\
\hline Cedrorana & 0,5473 & 0,5685 & 0,0256 & 0,83 & n.s. & 77 \\
\hline Cerejeira & 0,8799 & 0,8811 & 0,0551 & 0,02 & n.s. & 40 \\
\hline Cryptomeria & 0,7163 & 0,7337 & 0,0337 & 0,52 & n.s. & 57 \\
\hline Cumaru & 0,3598 & 0,3568 & 0,0351 & $-0,09$ & n.s. & 70 \\
\hline Cunninghamia & 0,5092 & 0,5156 & 0,0354 & 0,18 & n.s. & 57 \\
\hline E. cloeziana & 0,5174 & 0,5150 & 0,0238 & $-0,10$ & n.s. & 71 \\
\hline E. grandis & 0,4808 & 0,4744 & 0,0136 & $-0,47$ & n.s. & 149 \\
\hline E. nesophylla & 0,4973 & 0,4794 & 0,0193 & $-0,93$ & n.s. & 113 \\
\hline E. phaeotrycha & 0,4669 & 0,4753 & 0,0212 & 0,40 & n.s. & 110 \\
\hline Faveira vermelha & 1,1924 & 1,2033 & 0,0398 & 0,27 & n.s. & 65 \\
\hline Freijó & 0,6973 & 0,6959 & 0,0182 & $-0,08$ & n.s. & 102 \\
\hline Goiabão & 0,6874 & 0,6906 & 0,0237 & 0,14 & n.s. & 126 \\
\hline Guajará & 0,4154 & 0,4117 & 0,0328 & $-0,11$ & n.s. & 69 \\
\hline IImbuia & 0,5858 & 0,6695 & 0,0319 & 2,62 & ${ }^{*}$ & 112 \\
\hline |lpê & 0,7797 & 0,7835 & 0,0446 & 0,09 & n.s. & 60 \\
\hline Jatobá & 0,7571 & 0,7542 & 0,0308 & $-0,09$ & n.s. & 93 \\
\hline Louro vermelho & 0,5806 & 0,5870 & 0,0244 & 0,26 & n.s. & 105 \\
\hline Marfim & 0,5407 & 0,5341 & 0,0167 & $-0,40$ & n.s. & 118 \\
\hline Marupá & 0,7917 & 0,8406 & 0,0239 & 2,05 & ${ }^{*}$ & 47 \\
\hline Muiracatiara & 0,5822 & 0,6053 & 0,0160 & 1,44 & n.s. & 104 \\
\hline Pau amarelo & 0,6397 & 0,6475 & 0,0177 & 0,44 & n.s. & 85 \\
\hline Pinhero do Paraná & 0,7108 & 0,7332 & 0,0174 & 1,29 & n.s. & 83 \\
\hline Pinus patula & 0,6688 & 0,6912 & 0,0380 & 0,59 & n.s. & 56 \\
\hline Quarubarana & 0,8205 & 0,8413 & 0,0269 & 0,77 & n.s. & 99 \\
\hline
\end{tabular}

$B=$ parâmetro $B$ da equação

$s B=$ desvio padrão

$\mathrm{t}=$ teste $\mathrm{t}$, para comparar valores

$* \star=$ significativo a $1 \%$

$*$ = significativo a $5 \%$

n.s. = não significativo

$\mathrm{N}=$ número de leituras feitas 
Concha (1975) afirma que a colocação dos sensores ao longo da grã facilita a circulação da corrente elétrica, podendo assim provocar leituras menos precisas.

Embora o citado autor não justifique a sua afirmativa, a passagem da corrente elétrica no sentido do comprimento das fibras é facilitada em função da movimentação da água ser maior nesse sentido, já a passagem da corrente através das fibras tem que atravessar diferentes tecidos (espessuras e constituição), com variada quantidade de água.

$O$ teste $t$ (Tabelas 5 e 6 ) mostrou que somente duas espécies, Imbuia e Marupá, apresentaram diferenças significativas para os parâmetros $A$ e $B$, entre os sentidos de medição.

$\mathrm{Na}$ Tabela 4 observa-se que, para as duas espécies citadas, 0 coeficiente de determinação para o sentido perpendicular é superior em relação ao sentido paralelo.

Das 27 espécies estudas apenas o Breu, a Cerejeira, o Freijó, o Ipê, e o Pinus patula apresentaram coeficiente de determinação maior para o sentido paralelo que para o perpendicular, mas com uma diferença muito pequena. $A$ diferença máxima observada para essas espécies foi da ordem de $2,7 \%$ ou em número absoluto, de 0,024 no coeficiente de determinação.

Para as outras espécies a medição no sentido perpendicular sempre apresentou um maior valor do coeficiente de determinação, com diferenças de até $19,8 \%$ (ou 0,158 no coeficiente de determinação).

Esses resultados permitem afirmar que a medição da resistência elétrica no sentido perpendicular as fibras é mais adequada para determinar o teor de umidade da madeira.

5.2. Interação entre a resistência elétrica e a densidade básica

A Tabela 7 apresenta valores de resistência elétrica calculados, para teores de umidade de $5 \%$ e $15 \%$, usando as equações da Tabela 4 para o 
sentido perpendicular. Comparativamente são apresentadas as respectivas densidades básicas.

Tabela 7 : Resistência elétrica calculada para teores de umidade de $5 \%$ e $15 \%$

\begin{tabular}{|c|c|c|c|c|}
\hline \multirow[t]{2}{*}{ Espécie } & \multirow{2}{*}{$\begin{array}{c}\mathrm{Db} \\
\left(\mathrm{g} / \mathrm{cm}^{3}\right)\end{array}$} & \multirow{2}{*}{$\begin{array}{l}\text { CV } \\
(\%)\end{array}$} & \multicolumn{2}{|c|}{ Resistência $\left(10^{3} \mathrm{k} \Omega\right)$} \\
\hline & & & $U=5 \%$ & $U=15 \%$ \\
\hline Angelim pedra & 0,606 & 13,37 & 142,37 & 0,084 \\
\hline Breu & 0,700 & 7,86 & 7,67 & 0,024 \\
\hline Cedro & 0,394 & 4,57 & 205,81 & 0,331 \\
\hline Cedrorana & 0,494 & 3,64 & 19,94 & 0,068 \\
\hline Cerejeira & 0,549 & 8,74 & 574,76 & 0,086 \\
\hline Cryptomeria & 0,352 & 14,20 & 116,60 & 0,076 \\
\hline Cumaru & 0,874 & 6,29 & 1,73 & 0,049 \\
\hline Cunninghamia & 0,335 & 2,69 & 59,20 & 0,341 \\
\hline E. cloeziana & 0,652 & 8,44 & 6,90 & 0,040 \\
\hline E. grandis & 0,646 & 3,56 & 8,84 & 0,077 \\
\hline E. nesophylla & 0,652 & 7,36 & 12,81 & 0,106 \\
\hline E. phaeotrycha & 0,738 & 8,54 & 8,23 & 0,071 \\
\hline Faveira vermelha & 0,580 & 2,24 & 2,47 & 0,0001 \\
\hline Freijó & 0,482 & 6,02 & 43,04 & 0,041 \\
\hline Goiabão & 0,716 & 4,33 & 7,19 & 0,007 \\
\hline Guajará & 0,797 & 5,27 & 2,55 & 0,042 \\
\hline Imbuia & 0,578 & 6,23 & 20,39 & 0,025 \\
\hline Ipê & 0,928 & 3,56 & 60,55 & 0,024 \\
\hline Jatobá & 0,868 & 2,53 & 14,43 & 0,008 \\
\hline Louro vermelho & 0,532 & 3,01 & 22,91 & 0,065 \\
\hline Marfim & 0,677 & 3,10 & 37,22 & 0,178 \\
\hline Marupá & 0,365 & 7,12 & 201,93 & 0,045 \\
\hline Muiracatiara & 0,641 & 1,56 & 153,60 & 0,361 \\
\hline Pau amarelo & 0,709 & 10,86 & 45,73 & 0,071 \\
\hline Pinheiro do Paraná & 0,447 & 2,91 & 511,14 & 0,334 \\
\hline Pinus patula & 0,474 & 1,90 & 322,64 & 0,321 \\
\hline Quarubarana & 0,494 & 2,02 & 98,70 & 0,022 \\
\hline
\end{tabular}

A correlaçảo entre a densidade básica e a resistência elétrica pode ser examinada nas Figuras 11 e 12, para os teores de umidade de 5 e $15 \%$, respectivamente. 


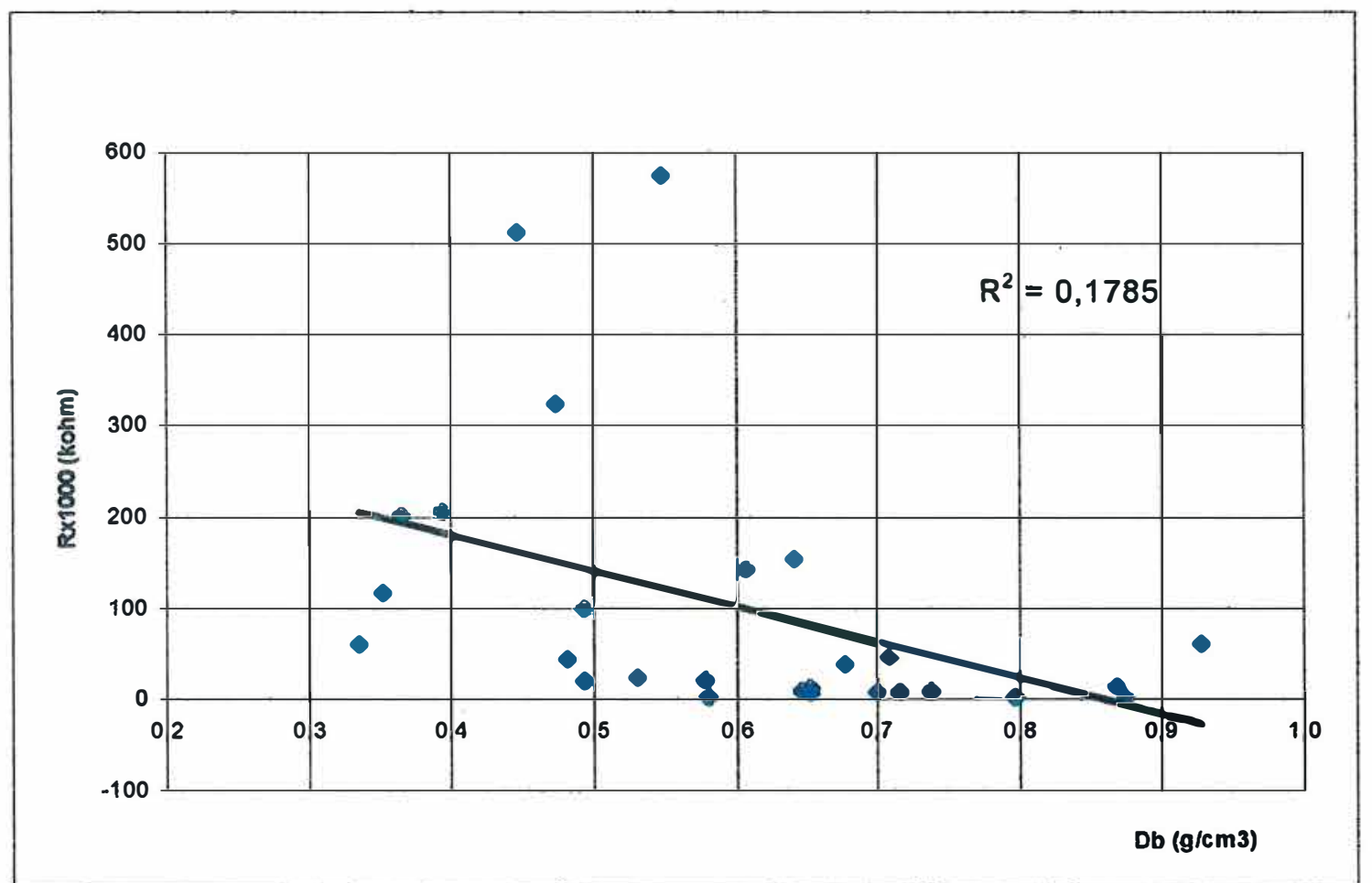

Figura 11 : Relação entre a densidade básica e a resistência elétrica, no sentido perpendicular, calculada a $5 \%$ de umidade.

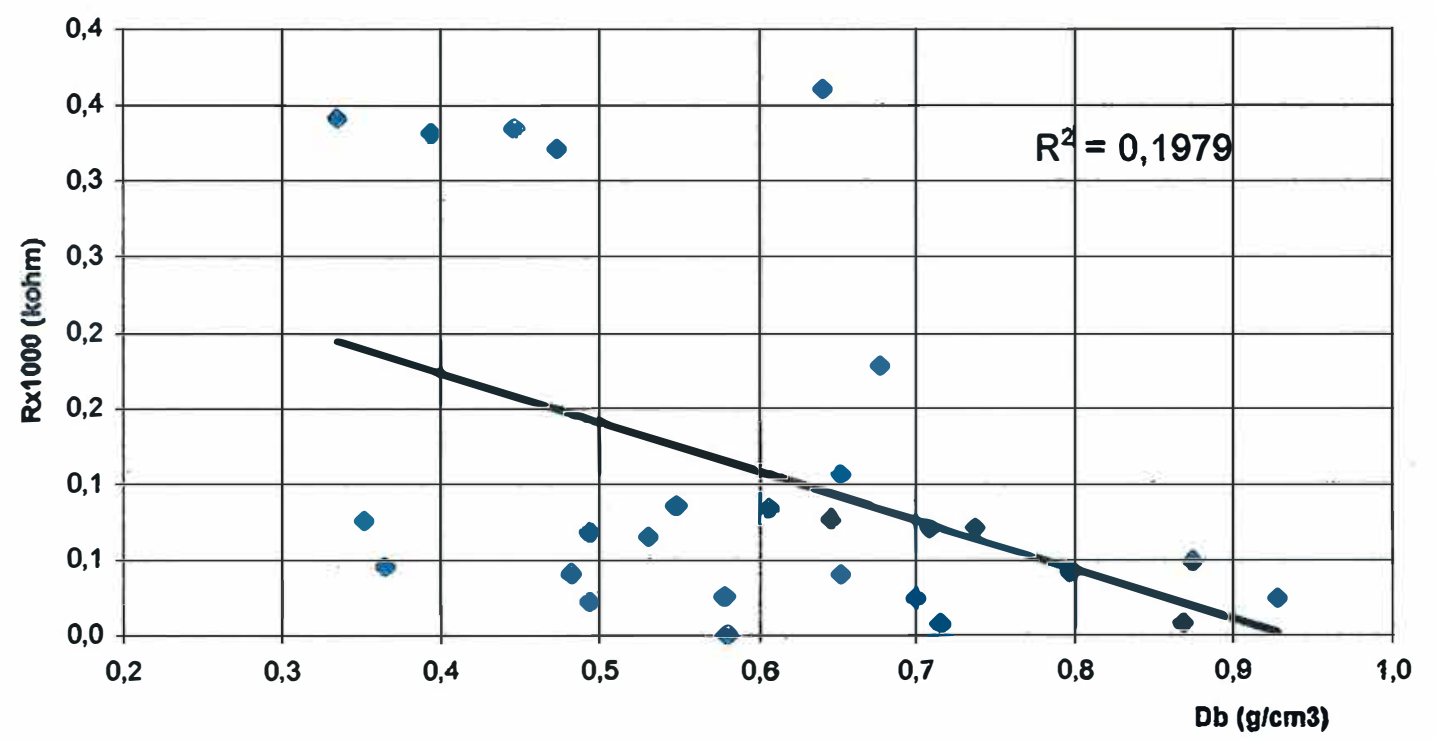

Figura 12 : Relação entre a densidade básica e a resistência elétrica, no sentido perpendicular, calculada a $15 \%$ de umidade. 
Curiosamente diversos modelos de medidores elétricos de umidade do tipo resistência, usam a densidade básica ou a massa especifica da madeira como fator de correção para espécie.

Porém, de todo levantamento feito em literatura sobre medidores elétricos de umidade, raramente encontra-se alguma referência que relacione a densidade básica como um fator de correção importante, com exceção dos medidores elétricos que utilizam o princípio da capacitância ou perda de carga (Vermaas, 1982a). Para esse último tipo de medidor existem trabalhos que mostram a melhoria da leitura com a adição de um fator de correção.

Em relação aos medidores do tipo resistência, Skaar(1988) afirma que a presença de íons é mais relevante do que a densidade básica, que "os extrativos não solúveis em água são tidos como redutores da condutividade da madeira, devido a serem péssimos condutores, mas os solúveis em água o efeito é oposto, pois podem conter complexos que incluem eletrólitos, aumentando a condutividade".

Os resultados obtidos no presente estudo demonstram que não existe uma correlação entre a densidade básica das madeiras e a resistência elétrica.

Pela simples observação da Tabela 7 é possivel encontrar duas espécies com valores de densidade básica extremos, que apresentam praticamente o mesmo valor de resistência calculada a um teor de $5 \%$ de umidade, esta situação ocorre entre a Cunninghamia $\left(0,335 \mathrm{~g} / \mathrm{cm}^{3}\right)$ e $\circ$ Ipê $\left(0,928 \mathrm{~g} / \mathrm{cm}^{3}\right)$, onde ambas tem a resistência calculada de aproximadamente 60 $\times 10^{3} \mathrm{k} \Omega$. Porém, quando a resistência é calculada para $15 \%$ de umidade, o valor obtido para o Ipê é cerca de 14 vezes menor.

Os gráficos (Figuras 11 e 12) ilustram claramente a dispersão dos valores de resistência em relação a densidade básica, mostrando que as madeiras não se agrupam em função da densidade; mas provavelmente pelas diferenças químicas que apresentam.

Com base nesses resultados é possivel afirmar que o atual fator de correção para espécies (densidade básica), utilizado pelos medidores elétricos de umidade, está totalmente equivocado. 
Para que se tenha melhor precisão deve-se efetuar a calibração de acordo com o comportamento individual de cada espécie, ou seja, grupando espécies que tenham propriedades elétricas (resistência ou condutância) similares.

\subsection{Grupamento de espécies}

Os resultados principais do grupamento de espécies pela análise de Cluster são apresentados na Figura 13, na forma de dendrograma, e na Tabela 8 para os niveis 0,$0 ; 0,2 ; 0,3 ; 0,4$ e 0,5 .

No dendrograma da Figura 13, o eixo y contém a distância Euclidiana entre as espécies, que é uma medida adimensional calculada com base nos valores dos parâmetros $A$ e $B$ de cada espécie e suas respectivas variâncias. No eixo $x$ estão dispostas as espécies de acordo com a afinidade para a formação dos grupos, ou seja, de acordo com a similaridade das equações que representam a correlação entre o teor de umidade e a resistência elétrica.

A medida em que são formados os grupos, são calculadas novas equações de correlação englobando os dados experimentais de todas as espécies incluídas em um mesmo grupo. Os parâmetros A e B das equações individuais e dos grupos constam da Tabela 9.

Os parâmetros A e B para o nivel 0,0 (Tabela 9) representam as equações individuais de cada espécie. Examinando esses valores nota-se que não existem duas espécies que possuam a mesma equação, mas que existem espécies cujas equações são bastante similares.

Essa similaridade pode ser mais facilmente visualizada no diagrama da figura 13. Quanto mais próximo do zero do eixo y estiver a ligação das espécies mais afinidade elas terão, como é o caso dos Eucaliptos, E. cloeziana, E. grandis, e E. phaeotricha. 


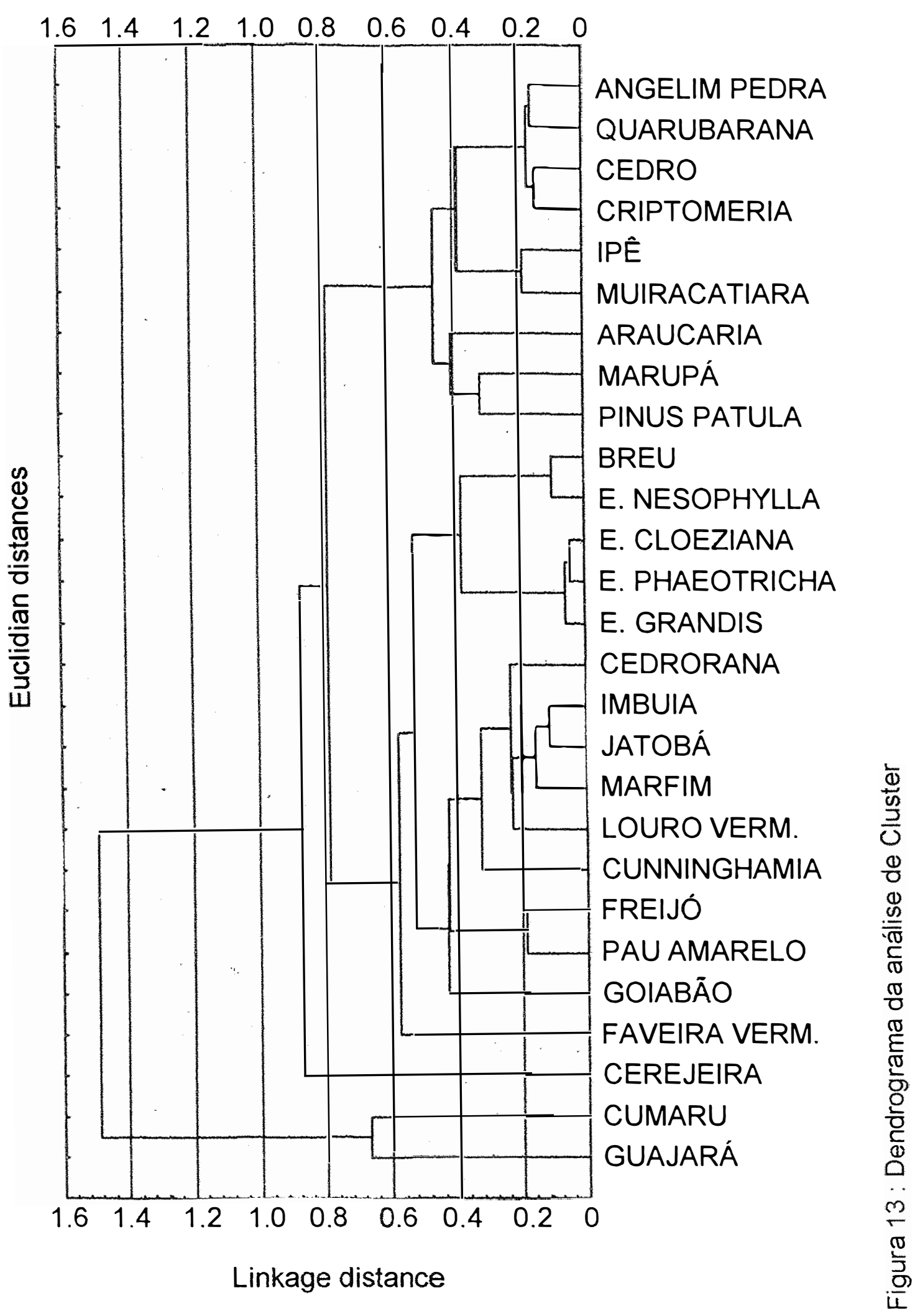



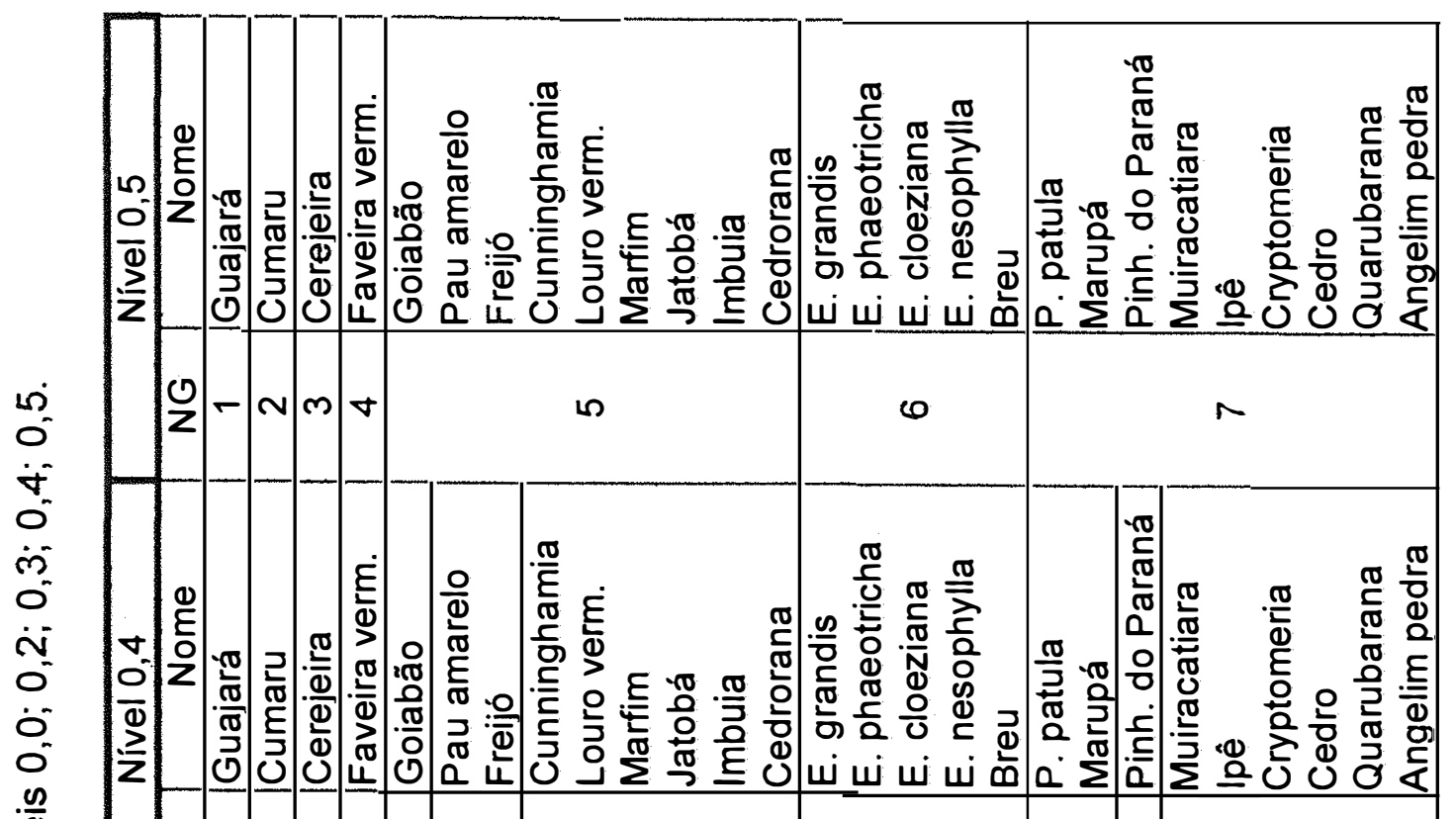

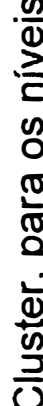

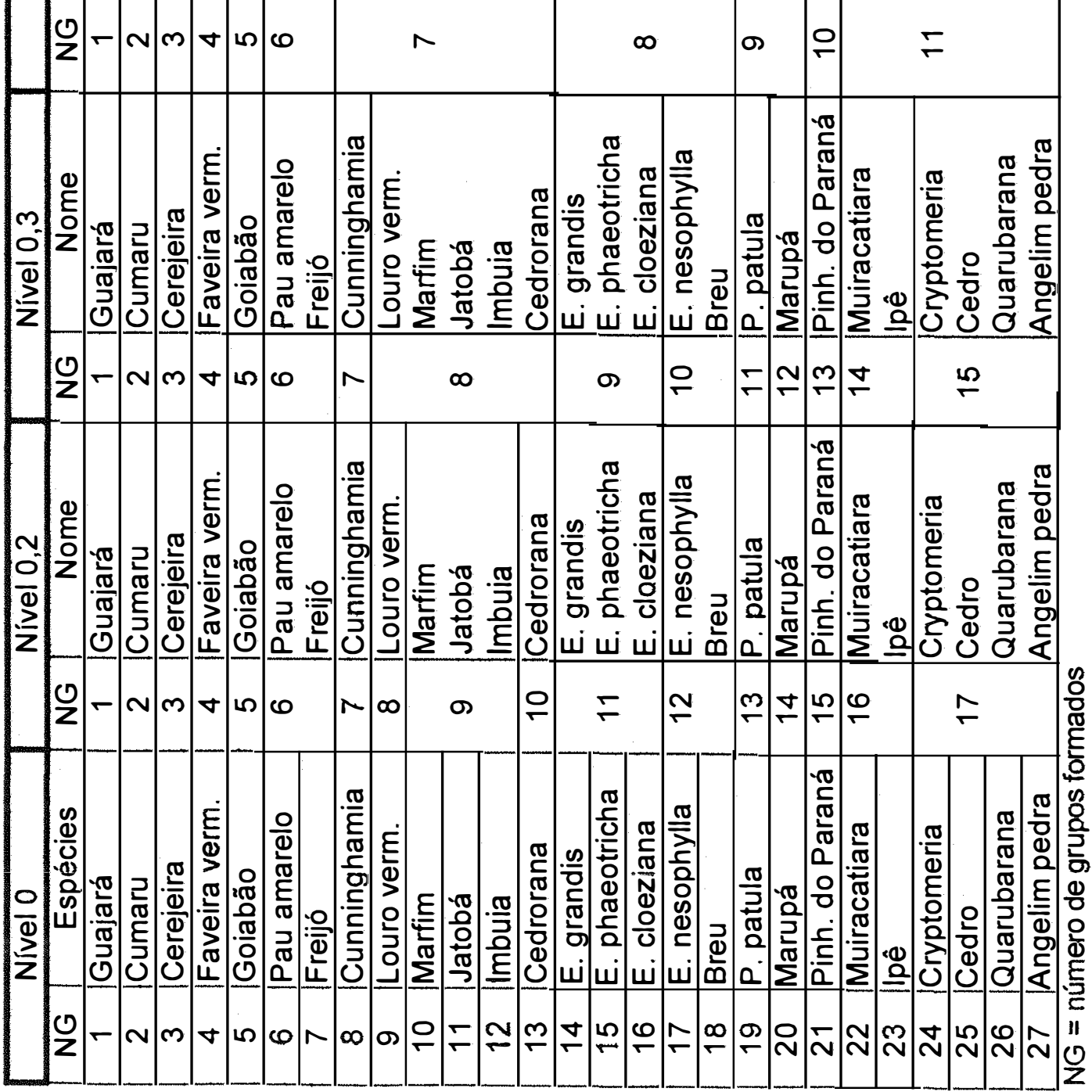




\begin{tabular}{|c|c|c|c|c|c|c|c|c|c|c|c|c|c|c|c|c|c|c|c|c|c|c|c|c|c|}
\hline $\mid \begin{array}{l}n \\
0 \\
0\end{array}$ & $\infty$ & 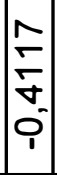 & $\begin{array}{l}\infty \\
0 \\
0 \\
n \\
0 \\
0 \\
1\end{array}$ & $\left|\begin{array}{c}\sigma \\
\infty \\
\infty \\
\infty \\
0 \\
1\end{array}\right|$ & 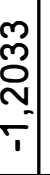 & \multicolumn{8}{|c|}{$\begin{array}{l}\infty \\
\infty \\
0 \\
0 \\
0 \\
0 \\
1\end{array}$} & \multicolumn{4}{|c|}{$\begin{array}{l}N \\
N \\
\infty \\
+ \\
0\end{array}$} & \multicolumn{8}{|c|}{ 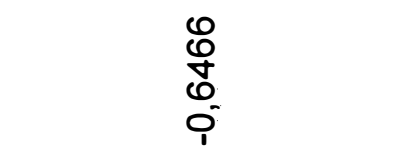 } \\
\hline$\sum_{\bar{Z}}^{\bar{\alpha}}$ & $\varangle$ & 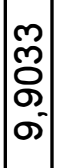 & 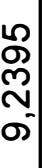 & $\left|\begin{array}{c}N \\
N \\
0 \\
0 \\
N \\
-\end{array}\right|$ & 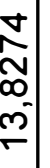 & \multicolumn{8}{|c|}{ 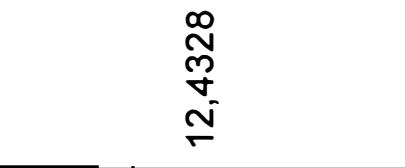 } & & & 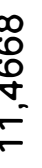 & & \multicolumn{8}{|c|}{$\begin{array}{l}0 \\
8 \\
0 \\
\mathbb{0} \\
\mathbb{-}\end{array}$} \\
\hline $\begin{array}{l}\nabla \\
0\end{array}$ & $\infty$ & $\mid \begin{array}{c}n \\
\frac{1}{8} \\
0 \\
1\end{array}$ & $\begin{array}{l}\infty \\
0 \\
0 \\
m \\
0 \\
0\end{array}$ & $\mid \begin{array}{c}\mp \\
\infty \\
\infty \\
\infty \\
0 \\
1\end{array}$ & 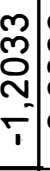 & $\begin{array}{l}0 \\
0 \\
\\
0 \\
0 \\
\\
\end{array}$ & 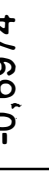 & & \multicolumn{5}{|c|}{$\begin{array}{l}\mathbb{N} \\
\text { ñ } \\
0 \\
0\end{array}$} & \multicolumn{4}{|c|}{ 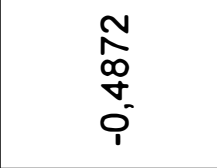 } & 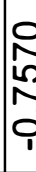 & & 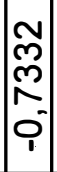 & \multicolumn{5}{|c|}{$\begin{array}{l}\frac{0}{5} \\
\frac{\sigma}{0} \\
0\end{array}$} \\
\hline$\frac{\bar{\alpha}}{\bar{Z}}$ & $\varangle$ & $\mid \begin{array}{l}m \\
\text { m. } \\
\text { ळి } \\
\sigma^{\prime}\end{array}$ & 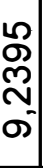 & $\left|\begin{array}{c}N \\
N \\
0 \\
0 \\
N \\
-\end{array}\right|$ & 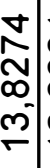 & $\begin{array}{c}\bar{m} \\
m \\
m \\
v \\
v\end{array}$ & 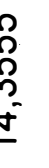 & \multicolumn{6}{|c|}{ 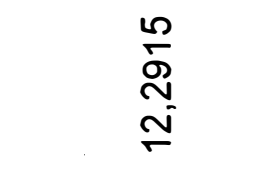 } & \multicolumn{4}{|c|}{$\begin{array}{l}\infty \\
\mathbb{8} \\
\mathbb{8} \\
\tilde{\sigma} \\
\leftarrow\end{array}$} & $\begin{array}{l}\sigma \\
\sigma \\
\\
\cdots \\
\cdots\end{array}$ & & $\left|\begin{array}{l}\mathbf{0} \\
\frac{0}{\infty} \\
6 \\
6\end{array}\right|$ & \multicolumn{5}{|c|}{ 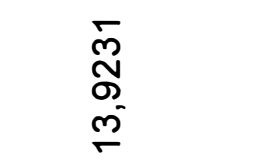 } \\
\hline m & $\infty$ & 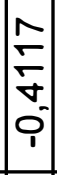 & $\begin{array}{l}\infty \\
0 \\
0 \\
m \\
m \\
0 \\
1\end{array}$ & $\left|\begin{array}{c}\sigma \\
\infty \\
\infty \\
\infty \\
0 \\
1\end{array}\right|$ & $\begin{array}{c}m \\
m \\
0 \\
N \\
-1\end{array}$ & $\begin{array}{l}0 \\
8 \\
0 \\
0 \\
0 \\
\end{array}$ & $\begin{array}{l}\text { J } \\
0 \\
0 \\
0 \\
\end{array}$ & 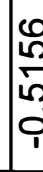 & \multicolumn{5}{|c|}{ 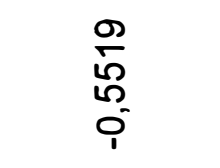 } & & 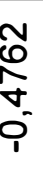 & & 'מ & & $\begin{array}{l}0 \\
0 \\
y \\
\infty \\
0 \\
1\end{array}$ & $\left|\begin{array}{c}\mathcal{N} \\
\tilde{m} \\
\\
0 \\
\end{array}\right|$ & \multicolumn{2}{|l|}{ 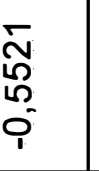 } & \multicolumn{3}{|c|}{$\begin{array}{l}\text { N } \\
\text { గొ } \\
0 \\
0 \\
0\end{array}$} \\
\hline$\sum_{\bar{\alpha}}^{\bar{\alpha}}$ & $\varangle$ & $\mid \begin{array}{l}m \\
\text { m. } \\
\text { ळి } \\
\sigma \\
\sigma\end{array}$ & 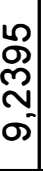 & 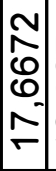 & $\begin{array}{c}\mathbb{N} \\
\underset{\infty}{\infty} \\
\boldsymbol{N}^{-} \\
\stackrel{2}{\sim}\end{array}$ & $\begin{array}{c}\underset{m}{m} \\
m \\
m \\
v \\
v\end{array}$ & 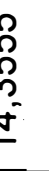 & $\begin{array}{l}c \\
c \\
c \\
n \\
n \\
m\end{array}$ & \multicolumn{5}{|c|}{$\begin{array}{l}\text { J } \\
\text { O } \\
\text { m } \\
\stackrel{N}{\sim}\end{array}$} & & 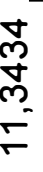 & & 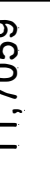 & & $\mid \begin{array}{c}\frac{1}{\infty} \\
\frac{\nabla}{\square} \\
0 \\
\sigma\end{array}$ & $\left|\begin{array}{l}\mathbf{0} \\
\stackrel{0}{\infty} \\
0 \\
6\end{array}\right|$ & 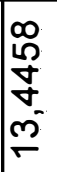 & \multicolumn{4}{|c|}{ 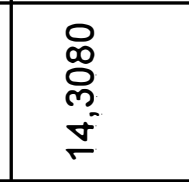 } \\
\hline$N^{N}$ & $\infty$ & 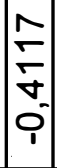 & $\begin{array}{l}\infty \\
0 \\
0 \\
n \\
m \\
0 \\
0\end{array}$ & $\left|\begin{array}{c}\sigma \\
\infty \\
\infty \\
\infty \\
0 \\
1\end{array}\right|$ & $\begin{array}{c}m \\
m \\
0 \\
N \\
-1\end{array}$ & $\begin{array}{l}0 \\
0 \\
0 \\
0 \\
0 \\
\end{array}$ & 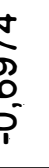 & $\begin{array}{l}c \\
5 \\
5 \\
0 \\
0\end{array}$ & \begin{tabular}{c}
0 \\
0 \\
$\infty$ \\
$\infty$ \\
0 \\
\hdashline
\end{tabular} & & 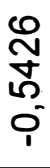 & & 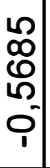 & & 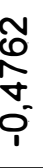 & & 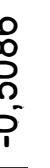 & $\frac{7}{\sigma}$ & $\mid \begin{array}{l}0 \\
0 \\
y \\
\infty \\
0 \\
1\end{array}$ & $\left|\begin{array}{c}\tilde{N} \\
\tilde{m} \\
\\
\hdashline \\
\end{array}\right|$ & 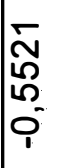 & \multicolumn{4}{|c|}{$\begin{array}{l}\text { N } \\
\text { గొ } \\
0 \\
0\end{array}$} \\
\hline$\frac{\bar{Q}}{z}$ & $\varangle$ & 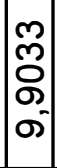 & 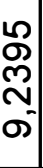 & $\left|\begin{array}{c}N \\
N \\
0 \\
0 \\
N \\
\hdashline\end{array}\right|$ & $\begin{array}{c}\mathbb{N} \\
\underset{\infty}{\infty} \\
\boldsymbol{N}^{-} \\
\sim\end{array}$ & $\begin{array}{c}\bar{m} \\
m \\
m \\
v \\
v \\
\\
m\end{array}$ & 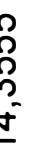 & $\begin{array}{l}c \\
c \\
c \\
n \\
n \\
m\end{array}$ & 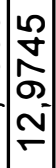 & & $\begin{array}{l}\infty \\
\text { ల్ } \\
\text { o } \\
\stackrel{N}{N}\end{array}$ & & \begin{tabular}{l}
0 \\
$m$ \\
\multirow{N}{N}{} \\
$\sim$ \\
$N$
\end{tabular} & & 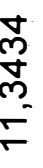 & & 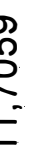 & & $\mid \begin{array}{c}\frac{1}{\infty} \\
\frac{\square}{ \pm} \\
0 \\
\sigma\end{array}$ & $\left|\begin{array}{c}\forall \\
0 \\
\infty \\
6 \\
6\end{array}\right|$ & 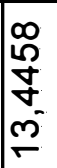 & & \multicolumn{3}{|c|}{ 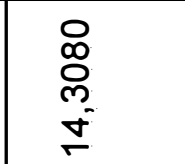 } \\
\hline 10 & $\infty$ & 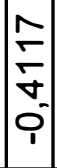 & $\begin{array}{l}\infty \\
0 \\
0 \\
n \\
0 \\
0 \\
1\end{array}$ & $\mid \begin{array}{c}\sigma \\
\dot{\infty} \\
\infty \\
0-1 \\
0 \\
1\end{array}$ & $\begin{array}{c}m \\
m \\
0 \\
N \\
-1\end{array}$ & $\begin{array}{l}0 \\
0 \\
\\
0 \\
0 \\
\end{array}$ & 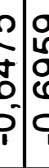 & $\left\{\begin{array}{l}6 \\
10 \\
5 \\
10 \\
9\end{array}\right.$ & $\mid \begin{array}{c}0 \\
0 \\
0 \\
0 \\
0 \\
0 \\
1\end{array}$ & 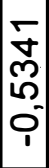 & 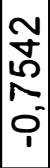 & $\begin{array}{l}0 \\
0 \\
0 \\
-\end{array}$ & $\begin{array}{l}n \\
\infty \\
0 \\
0 \\
\sim \\
0 \\
1 \\
1\end{array}$ & \begin{tabular}{l}
8 \\
\multirow{2}{*}{} \\
8 \\
8
\end{tabular} & $\begin{array}{c}n \\
0 \\
0 \\
\forall \\
0 \\
1\end{array}$ & $\begin{array}{l}0 \\
0 \\
\\
0 \\
0 \\
1\end{array}$ & 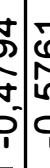 & 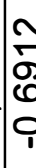 & $\begin{array}{l}0 \\
0 \\
y \\
\infty \\
0 \\
1\end{array}$ & $\mid$\begin{tabular}{c}
$\mathcal{N}$ \\
$\tilde{m}$ \\
$\tilde{N}$ \\
\hdashline \\
\end{tabular} & $\mid \begin{array}{l}n \\
0 \\
0 \\
\wp \\
0 \\
1\end{array}$ & 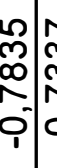 & 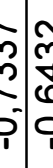 & $\mid \begin{array}{l}\frac{m}{8} \\
\frac{m}{\infty} \\
\infty\end{array}$ & 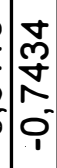 \\
\hline$\frac{\bar{\Phi}}{\bar{z}}$ & $\ll$ & 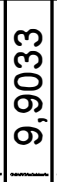 & 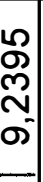 & $\mid \begin{array}{c}N \\
\hat{N} \\
0 \\
0 \\
N \\
-\end{array}$ & $\begin{array}{c}J \\
N \\
\infty \\
N^{-} \\
\sim\end{array}$ & $\begin{array}{c}\tilde{m} \\
m \\
m \\
v \\
v \\
v\end{array}$ & 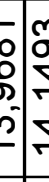 & $\begin{array}{l}0 \\
0 \\
0 \\
n \\
m\end{array}$ & 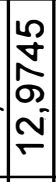 & 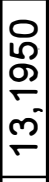 & $\begin{array}{l}0 \\
\infty \\
\dot{J} \\
m \\
m \\
m\end{array}$ & 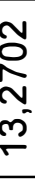 & \begin{tabular}{l}
0 \\
$m$ \\
\multirow{N}{N}{} \\
$\sim$ \\
$\sim$
\end{tabular} & 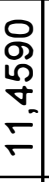 & $\begin{array}{c}\infty \\
\frac{\infty}{\infty} \\
m \\
\leftarrow \\
\leftarrow\end{array}$ & 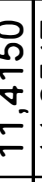 & 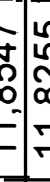 & $\begin{array}{l}m \\
y \\
0 \\
\sigma\end{array}$ & $\frac{\sqrt{\infty}}{\frac{\sigma}{\sigma}}$ & $\mid \begin{array}{l}\mathbf{0} \\
\frac{0}{\infty} \\
6 \\
6\end{array}$ & 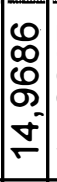 & 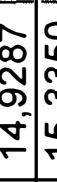 & 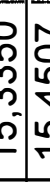 & 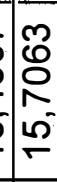 & $\begin{array}{l}\mathcal{N} \\
\infty \\
\infty \\
\infty \\
\sim \\
\sim\end{array}$ \\
\hline & $\begin{array}{l}\frac{0}{0} \\
\frac{0}{0} \\
0 \\
\tilde{D} \\
w\end{array}$ & $\mid \begin{array}{c}-\frac{\pi}{0} \\
\frac{\pi}{\sigma} \\
\frac{\pi}{\partial} \\
0 \\
0\end{array}$ & 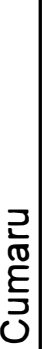 & 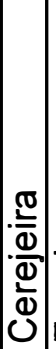 & 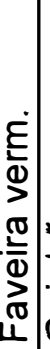 & $\begin{array}{l} \\
0 \\
0 \\
0 \\
0 \\
0 \\
0 \\
0 \\
0 \\
0\end{array}$ & 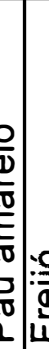 & 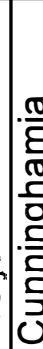 & $\begin{array}{l}\dot{\varepsilon} \\
\dot{\xi} \\
0 \\
0 \\
0 \\
0 \\
0 \\
0 \\
0\end{array}$ & 恼 & 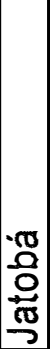 & $\frac{\pi}{3}$ & 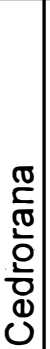 & 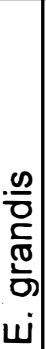 & 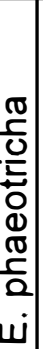 & 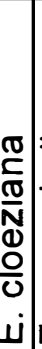 & 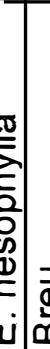 & 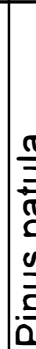 & 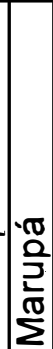 & 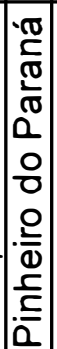 & 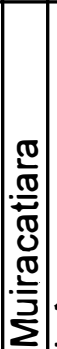 & 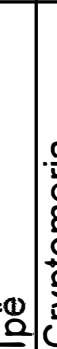 & 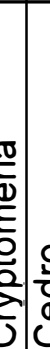 & 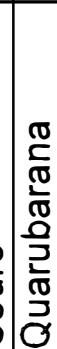 & 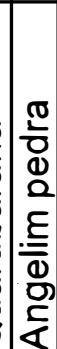 \\
\hline
\end{tabular}


Em situação oposta estão o Guajará e o Cumaru, que só se uniram a outras espécies a uma distância de 1,5; e mesmo a Cerejeira só participa de um grupo acima do nível 0,8 .

Considerando que muitos modelos de medidores elétricos e de controles para secadores possui três ou quatro escalas para corrigir a medição do teor de umidade em função da espécie, pode-se afirmar que esses aparelhos dificilmente apresentarão medições precisas quando usados para diferentes tipos de madeiras. Tomando como base os resultados da análise de grupamento, três grupos significariam ter uma escala só para a Cerejeira, uma para o Guajará e o Cumaru, e a terceira englobando as demais espécies.

No exame da Figura 13 e da Tabela 9 percebe-se que é possível agrupar espécies, e que a relação entre o teor de umidade e a resistência elétrica para as espécies contidas em um mesmo grupo pode ser representada por uma única equação.

Contudo, a análise de Cluster não indica qual o melhor nível para a seleção final dos grupos. Para possibilitar uma análise mais detalhada do grupamento foi feito também o estudo da variação dos desvios e dos coeficientes de determinação para os níveis da distância Euclidiana de 0,0 a 1,0 .

As Tabelas 10 a 14 mostram os resultados dessa análise até o nível 0,5 da distância Euclidiana, pois para níveis acima desse valor diminui acentuadamente a exatidão das equações representativas dos grupos.

Conforme já referido anteriormente, o nivel 0,0 representa as equações individuais, ou seja, o melhor ajuste dos dados experimentais. 
Tabela 10 : Variação do desvio absoluto máximo para os grupos formados nos níveis 0,0 a 0,5 da distância Euclidiana.

\begin{tabular}{|c|c|c|c|c|c|c|c|c|c|c|}
\hline \multirow{3}{*}{ Espécie } & \multicolumn{10}{|c|}{ Niveis da distância Euclidiana } \\
\hline & \multicolumn{2}{|c|}{0,0} & \multicolumn{2}{|c|}{0,2} & \multicolumn{2}{|c|}{0,3} & \multicolumn{2}{|c|}{0,4} & \multicolumn{2}{|c|}{0,5} \\
\hline & NG & $D_{\max }$ & NG & $D_{\max }$ & NG & $D_{\max }$ & NG & $D_{\max }$ & NG & $D_{\max }$ \\
\hline Guajará & 1 & 9,01 & 1 & 9,01 & 1 & 9,01 & 1 & 9,01 & 1 & 9,01 \\
\hline Cumaru & 2 & 8,70 & 2 & 8,70 & 2 & 8,70 & 2 & 8,70 & 2 & 8,70 \\
\hline Cerejeira & 3 & 3,28 & 3 & 3,28 & 3 & 3,28 & 3 & 3,28 & 3 & 3,28 \\
\hline Faveira verm. & 4 & 1,62 & 4 & 1,62 & 4 & 1,62 & 4 & 1,62 & 4 & 1,62 \\
\hline Goiabão & 5 & 3,49 & 5 & 3,49 & 5 & 3,49 & 5 & 3,49 & & \multirow{9}{*}{7,37} \\
\hline Pau amarelo & 6 & 1,75 & \multirow[t]{2}{*}{6} & \multirow[t]{2}{*}{6,12} & \multirow[t]{2}{*}{6} & \multirow[t]{2}{*}{6,12} & \multirow[t]{2}{*}{6} & \multirow[t]{2}{*}{6,12} & \multirow{8}{*}{5} & \\
\hline Freijó & 7 & 3,54 & & & & & & & & \\
\hline Cunninghamia & 8 & 4,02 & 7 & 4,02 & 7 & 4,02 & \multirow{6}{*}{7} & \multirow{6}{*}{6,68} & & \\
\hline Louro verm. & 9 & 4,16 & 8 & 4,16 & \multirow{5}{*}{8} & \multirow{5}{*}{6,41} & & & & \\
\hline Marfim & 10 & 4,10 & \multirow{3}{*}{9} & \multirow{3}{*}{6,47} & & & & & & \\
\hline Jatobá & 11 & 3,51 & & & & & & & & \\
\hline Imbuia & 12 & 5,06 & & & & & & & & \\
\hline Cedrorana & 13 & 4,11 & 10 & 4,11 & & & & & & \\
\hline E. grandis & $\overline{14}$ & 4,02 & \multirow{3}{*}{11} & \multirow{3}{*}{8,90} & \multirow{3}{*}{9} & \multirow{3}{*}{8,90} & & \multirow{5}{*}{8,67} & \multirow{5}{*}{6} & \multirow{5}{*}{8,67} \\
\hline E. phaeotricha & 15 & 8,80 & & & & & & & & \\
\hline E. cloeziana & 16 & 4,48 & & & & & 8 & & & \\
\hline E. nesophylla & 17 & 5,50 & \multirow[t]{2}{*}{12} & 5,94 & 10 & 5,94 & & & & \\
\hline Breu & 18 & 5,74 & & & & & & & & \\
\hline P. patula & 19 & 4,84 & 13 & 4,84 & 11 & 4,84 & 9 & 5,17 & & \\
\hline Marupá & 20 & 1,06 & 14 & 1,06 & 12 & 1,06 & & & & \\
\hline Pinh. do Paraná & 21 & 2,32 & 15 & 2,32 & 13 & 2,32 & 10 & 2,32 & & \\
\hline Muiracatiara & 22 & 4,48 & 16 & 6,58 & 14 & 6,58 & & & & \\
\hline Ipê & 23 & 3,15 & & & & & & & 7 & 6,84 \\
\hline Cryptomeria & 24 & 2,38 & & & & & 11 & 6,27 & & \\
\hline Cedro & 25 & 2,52 & 17 & 4,59 & 15 & 4,59 & & & & \\
\hline Quarubarana & 26 & 2,86 & & & & & & & & \\
\hline Angelim pedra & 27 & 3,01 & & & & & & & & \\
\hline
\end{tabular}

NG = Número de Grupos formados

$D_{\max }=$ Desvio absoluto máximo 
Tabela 11 : Variação do desvio absoluto mínimo para os grupos formados nos niveis 0,0 a 0,5 da distância Euclidiana.

\begin{tabular}{|c|c|c|c|c|c|c|c|c|c|c|}
\hline \multirow{3}{*}{ Espécie } & \multicolumn{10}{|c|}{ Niveis da distância Euclidiana } \\
\hline & \multicolumn{2}{|c|}{0,0} & \multicolumn{2}{|c|}{0,2} & \multicolumn{2}{|c|}{0,3} & \multicolumn{2}{|c|}{0,4} & \multicolumn{2}{|c|}{0,5} \\
\hline & NG & $D_{\min }$ & NG & $\mathrm{D}_{\min }$ & NG & $D_{\min }$ & NG & $\mathrm{D}_{\min }$ & NG & $D_{\min }$ \\
\hline Guajará & 1 & $-7,96$ & 1 & $-7,96$ & 1 & $-7,96$ & 1 & $-7,96$ & 1 & $-7,96$ \\
\hline Cumaru & 2 & $-7,07$ & 2 & $-7,07$ & 2 & $-7,07$ & 2 & $-7,07$ & 2 & $-7,07$ \\
\hline Cerejeira & 3 & $-3,02$ & 3 & $-3,02$ & 3 & $-3,02$ & 3 & $-3,02$ & 3 & $-3,02$ \\
\hline Faveira verm. & 4 & $-1,27$ & 4 & $-1,27$ & 4 & $-1,27$ & 4 & $-1,27$ & 4 & $-1,27$ \\
\hline Goiabão & 5 & $-2,58$ & 5 & $-2,58$ & 5 & $-2,58$ & 5 & $-2,58$ & & \\
\hline Pau amarelo & 6 & $-1,38$ & 6 & $-2,85$ & 6 & $-2,85$ & 6 & $-2,85$ & & \\
\hline Freijó & 7 & $-2,07$ & & & & & & & & \\
\hline Cunninghamia & 8 & $-6,82$ & 7 & $-6,82$ & 7 & $-6,82$ & & & & \\
\hline Louro verm. & 9 & $-4,38$ & 8 & $-4,38$ & & & & & 5 & $-5,95$ \\
\hline Marfim & 10 & $-2,88$ & & & & & 7 & $-6,83$ & & \\
\hline Jatobá & 11 & $-2,00$ & 9 & $-6,27$ & 8 & $-6,32$ & & & & \\
\hline Imbuia & 12 & $-4,25$ & & & & & & & & \\
\hline Cedrorana & 13 & $-4,41$ & $\mid 10$ & $-4,41$ & & & & & & \\
\hline E. grandis & 14 & $-3,90$ & & & & & & & & \\
\hline E. phaeotricha & 15 & $-3,82$ & 11 & $-5,48$ & 9 & $-5,48$ & & & & \\
\hline E. cloeziana & 16 & $-4,20$ & & & & & 8 & $-6,18$ & 6 & $-6,18$ \\
\hline E. nesophylla & 17 & $-4,44$ & 12 & $-5,76$ & 10 & $-5,76$ & & & & \\
\hline Breu & 18 & $-3,53$ & & & & & & & & \\
\hline P. patula & 19 & $-2,06$ & 13 & $-2,06$ & 11 & $-2,06$ & 9 & $-3,07$ & & \\
\hline Marupá & 20 & $-1,75$ & 14 & $-1,75$ & 12 & $-1,75$ & & & & \\
\hline Pinh. do Paraná & 21 & $-1,56$ & 15 & $-1,56$ & 13 & $-1,56$ & 10 & $-1,56$ & & \\
\hline Muiracatiara & 22 & $-3,06$ & 16 & $-7,75$ & 14 & $-7,75$ & & & & \\
\hline Ipê & 23 & $-3,32$ & & & & & & & 7 & $-6,41$ \\
\hline Cryptomeria & 24 & $-2,12$ & & & & & 11 & $-6,43$ & & \\
\hline Cedro & 25 & $-1,99$ & 17 & $-4,34$ & 15 & $-4,34$ & & & & \\
\hline Quarubarana & 26 & $-2,06$ & & & & & & & & \\
\hline Angelim pedra & 27 & $-1,73$ & & & & & & & & \\
\hline
\end{tabular}

NG = Número de Grupos formados

$\mathrm{D}_{\min }=$ Desvio absoluto mínino 
Tabela 12: Variação da soma dos quadrados dos desvios para os grupos formados nos niveis 0,0 a 0,5 da distância Euclidiana

\begin{tabular}{|c|c|c|c|c|c|c|c|c|c|c|}
\hline \multirow{3}{*}{ Espécie } & \multicolumn{10}{|c|}{ Niveis da distância Euclidiana } \\
\hline & \multicolumn{2}{|c|}{0,0} & \multicolumn{2}{|c|}{0,2} & \multicolumn{2}{|c|}{\begin{tabular}{|l|}
0,3 \\
\end{tabular}} & \multicolumn{2}{|c|}{0,4} & \multicolumn{2}{|r|}{0,5} \\
\hline & NG & SQD & NG & SQD & NG & SQD & NG & SQD & NG & SQD \\
\hline Guajará & 1 & 1207,1 & 1 & 1207,1 & 1 & 1207,1 & 1 & 1207,1 & 1 & 1207,1 \\
\hline Cumaru & 2 & 1188,1 & 2 & 1188,1 & 2 & 1188,1 & 2 & 1188,1 & 2 & 1188,1 \\
\hline Cerejeira & 3 & 69,6 & 3 & 69,6 & 3 & 69,6 & 3 & 69,6 & 3 & 69,6 \\
\hline Faveira verm. & 4 & 29,1 & 4 & 29,1 & 4 & 29,1 & 4 & 29,1 & 4 & 29,1 \\
\hline Goiabão & 5 & 316,1 & 5 & 316,1 & 5 & 316,1 & 5 & 316,1 & & \\
\hline Pau amarelo & 6 & 38,5 & 6 & 406,4 & 6 & 406,4 & 6 & 406,4 & & \\
\hline Freijó & 7 & 127,7 & & & & & & & & \\
\hline Cunninghamia & 8 & 300,8 & 7 & 300,8 & 7 & 300,8 & & & & \\
\hline Louro verm. & 9 & 432,6 & 8 & 432,6 & & & & & 5 & 8322,5 \\
\hline Marfim & 10 & 295,8 & & & & & 7 & 4480,4 & & \\
\hline Jatobá & 11 & 186,0 & 9 & 2758,1 & 8 & 3442,6 & & & & \\
\hline Imbuia & 12 & 477,7 & & & & & & & & \\
\hline Cedrorana & 13 & 233,7 & 10 & 233,7 & & & & & & \\
\hline E. grandis & 14 & 515,9 & & & & & & & & \\
\hline E. phaeotricha & 15 & 431,3 & 11 & 1438,7 & 9 & 1438,7 & & & & \\
\hline E. cloeziana & 16 & 356,6 & & & & & 8 & 2758,4 & 6 & 2758,3 \\
\hline E. nesophylla & 17 & 483,9 & 12 & 1253,0 & 10 & 1253,0 & & & & \\
\hline Breu & 18 & 347,5 & & & & & & & & \\
\hline P. patula & 19 & 100,5 & 13 & 100,5 & 11 & 100,5 & 9 & 259,5 & & \\
\hline Marupá & 20 & 20,3 & 14 & 20,3 & 12 & 20,3 & & & & \\
\hline Pinh.do Paraná & 21 & 46,8 & 15 & 46,8 & 13 & 46,8 & 10 & 46,8 & & \\
\hline Muiracatiara & 22 & 153,9 & 16 & 942,0 & 14 & 942,0 & & & & \\
\hline Ipê & 23 & 75,1 & & & & & & & 7 & 2591,4 \\
\hline Cryptomeria & 24 & 58,7 & & & & & 11 & 2052,7 & & \\
\hline Cedro & 25 & 80,6 & 17 & 1020,2 & 15 & 1020,2 & & & & \\
\hline Quarubarana & 26 & 95,5 & & & & & & & & \\
\hline Angelim pedra & 27 & 87,7 & & & & & & & & \\
\hline
\end{tabular}

NG = Número de Grupos formados

$S Q D=$ Soma do Quadrado dos Desvios 
Tabela 13 : Variação do quadrado médio dos desvios para os grupos formados nos niveis 0,0 a 0,5 da distância Euclidiana

\begin{tabular}{|c|c|c|c|c|c|c|c|c|c|c|}
\hline \multirow{3}{*}{ Espécie } & \multicolumn{10}{|c|}{ Níveis da distância Euclidiana } \\
\hline & \multicolumn{2}{|c|}{0,0} & \multicolumn{2}{|c|}{0,2} & \multicolumn{2}{|c|}{0,3} & \multicolumn{2}{|c|}{0,4} & \multicolumn{2}{|c|}{0,5} \\
\hline & ING & QMD & NG & QMD & NG & QMD & NG & QMD & NG & QMD \\
\hline Guajará & 1 & 17,49 & 1 & 17,49 & 1 & 17,49 & 1 & 17,49 & 1 & 17,49 \\
\hline Cumaru & 2 & 16,97 & 2 & 16,97 & 2 & 16,97 & 2 & 16,97 & 2 & 16,97 \\
\hline Cerejeira & 3 & $\overline{1,74}$ & 3 & 1,74 & 3 & $\overline{1,74}$ & 3 & 1,74 & 3 & 1,74 \\
\hline Faveira verm. & 4 & 0,45 & 4 & 0,45 & 4 & 0,45 & 4 & 0,45 & 4 & 0,45 \\
\hline Goiabão & 5 & 2,51 & 5 & 2,51 & 5 & 2,51 & 5 & 2,51 & & \\
\hline Pau amarelo & 6 & 0,45 & 6 & 2,17 & 6 & 2,17 & 6 & 2,17 & & \\
\hline Freijó & 7 & 1,25 & & & & & & & & \\
\hline Cunninghamia & 8 & 5,28 & 7 & 5,28 & 7 & 5,28 & & & & \\
\hline Louro verm. & 9 & 4,12 & 8 & 4,12 & & & & & 5 & 9,51 \\
\hline Marfim & 10 & 2,51 & & & & & 7 & 7,97 & & \\
\hline Jatobá & 11 & 2,00 & 9 & 8,54 & 8 & 6,82 & & & & \\
\hline Imbuia & 12 & 4,27 & & & & & & & & \\
\hline Cedrorana & 13 & 3,04 & 10 & 3,04 & & & & & & \\
\hline E. grandis & 14 & 3,46 & & & & & & & & \\
\hline E. phaeotricha & 15 & 3,92 & 11 & 4,36 & 9 & 4,36 & & & & \\
\hline E. cloeziana & 16 & 5,02 & & & & & 8 & 5,24 & 6 & 5,24 \\
\hline E. nesophylla & 17 & 4,28 & 12 & 6,39 & 10 & 6,39 & & & & \\
\hline Breu & 18 & 4,19 & & & & & & & & \\
\hline P. patula & 19 & 1,80 & 13 & 1,80 & 11 & 1,80 & 9 & 2,52 & & \\
\hline Marupá & 20 & 0,43 & 14 & 0,43 & 12 & 0,43 & & & & \\
\hline Pinh. do Paraná & 21 & 0,56 & 15 & 0,56 & 13 & 0,56 & 10 & 0,56 & & \\
\hline Muiracatiara & 22 & 1,48 & 16 & 5,74 & 14 & 5,74 & & & & \\
\hline $\mid \overline{\mid l p e ̂}$ & 23 & 1,25 & & & & & & & 7 & 3,94 \\
\hline Cryptomeria & 24 & 1,03 & & & & & 11 & 4,36 & & \\
\hline Cedro & 25 & 1,12 & 17 & 3,32 & 15 & 3,32 & & & & \\
\hline Quarubarana & 26 & 0,96 & & & & & & & & \\
\hline Angelim pedra & 27 & 1,11 & & & & & & & & \\
\hline
\end{tabular}

$N G=$ Número de Grupos formados

QMD = Quadrado médio dos desvios 
Tabela 14 : Variação do coeficiente de determinação para os grupos formados nos níveis 0,0 a 0,5 da distância Euclidiana

\begin{tabular}{|c|c|c|c|c|c|c|c|c|c|c|}
\hline \multirow{3}{*}{ Espécie } & \multicolumn{10}{|c|}{ Níveis da distância Euclidiana } \\
\hline & \multicolumn{2}{|c|}{0,0} & \multicolumn{2}{|c|}{0,2} & \multicolumn{2}{|c|}{0,3} & \multicolumn{2}{|c|}{0,4} & \multicolumn{2}{|c|}{0,5} \\
\hline & $\widehat{N G}$ & $r^{2}$ & NG & $r^{2}$ & NG & $r^{2}$ & NG & $r^{2}$ & NG & $r^{2}$ \\
\hline Guajará & 1 & 70,1 & 1 & 70,1 & 1 & 70,1 & 1 & 70,1 & 1 & 70,1 \\
\hline Cumaru & 2 & 60,3 & 2 & 60,3 & 2 & 60,3 & 2 & 60,3 & 2 & 60,3 \\
\hline Cerejeira & 3 & 87,1 & 3 & 87,1 & 3 & 87,1 & 3 & 87,1 & 3 & 87,1 \\
\hline Faveira verm. & 4 & 93,5 & 4 & 93,5 & 4 & 93,5 & 4 & 93,5 & 4 & 93,5 \\
\hline Goiabão & 5 & 87,2 & 5 & 87,2 & 5 & 87,2 & 5 & 87,2 & & \\
\hline Pau amarelo & 6 & 94,2 & 6 & 93,6 & 6 & 93,6 & 6 & 93,6 & & \\
\hline Freijó & 7 & 93,6 & & & & & & & & \\
\hline Cunninghamia & 8 & 79,4 & 7 & 79,4 & 7 & 79,4 & & & & \\
\hline Louro verm. & 9 & 84,9 & 8 & 84,9 & & & & & 5 & 73,6 \\
\hline Marfim & 10 & 89,8 & & & & & 7 & 73,3 & & \\
\hline Jatobá & 11 & 86,8 & 9 & 70,4 & 8 & 76,2 & & & & \\
\hline Imbuia & 12 & 79,9 & & & & & & & & \\
\hline Cedrorana & 13 & 86,8 & 10 & 86,8 & & & & & & \\
\hline E. grandis & 14 & 89,2 & & & & & & & & \\
\hline E. phaeotricha & 15 & 82,3 & 11 & 86,5 & 9 & 86,5 & & & & \\
\hline E. cloeziana & 16 & 87,1 & & & & & 8 & 83,7 & 6 & 83,7 \\
\hline E. nesophylla & 17 & 84,8 & 12 & 79,8 & 10 & 79,8 & & & & \\
\hline Breu & 18 & 86,4 & & & & & & & & \\
\hline P. patula & 19 & 86,0 & 13 & 86,0 & 11 & 86,0 & 9 & 81,9 & & \\
\hline Marupá & 20 & 96,5 & 14 & 96,5 & 12 & 96,5 & & & & \\
\hline Pinh. do Paraná & 21 & 95,7 & 15 & 95,7 & 13 & 95,7 & 10 & 95,7 & & \\
\hline Muiracatiara & 22 & 93,3 & 316 & 75,0 & 14 & 75,0 & & & & \\
\hline |lpê & 23 & 84,2 & & & & & & & 7 & 77,7 \\
\hline Cryptomeria & 24 & 89,6 & & & & & 11 & 76,9 & & \\
\hline Cedro & 25 & 93,2 & 17 & 79,7 & 15 & 79,7 & & & & \\
\hline Quarubarana & 26 & 91,0 & & & & & & & & \\
\hline Angelim pedra & 27 & 91,2 & & & & & & & & \\
\hline
\end{tabular}

NG = Número de Grupos formados $r^{2}=$ Coeficiente de Determinação 
Analisando-se o nivel 0,2 nota-se a formação de pequenos grupos, isto porque é um nivel ainda baixo, onde as espécies selecionadas pela análise de Cluster tem maiores afinidades entre si, e na maioria dos casos a formação de uma equação comum não resultaria em diferenças significativas nas leituras. Nesse nivel são formados 17 grupos, contendo de uma a quatro espécies.

No próximo nivel a alteração na formação de grupos foi muito pequena. Duas espécies que formavam grupos individuais passaram a fazer parte de um grupo formado por três espécies, dando origem a um novo grupo. Portanto, foram formados 15 grupos no nível 0,3 .

Quando a distância é aumentada para 0,4 , das 27 espécies utilizadas, são formados 11 grupos, mesmo nesse nivel muitas espécies ainda se mantém totalmente isoladas, como é o caso do Guajará, do Cumaru, da Cerejeira, da Faveira vermelha, e do Goiabão. A partir desse nível todos os Eucaliptos se dispõem no mesmo grupo.

No último nivel escolhido $(0,5)$ há formação de 3 grandes grupos, e 4 espécies continuam formando grupos isolados, talvez isso seja a evidência de que essas espécies necessitariam de novo levantamento em laboratório para confirmação dos resultados obtidos. A Faveira vermelha confirma essa idéia em função de ter desenvolvido um gradiente de secagem muito acentuado durante o experimento.

Observa-se que do nivel 0,4 para o nivel 0,5 aumentam os desvios e diminui o coeficiente de determinação a medida que novos grupos são formados, incluindo mais espécies.

Definir exatamente qual o melhor nivel ou o número mínimo de grupos admissiveis é difícil, pois essa decisão depende também tanto da capacidade do medidor em dispor nos seus circuitos processadores suficientes para operar várias escalas de ajuste (equações que transformaram a medida da resistência elétrica em umidade), como da precisão que se deseja para as medições. 
Para sistemas de controle baseados em microcomputadores será mais fácil aplicar uma equação para cada espécie, opção menos viável quando se considera os medidores portáteis.

Numa análise final é possivel identificar o nivel 0,3 como a forma de grupamento que provavelmente levaria a erros aceitáveis, com relativo sucesso no grupamento das espécies.

Resta ainda analisar o caso das poucas espécies que se mantém isoladas até os niveis 0,4 e 0,5 de distância Euclidiana.

No caso da Faveira vermelha, o tipo de gradiente de umidade apresentado durante a secagem restringiu a faixa de umidade $(3,6$ a $12,8 \%)$ em que foram obtidos resultados válidos. Situação similar verifica-se também para o Goiabão (faixa de umidade de 5,6 a 20,4 \%).

Para o Guajará e o Cumaru observa-se que os desvios são elevados e os coeficientes de determinação são os menores obtidos no experimento. Esse comportamento pode indicar tanto que a metodologia não foi adequada para essas espécies como também um aspecto intrínseco da espécie (decorrente da composição química dos componentes acidentais), que interfere na propriedade da resistência a passagem da corrente elétrica; tornando menos adequado esse método para a estimativa do teor de umidade.

De qualquer forma, sugere-se que essas espécies sejam novamente estudadas, visando aprimorar a metodologia experimental ou confirmar o comportamento representado nesse estudo.

Durante o desenvolvimento desse estudo a preocupação maior foi conseguir unir espécies com afinidades de leitura de resistência ao mesmo teor de umidade, justamente para poder fazer uso da automação sem prejuízo de erros de leitura de umidade. A leitura correta da umidade da madeira não é útil apenas para um secador automatizado, mas também é essencial em qualquer processamento que exige precisão do teor de umidade trabalhado. 


\section{CONCLUSÕES}

A análise dos resultados obtidos no presente estudo permite concluir :

a) como era esperado, o teor de umidade da madeira estimado a partir da sua resistência elétrica, utilizando o modelo geral ln $R=A+B . U$ (onde $R$ é o valor da resistência, $U$ é o valor da umidade, e $A$ e $B$ os parâmetros da equação), apresentou curvas individuais para cada espécie;

b) considerando o total das espécies estudadas, o modelo geral mostrou-se adequado para a faixa de umidade variando de 4 a $40 \%$;

c) o valor máximo do teor de umidade que pode ser estimado com precisão, variou de 19 a $40 \%$ (entre as espécies em estudo). Essa diferença entre espécies pode ter sido causada pela variação do teor de umidade no ponto de saturação das fibras, pela falta de sensibilidade do medidor quando a resistência elétrica é inferior a $1,5 \times 10^{3} \mathrm{k} \Omega$, ou pela baixa permeabilidade de algumas espécies (dificultando o fluxo de água capilar) associada com o posicionamento dos sensores;

d) a medição da resistência elétrica no sentido perpendicular as fibras resulta em estimativas mais precisas do teor de umidade, em comparação as medições no sentido paralelo as fibras; 
e) nas condições do experimento não foi constatada correlação entre a resistência elétrica e a densidade básica da madeira, a um mesmo teor de umidade. Essa constatação não recomenda o grupamento de espécies em função da densidade básica, como é comum em diversos medidores atualmente em uso;

f) é possível o grupamento de espécies tendo como base a equação que relaciona o teor de umidade com a resistência elétrica. O nível de grupamento a ser adotado irá depender da capacidade do medidor e da precisão desejada para estimar o teor de umidade, e deve ser baseado em testes ide laboratório;

Adicionalmente, sugere-se que espécies com restrições ao fluxo de água capilar (como a Faveira vermelha, por exemplo) sejam novamente avaliadas visando o aprimoramento da metodologia utilizada e conhecer mais profundamente o efeito do gradiente de umidade na relação entre a resistência elétrica e o teor de umidade.

Considerando que a metodologia procurou eliminar o efeito do gradiente de umidade, outra sugestão é a de repetir este estudo nas condições da secagem convencional, visando conferir a aplicabilidade dos resultados apresentados neste trabalho. 
ANEXO : Gráficos 


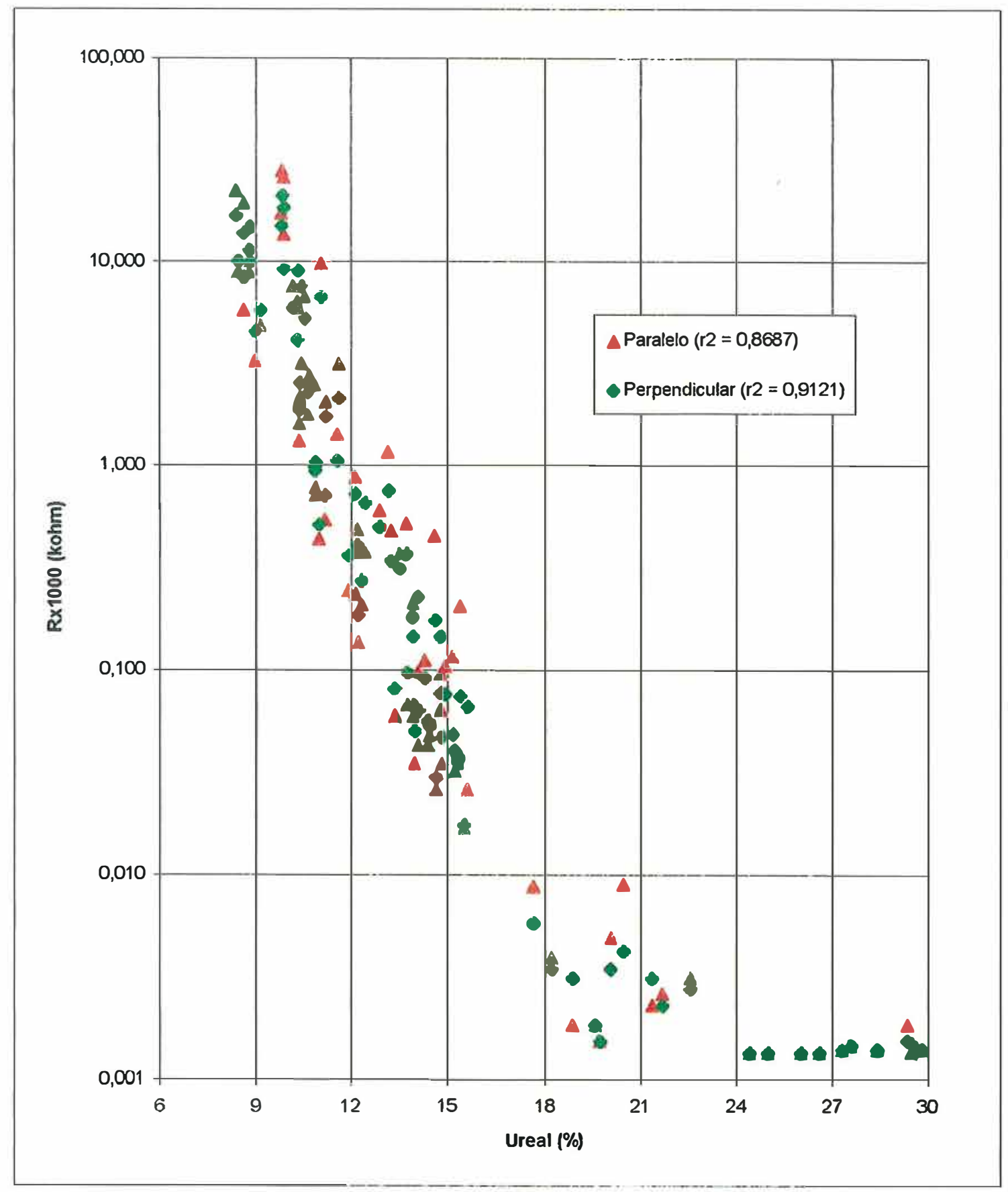

Anexo 1 : Variação da resistência elétrica, no sentido paralelo e perpendicular, em relação a umidade para a madeira de Angelim pedra. 


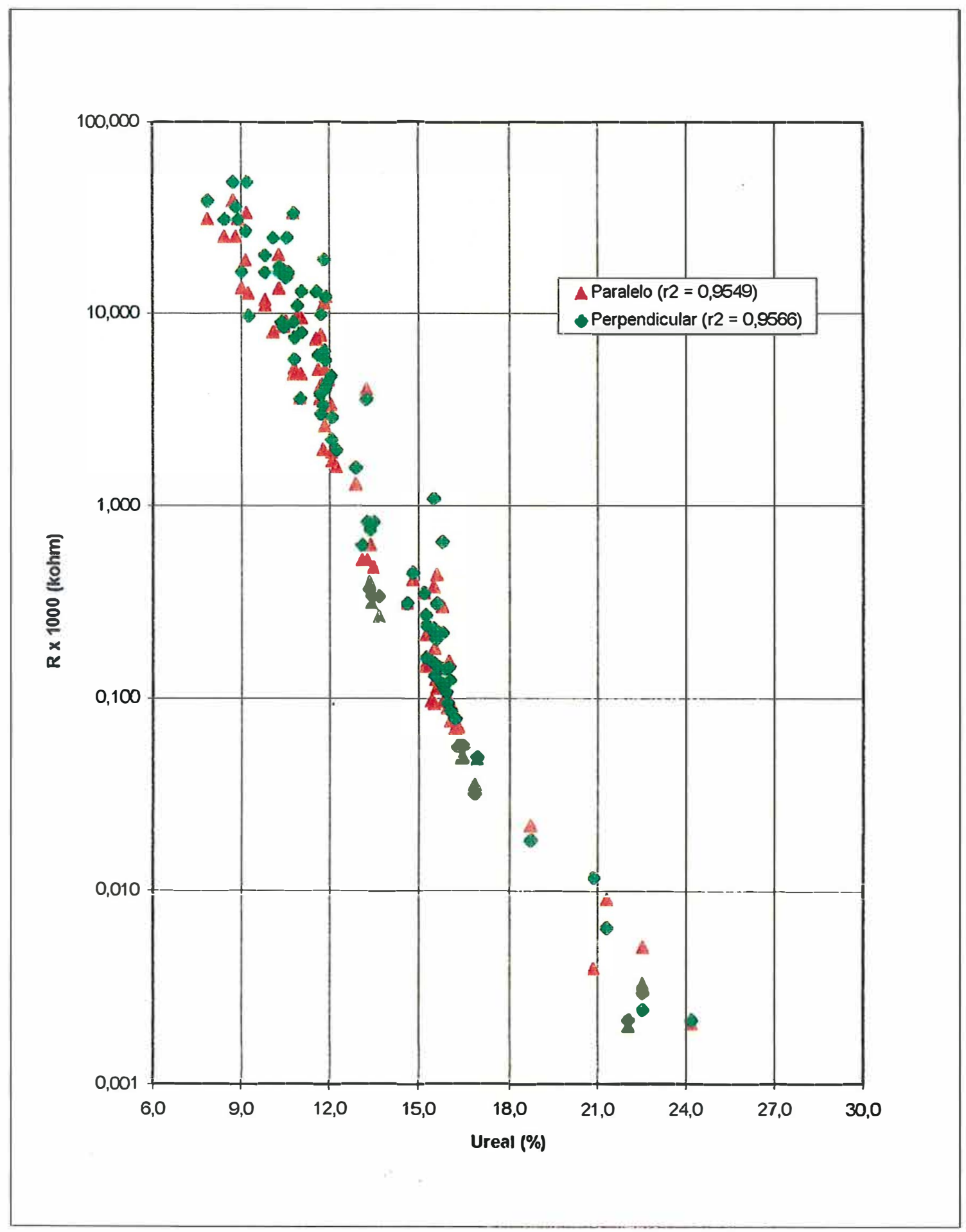

Anexo 2 : Variação da resistência elétrica, no sentido paralelo e perpendicular, em relação a umidade para a madeira de Araucaria. 


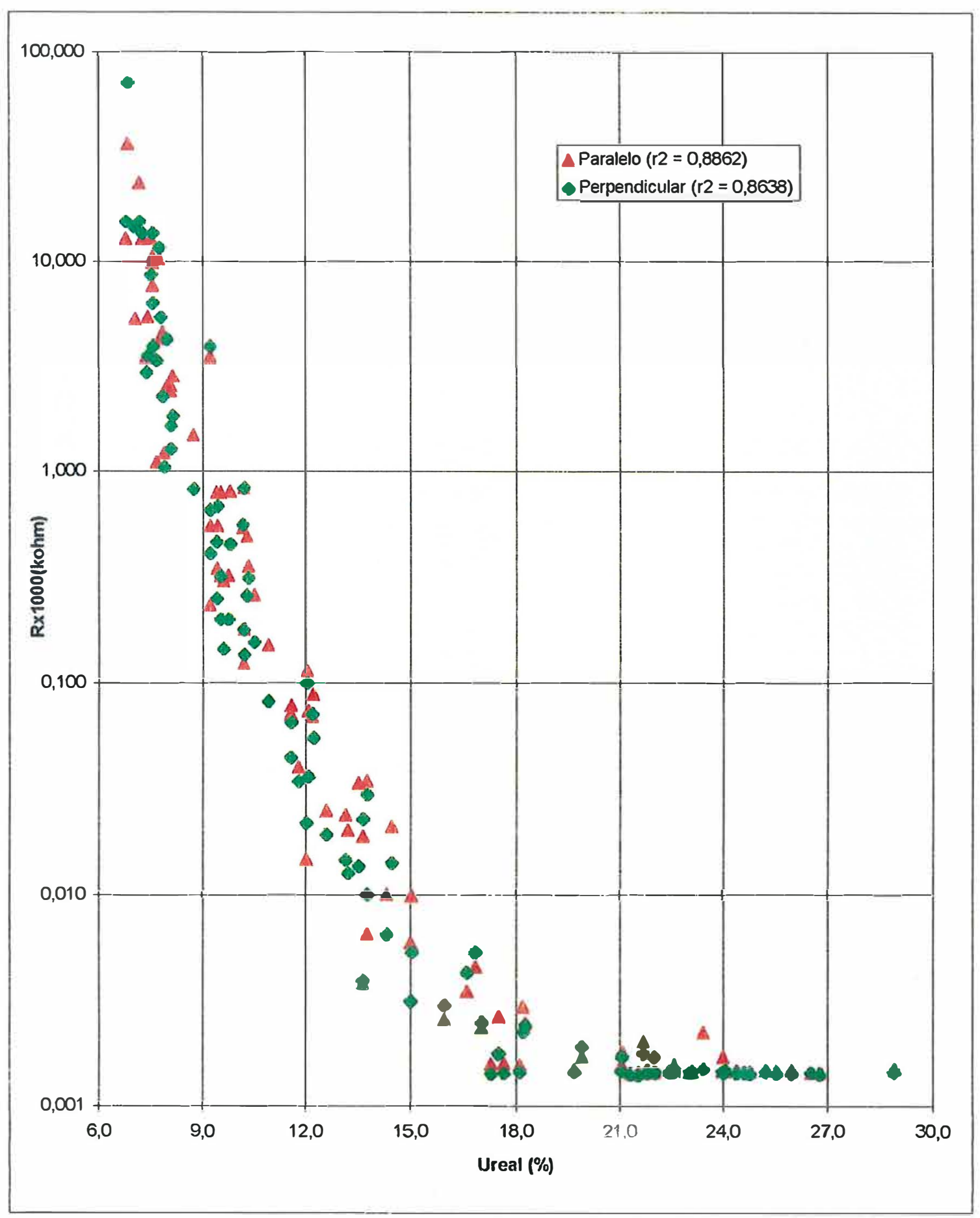

Anexo 3: Variação da resistência elétrica, no sentido paralelo e perpendicular, em relação a umidade para a madeira de Breu 


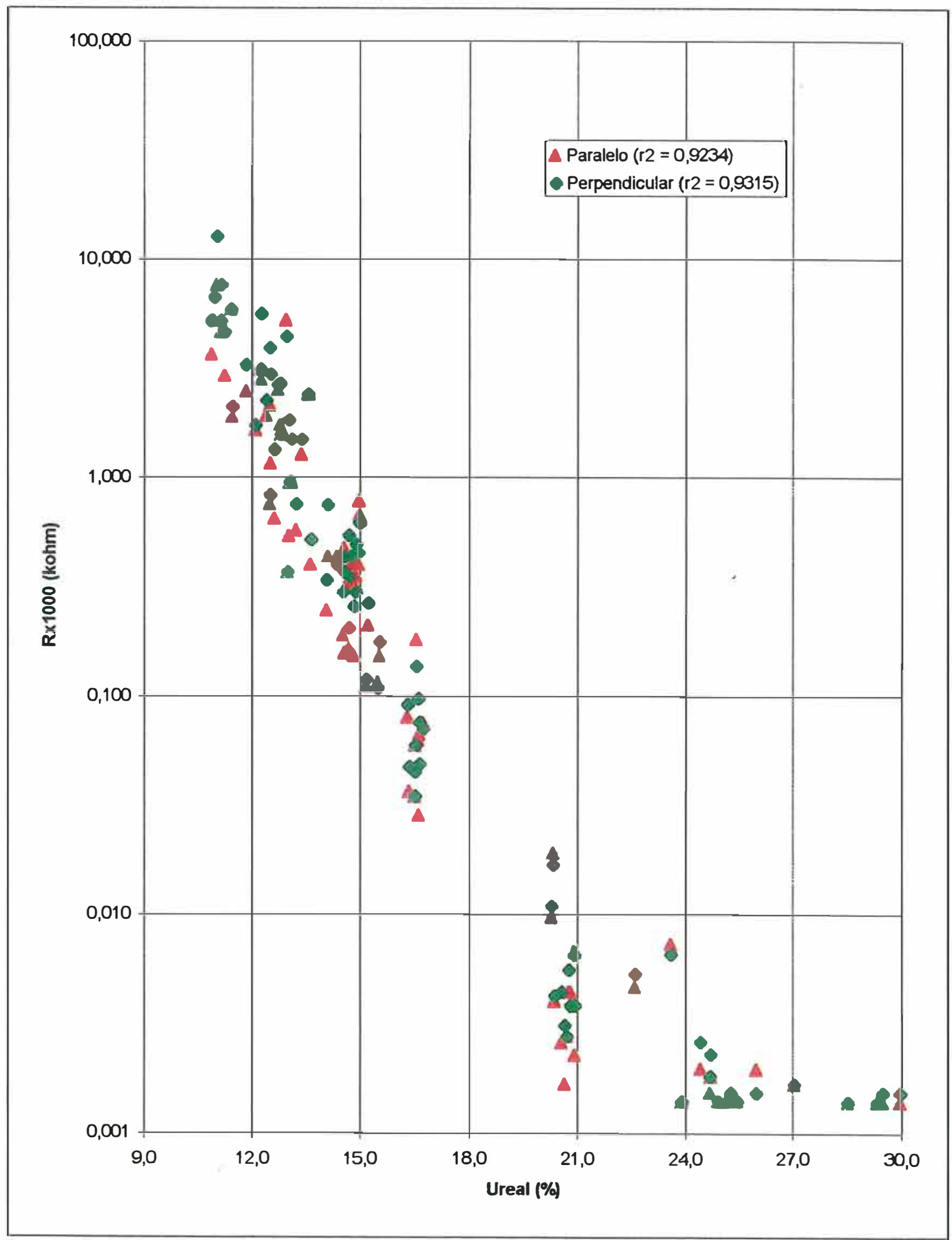

Anexo 4 : Variação da resistência elétrica, no sentido paralelo e perpendicular, em relação a umidade para a madeira de Cedro. 


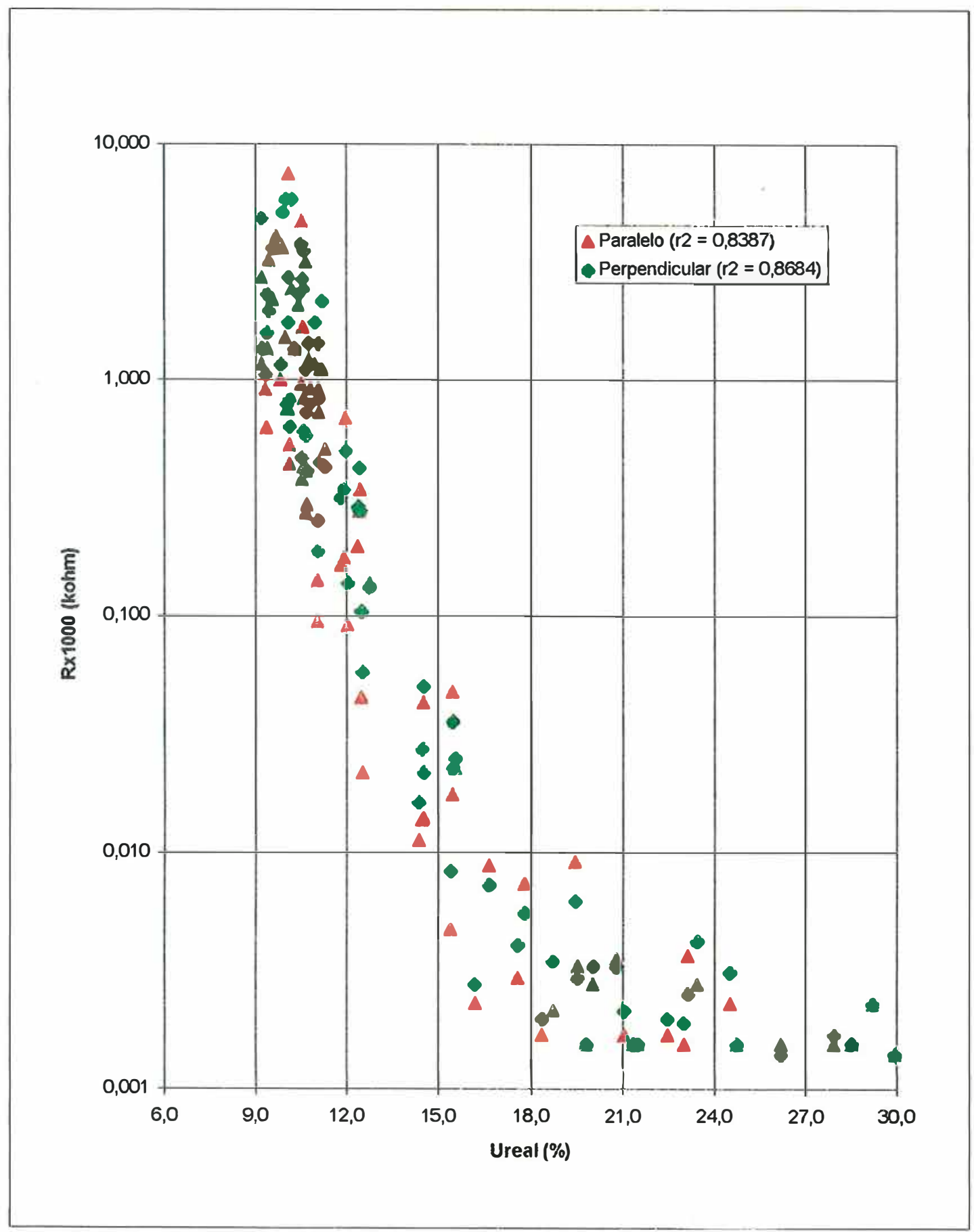

Anexo 5 : Variação da resistência elétrica, no sentido paralelo e perpendicular, em relação a umidade para a madeira de Cedrorana. 


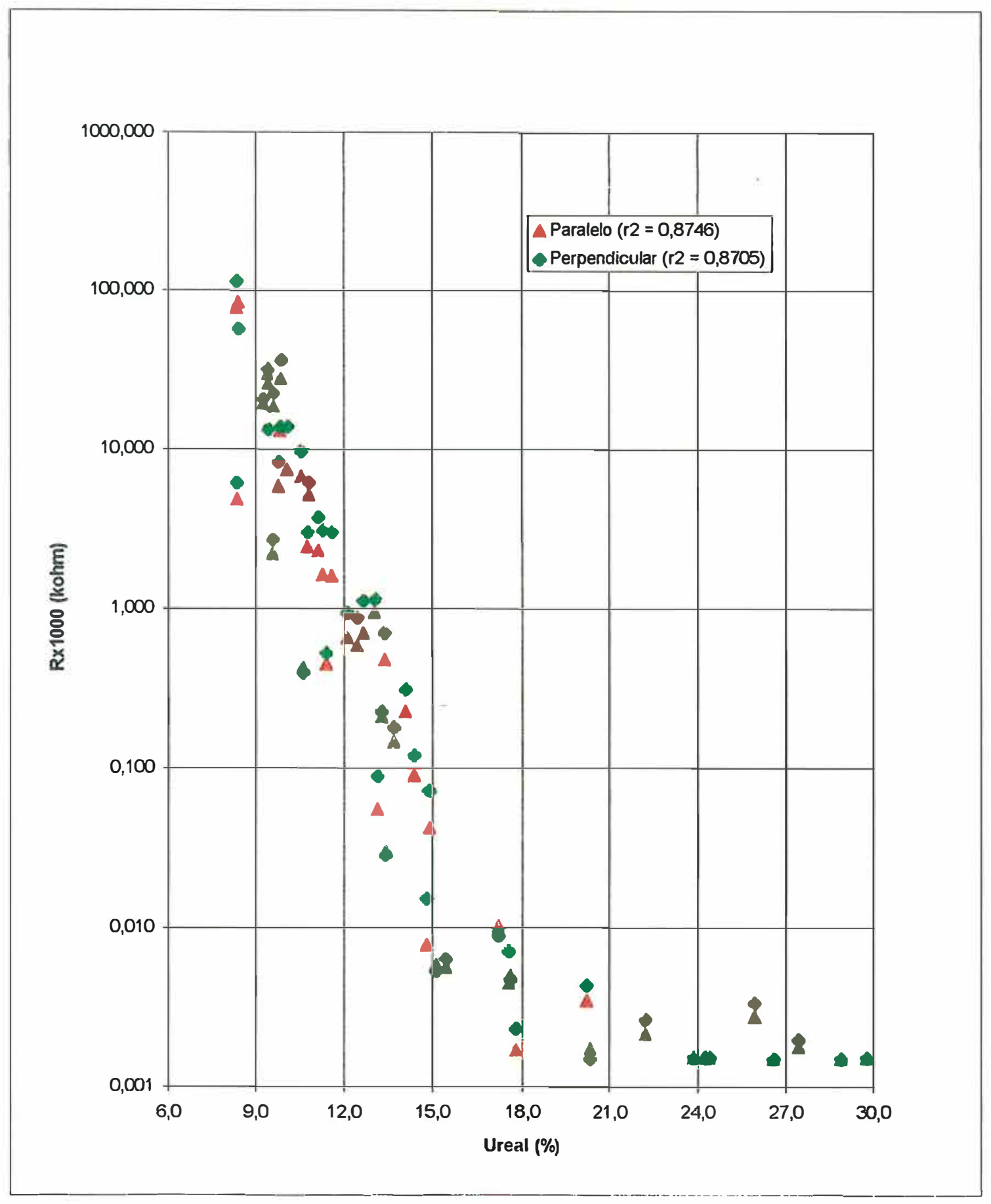

Anexo 6 : Variação da resistência elétrica, no sentido paralelo e perpendicular, em relação a umidade para a madeira de Cerejeira. 


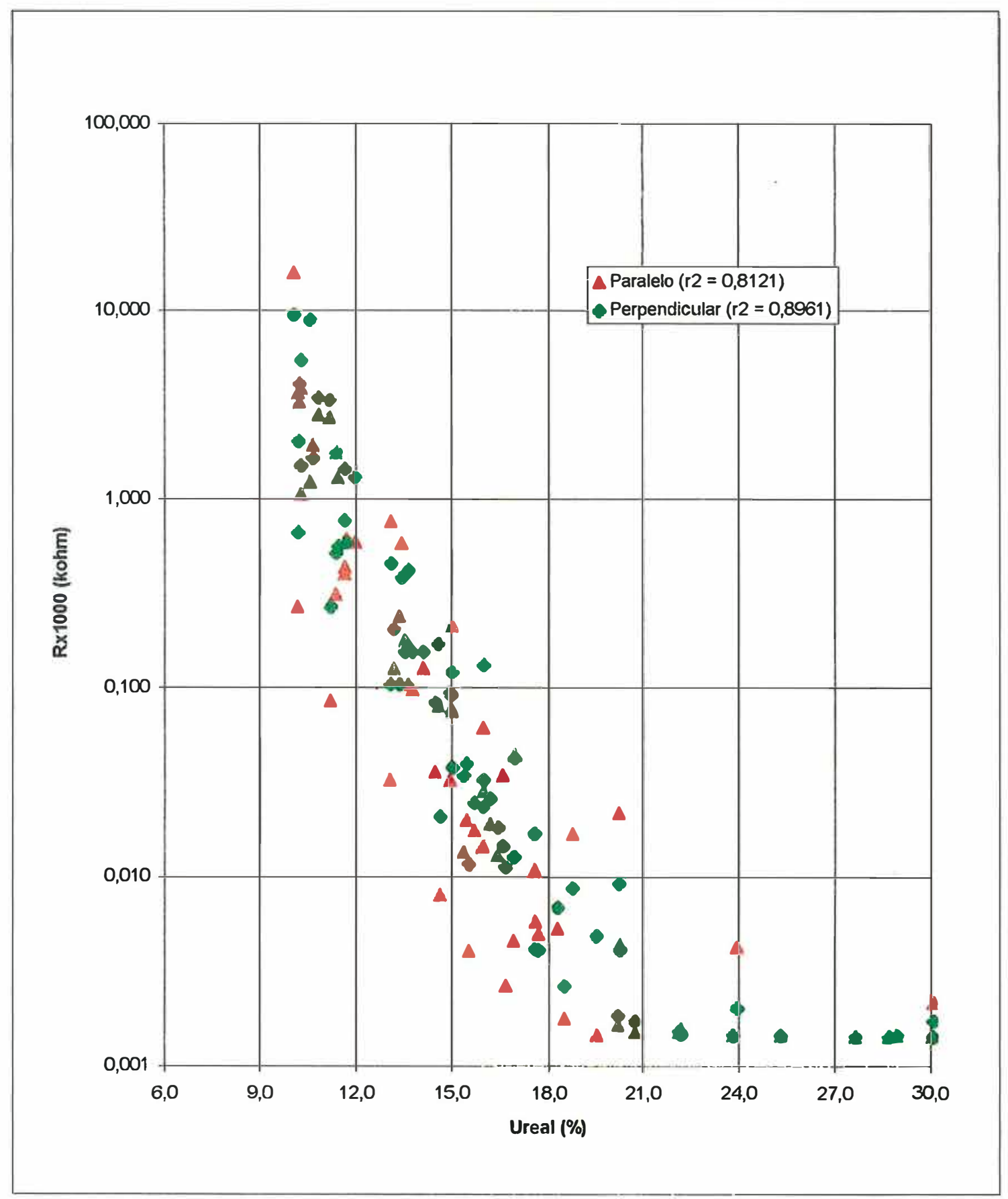

Anexo 7 : Variação da resistência elétrica, no sentido paralelo e perpendicular, em relação a umidade real para a madeira de Cryptomeria. 


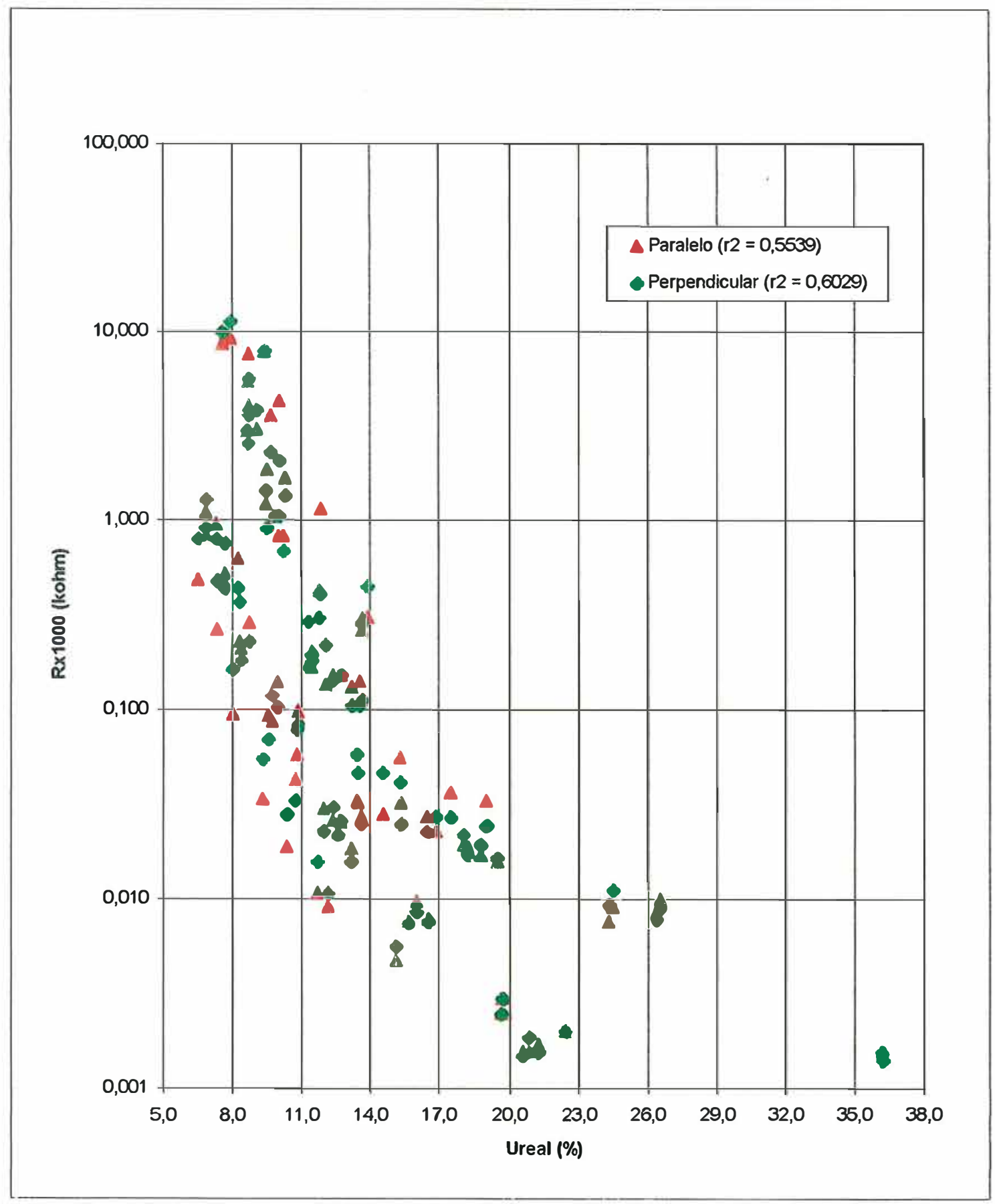

Anexo 8 : Variação da resistência elétrica, no sentido paralelo e perpendicular, 'em relação a umidade para a madeira de Cumaru. 


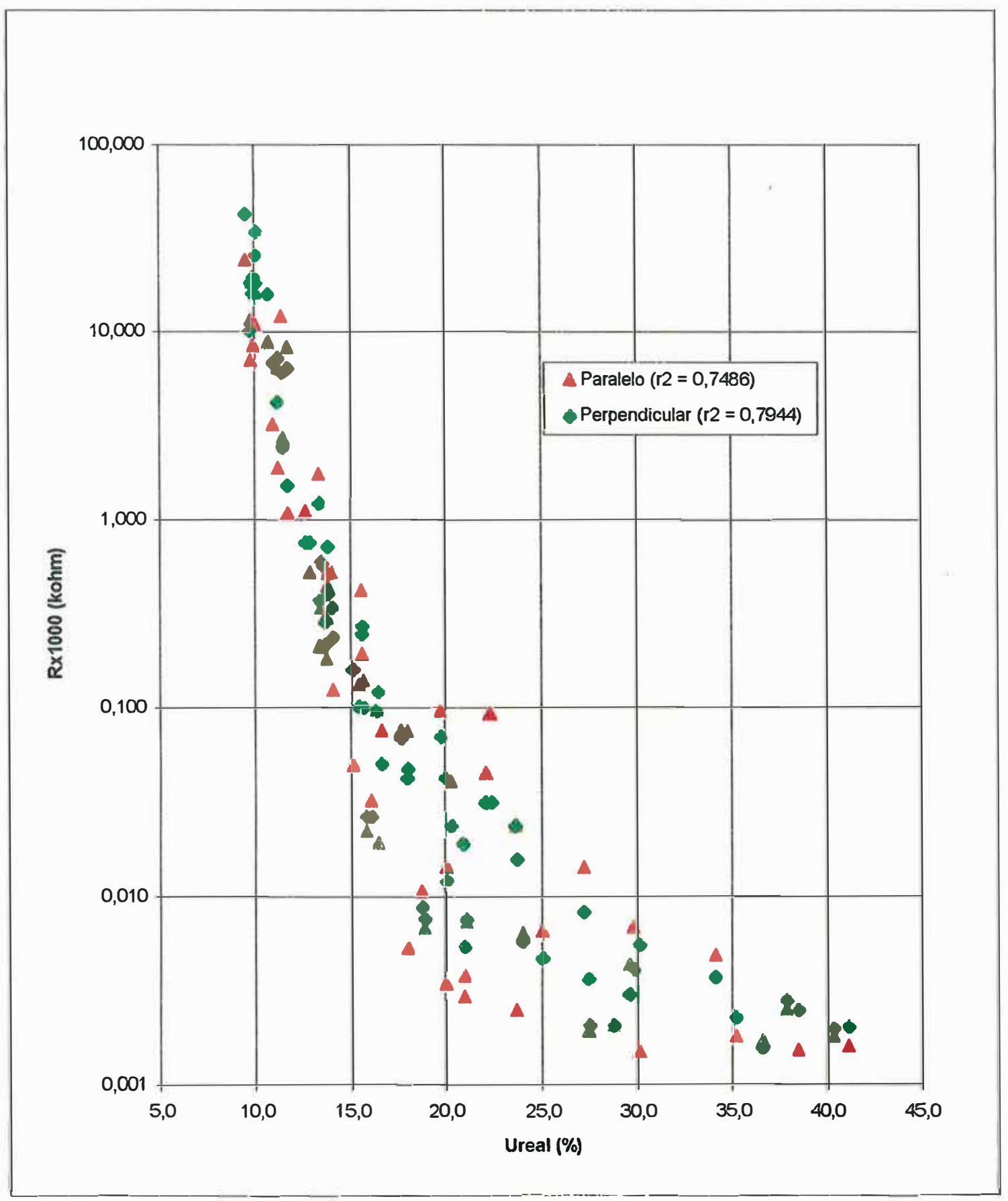

Anexo 9 : Variação da resistência elétrica, no sentido paralelo e perpendicular, em relação a umidade para a madeira de Cunninghamia. 


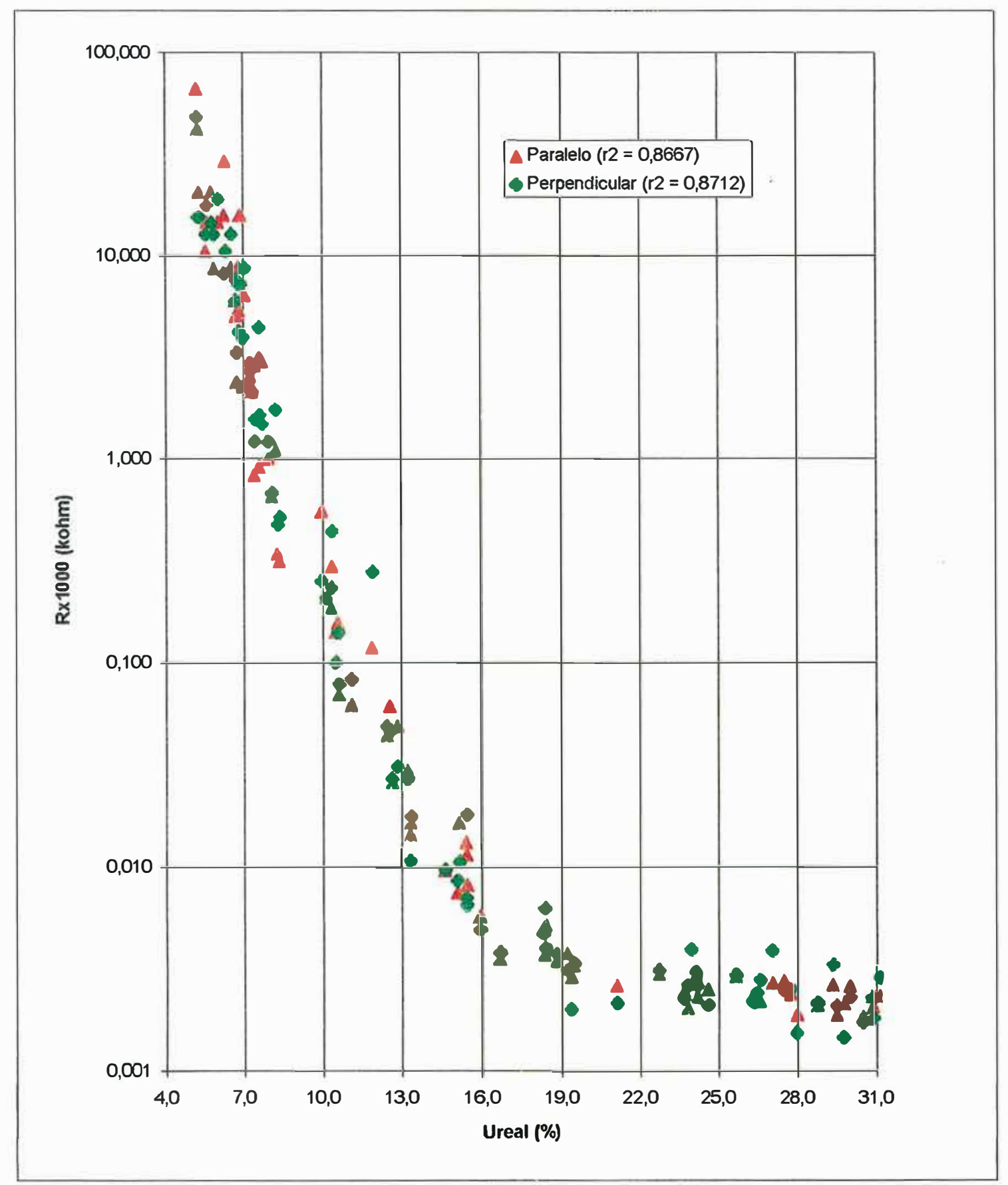

Anexo 10 : Variação da resistência elétrica, no sentido paralelo e perpendiculaı em relação a umidade para a madeira de E. cloeziana. 


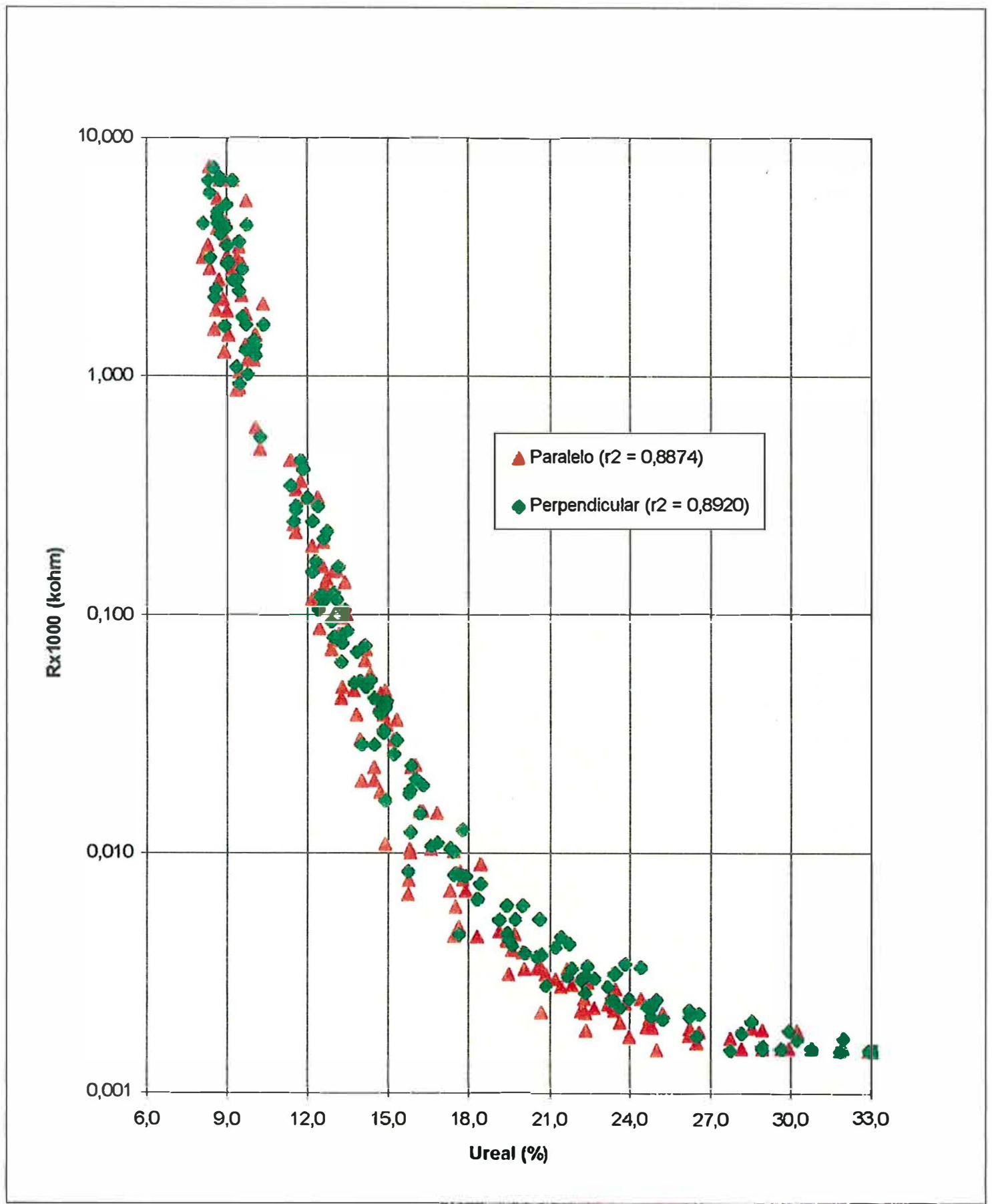

Anexo 11 : Variação da resistência elétrica, no sentido paralelo e perpendiculaı em relação a umidade para a madeira de $\mathrm{E}$. grandis. 


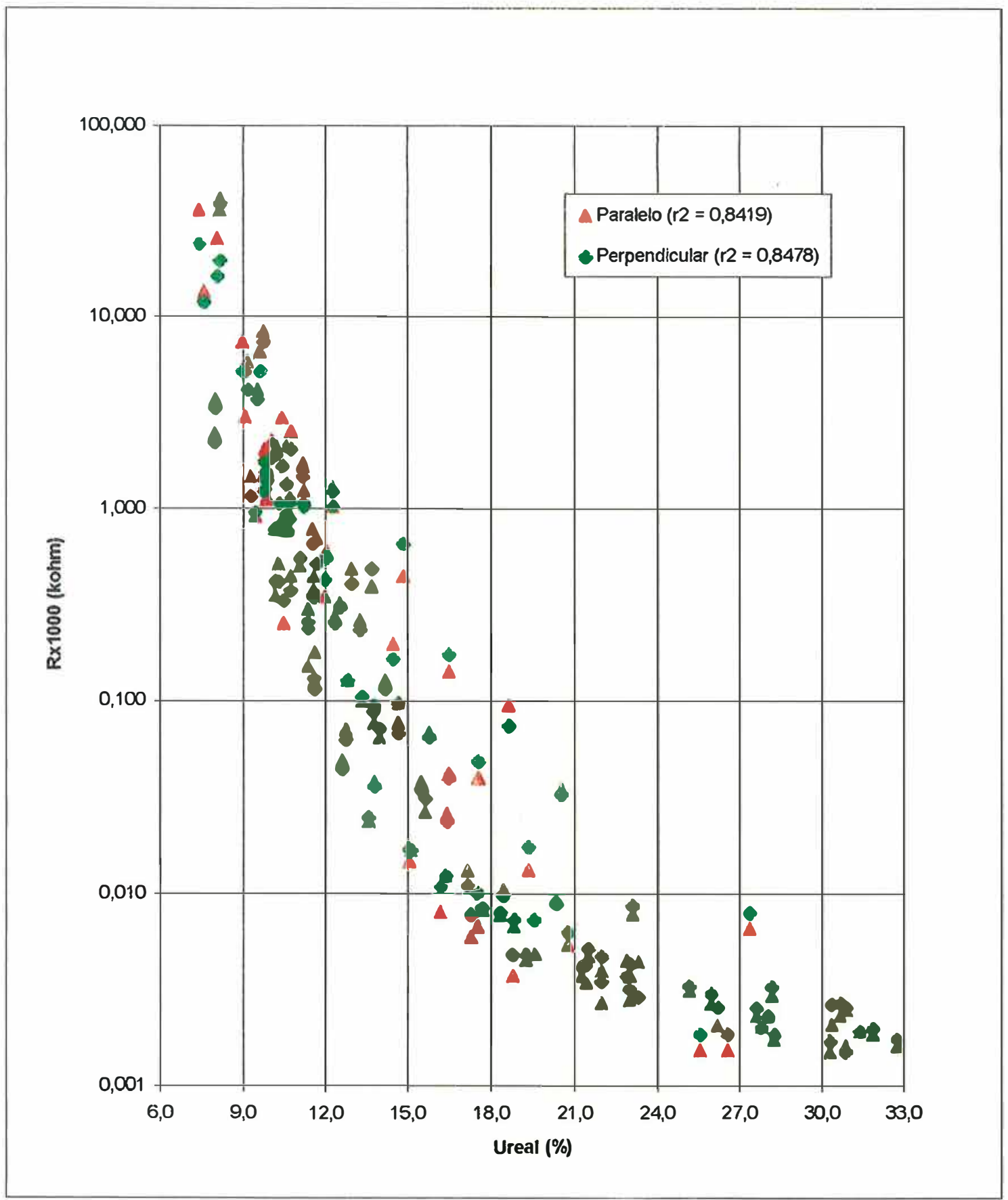

Anexo 12: Variação da resistência elétrica, no sentido paralelo e perpendicular em relação a umidade para a madeira de $\mathrm{E}$. nesophylla. 


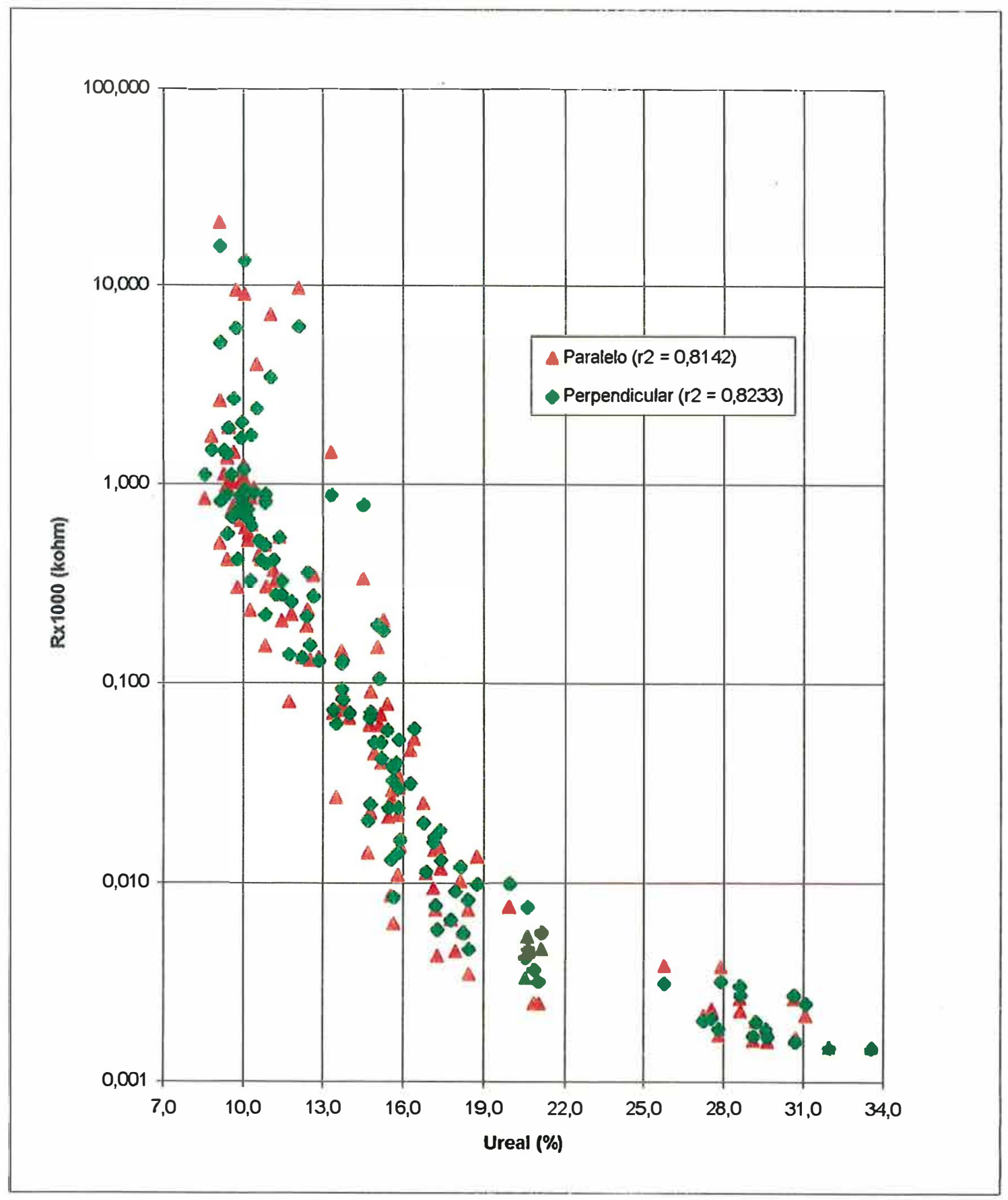

Anexo 13: Variação da resistência elétrica, no sentido paralelo e perpendicular em relação a umidade para a madeira de E. phaeotricha. 


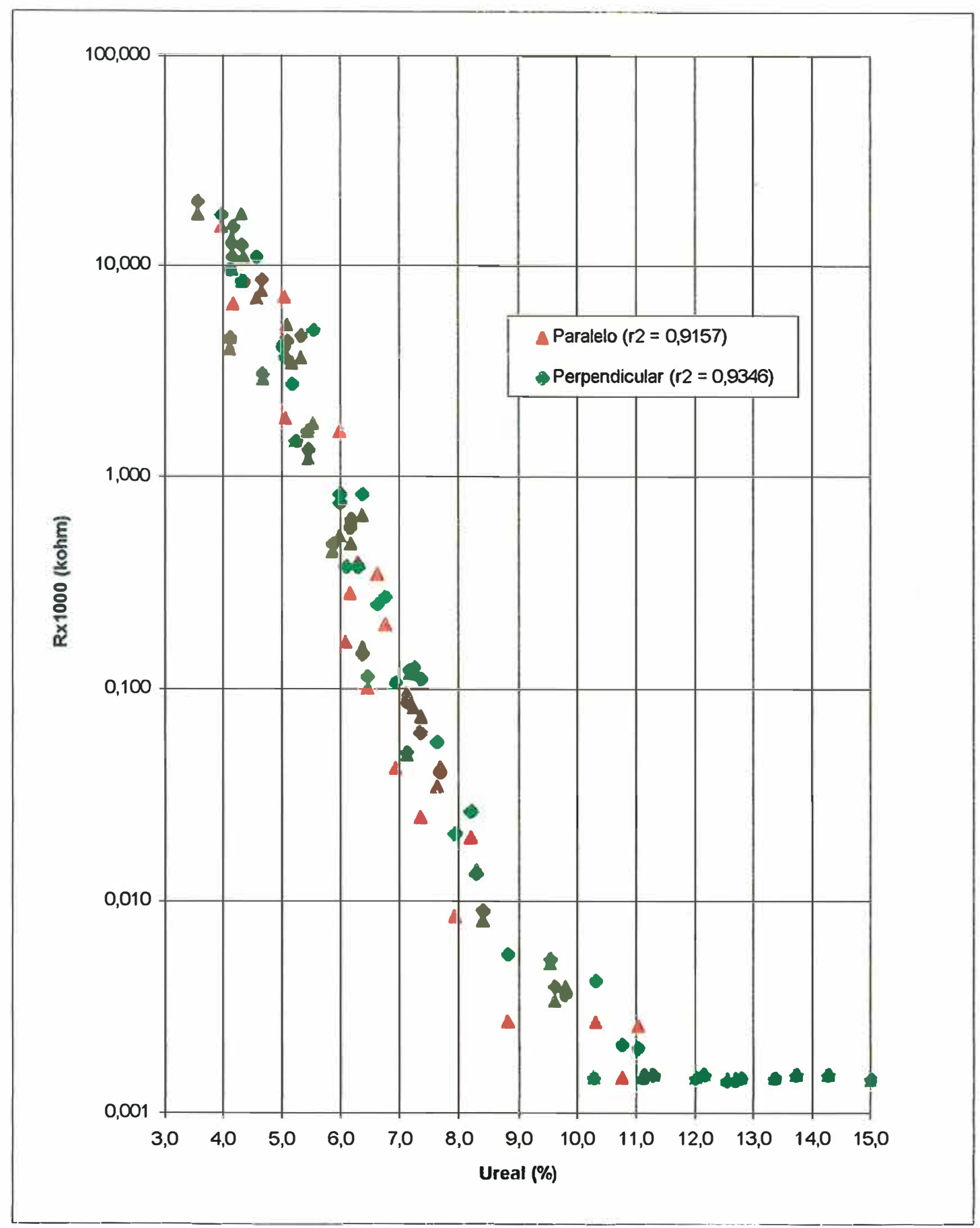

Anexo 14: Variação da resistência elétrica, no sentido paralelo e perpendicular em relação a umidade para a madeira de Faveira vermelha. 


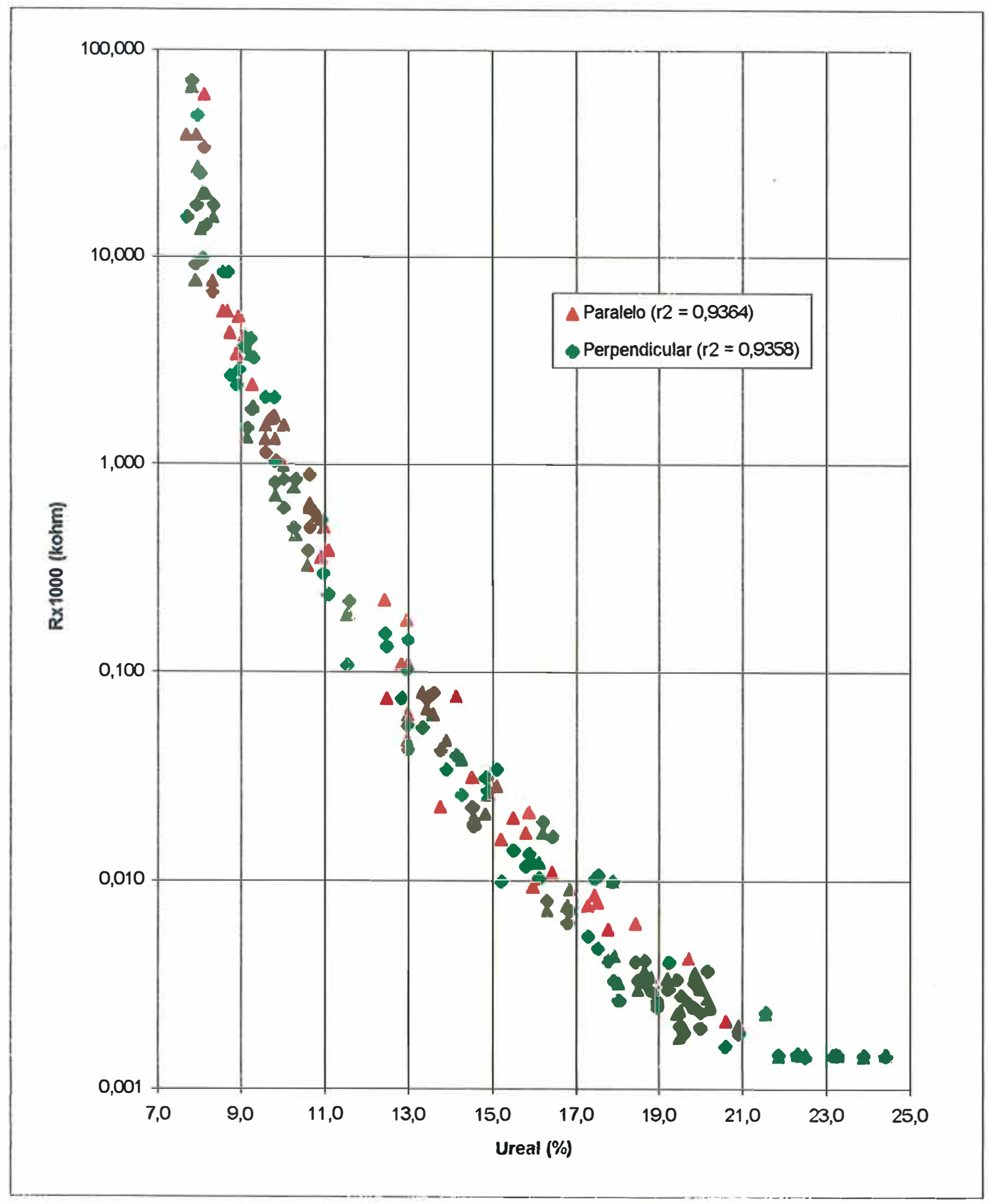

Anexo 15: Variação da resistência elétrica, no sentido paralelo e perpendicular em relação a umidade para a madeira de Freijó. 


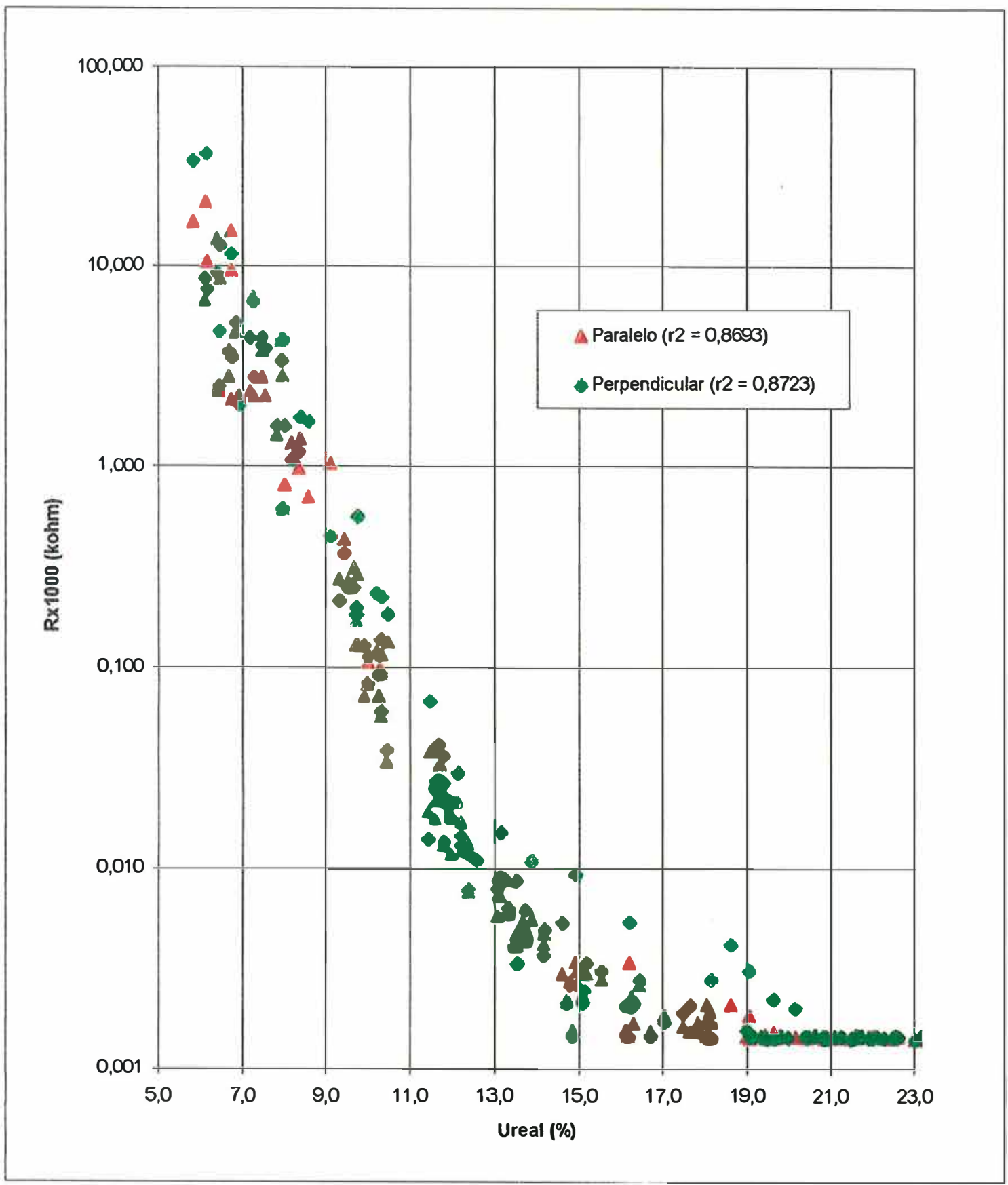

Anexo 16 : Variação da resistência elétrica, no sentido paralelo e perpendicular em relação a umidade para a madeira de Goiabão. 


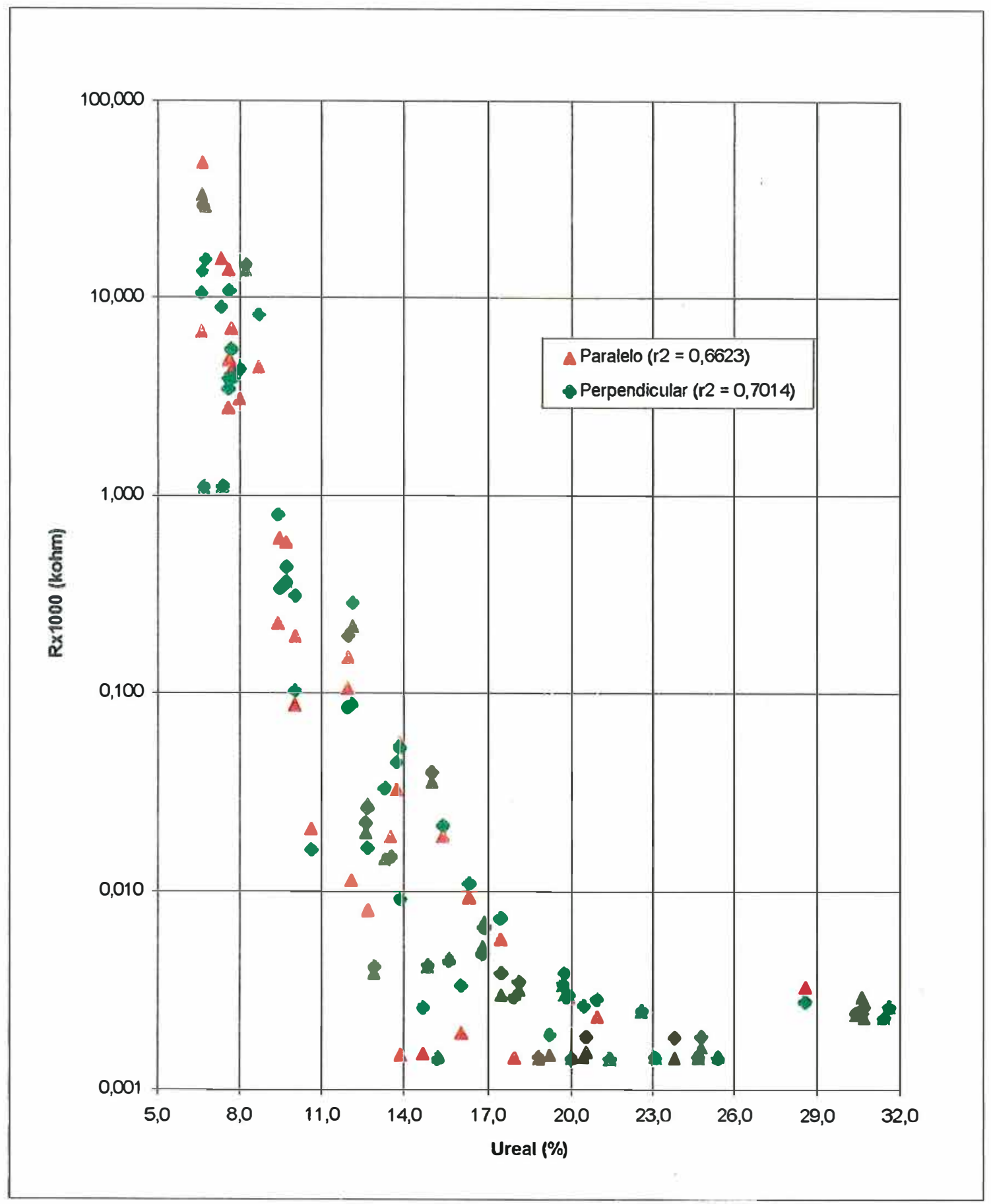

Anexo 17: Variação da resistência elétrica, no sentido paralelo e perpendicular em relação a umidade para a madeira de Guajará. 


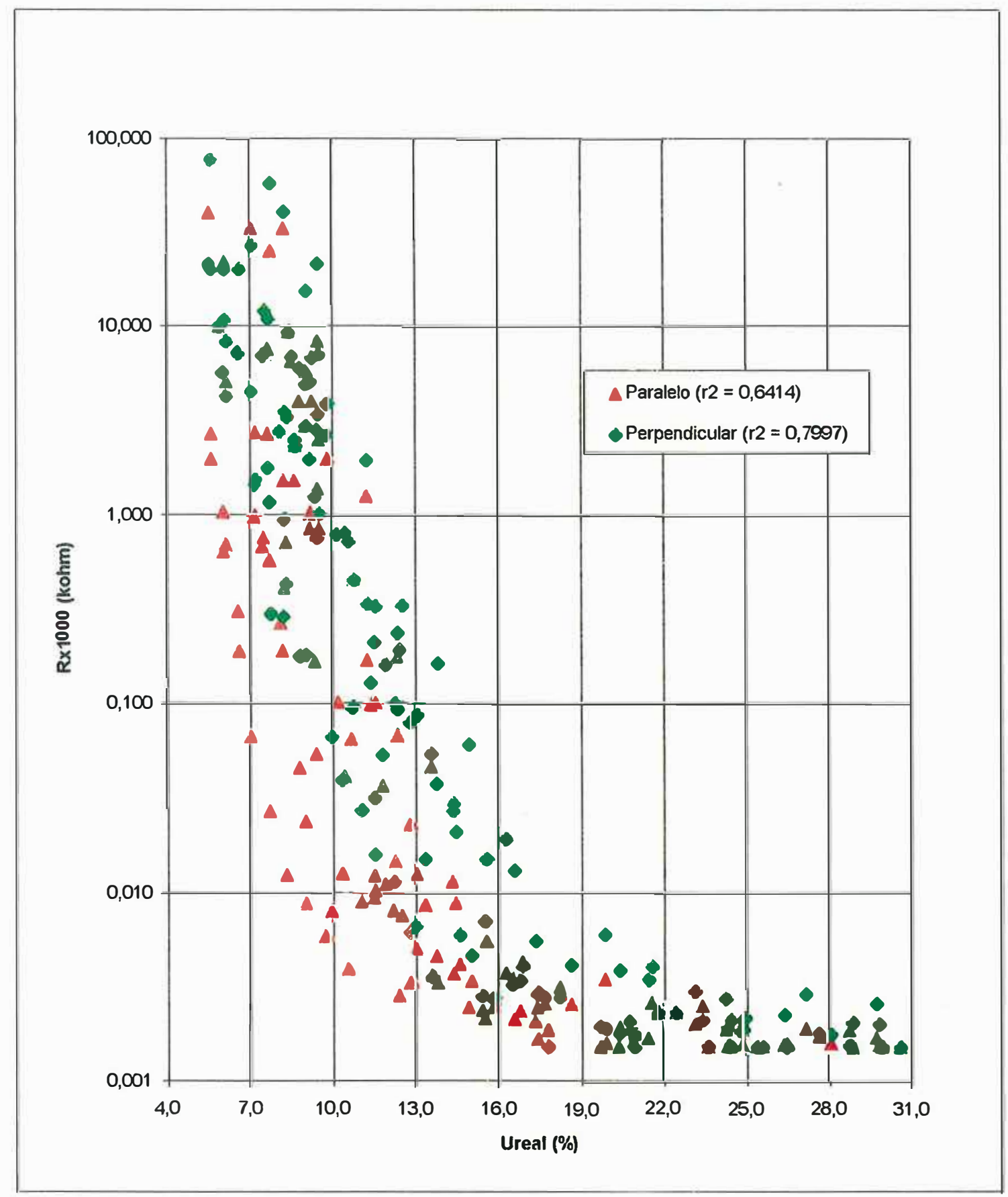

Anexo 18 : Variação da resistência elétrica, no sentido paralelo e perpendicular em relação a umidade para a madeira de Imbuia. 


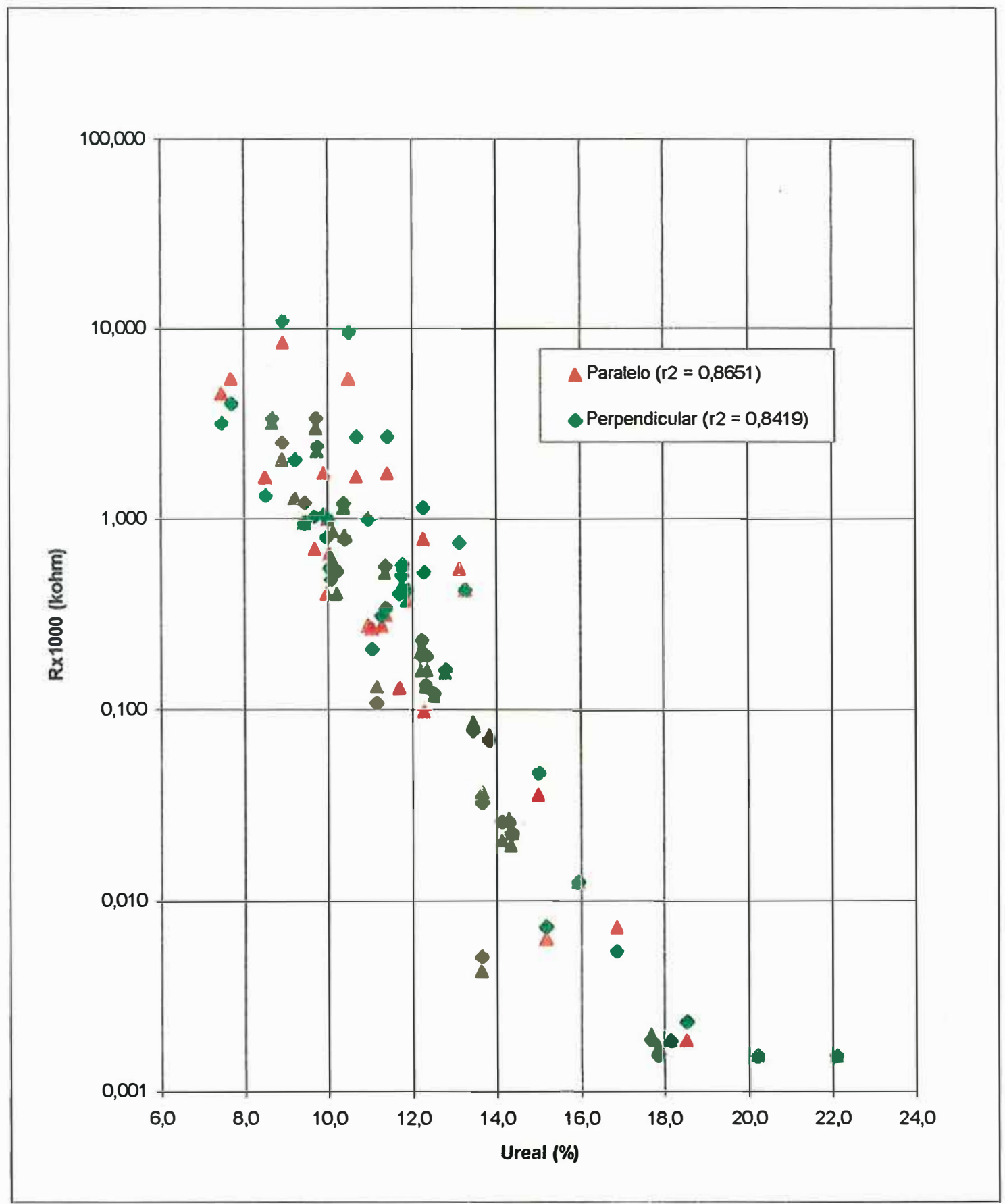

Anexo 19: Variação da resistência elétrica, no sentido paralelo e perpendicular em relação a umidade para a madeira de Ipê. 


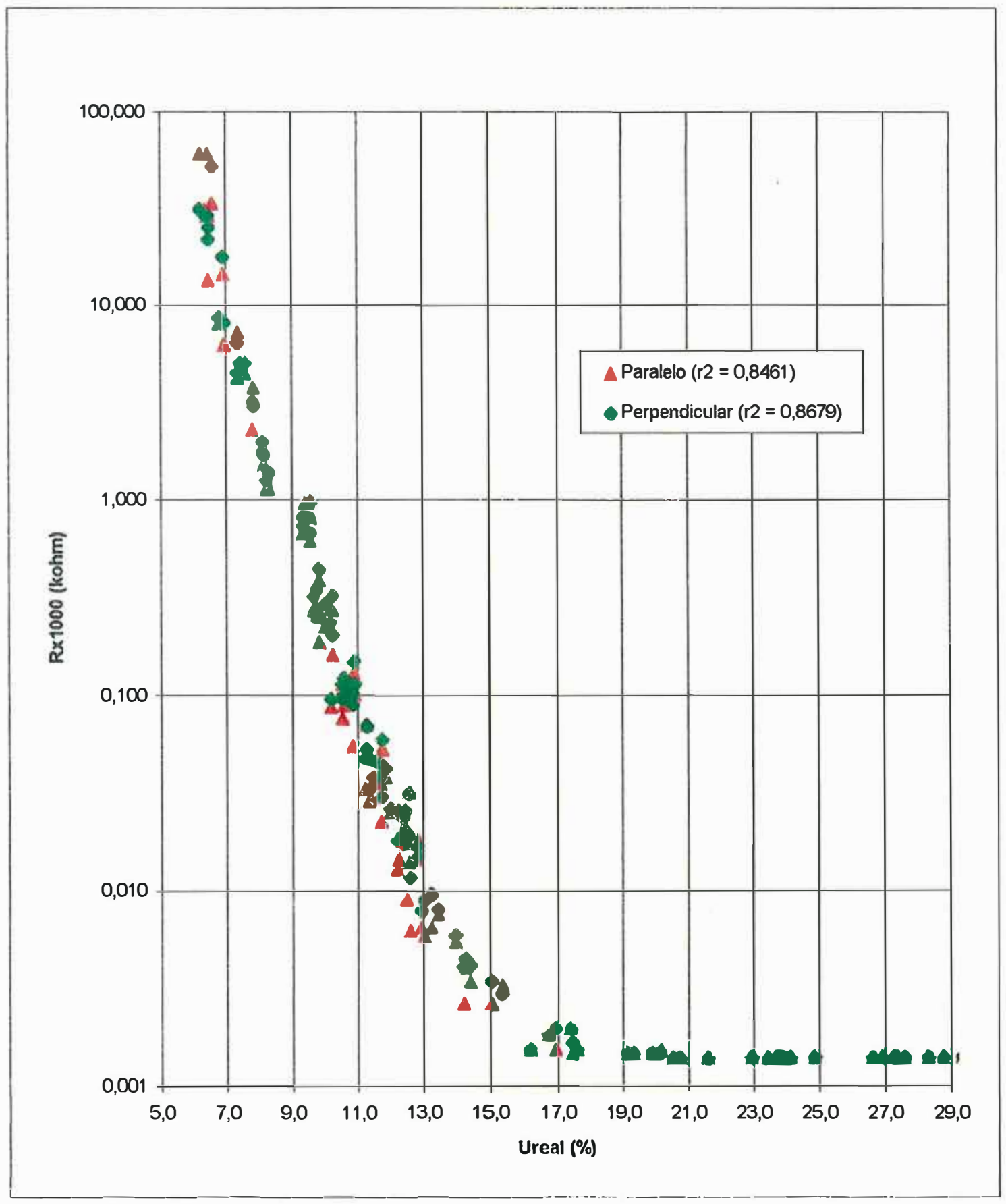

Anexo 20: Variação da resistência elétrica, no sentido paralelo e perpendicular em relação a umidade para a madeira de Jatobá. 


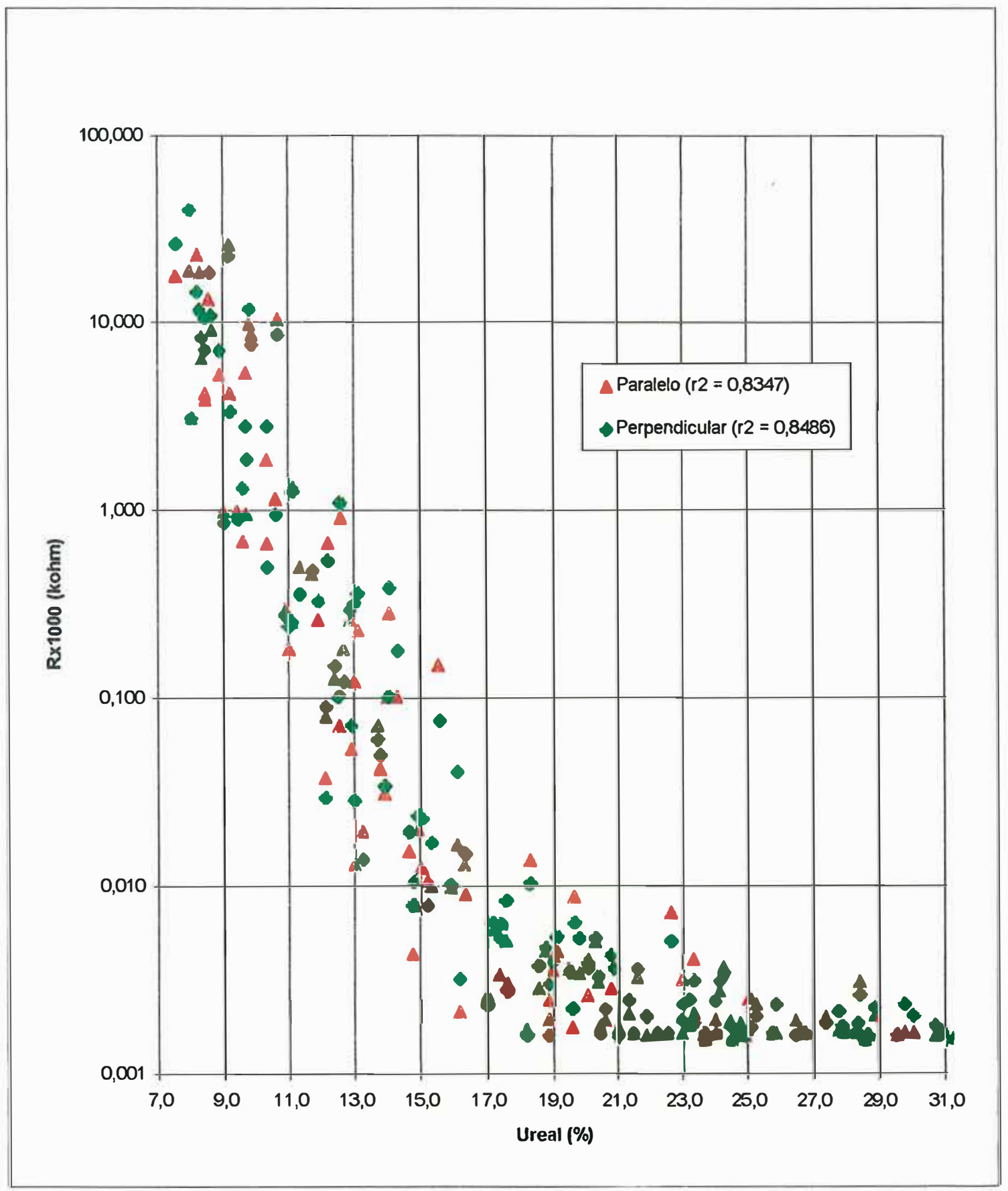

Anexo 21: Variação da resistência elétrica, no sentido paralelo e perpendicular em relação a umidade para a madeira de Louro vermelho. 


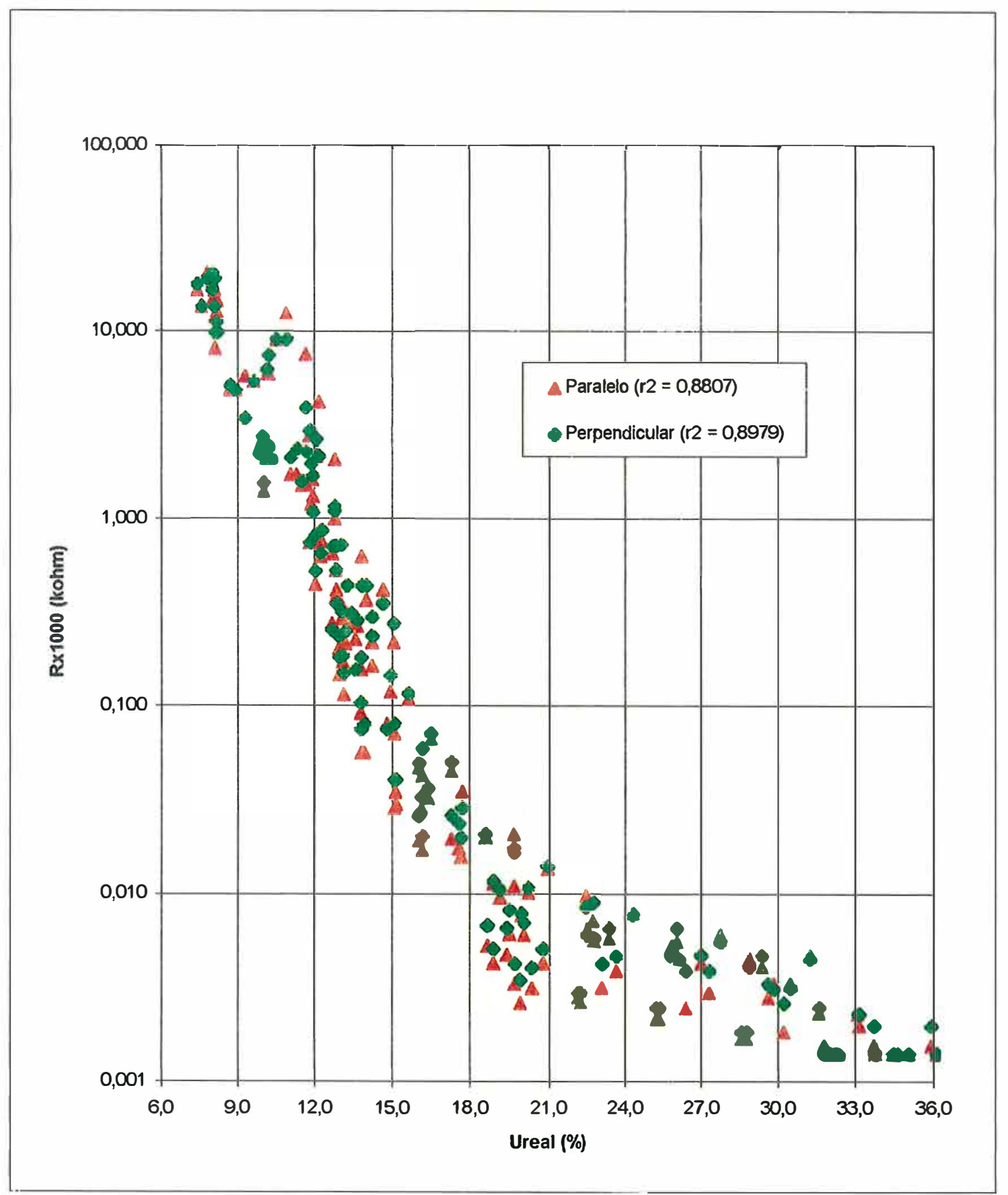

Anexo 22: Variação da resistência elétrica, no sentido paralelo e perpendicular em relação a umidade para a madeira de Marfim. 


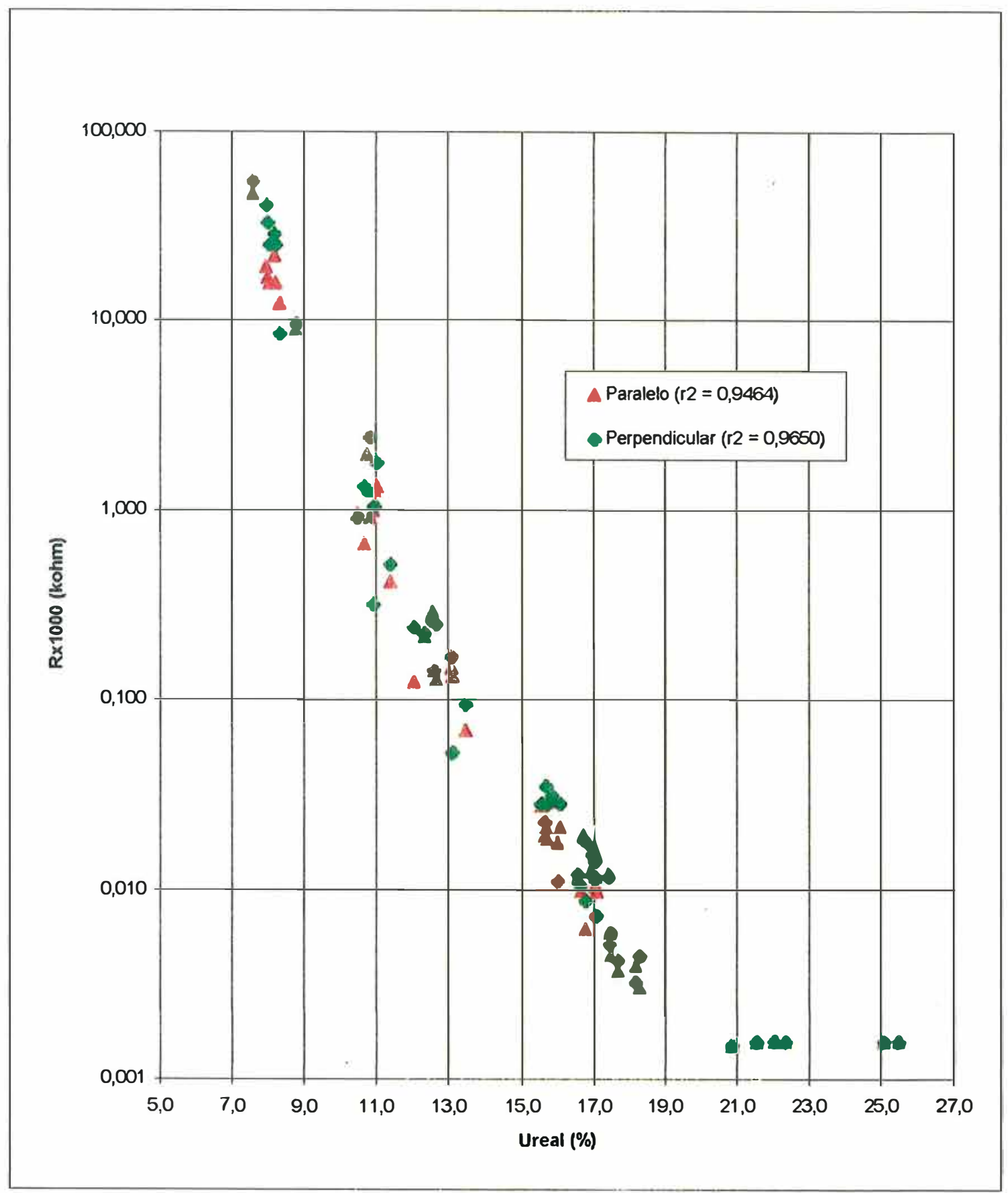

Anexo 23: Variação da resistência elétrica, no sentido paralelo e perpendicular em relação a umidade para a madeira de Marupá. 


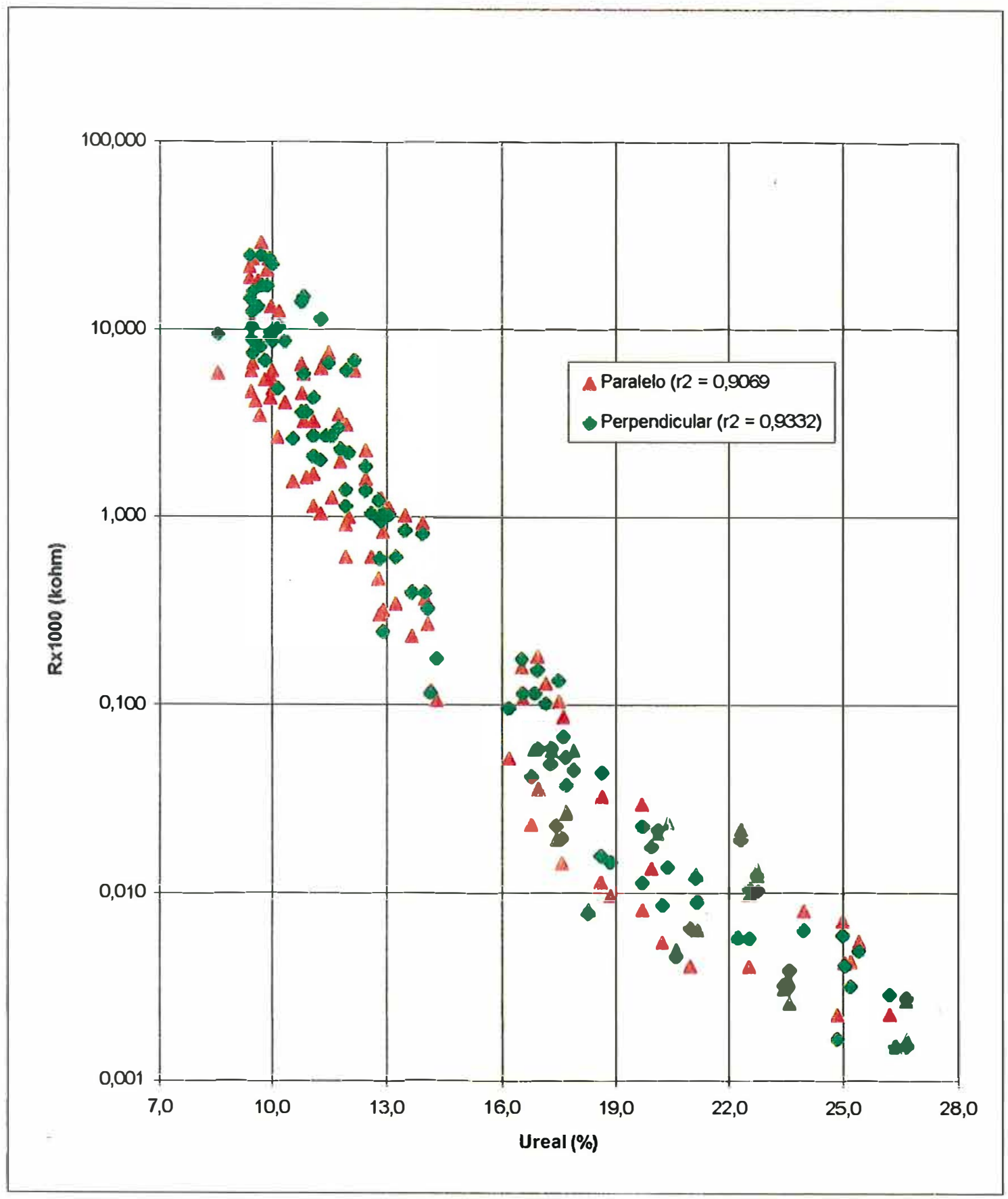

Anexo 24: Variação da resistência elétrica, no sentido paralelo e perpendicular em relação a umidade para a madeira de Muiracatiara. 


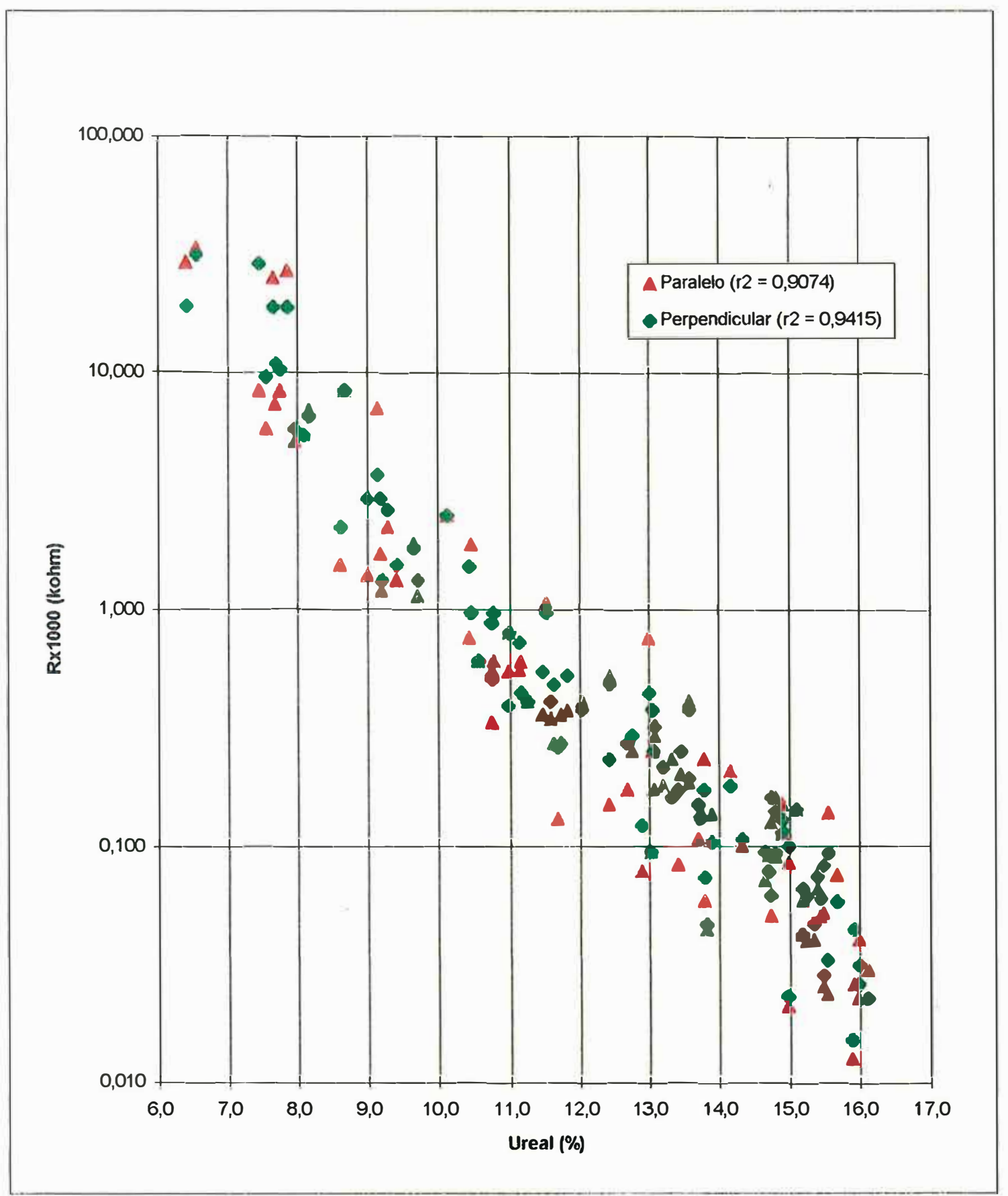

Anexo 25 : Variação da resistência elétrica, no sentido paralelo e perpendicular em relação a umidade para a madeira de Pau amarelo. 


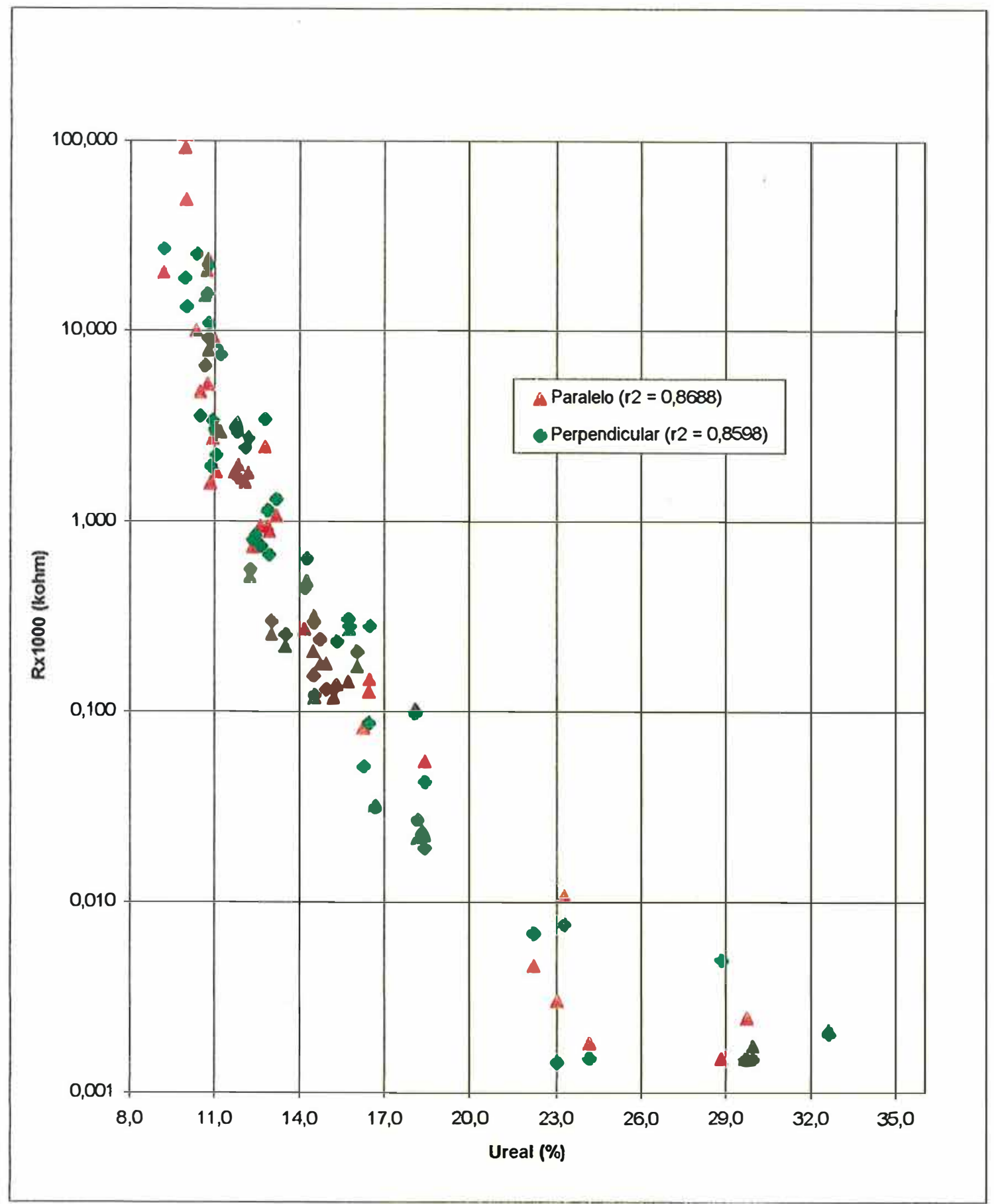

Anexo 26: Variação da resistência elétrica, no sentido paralelo e perpendicular em relação a umidade para a madeira de Pinus patula. 


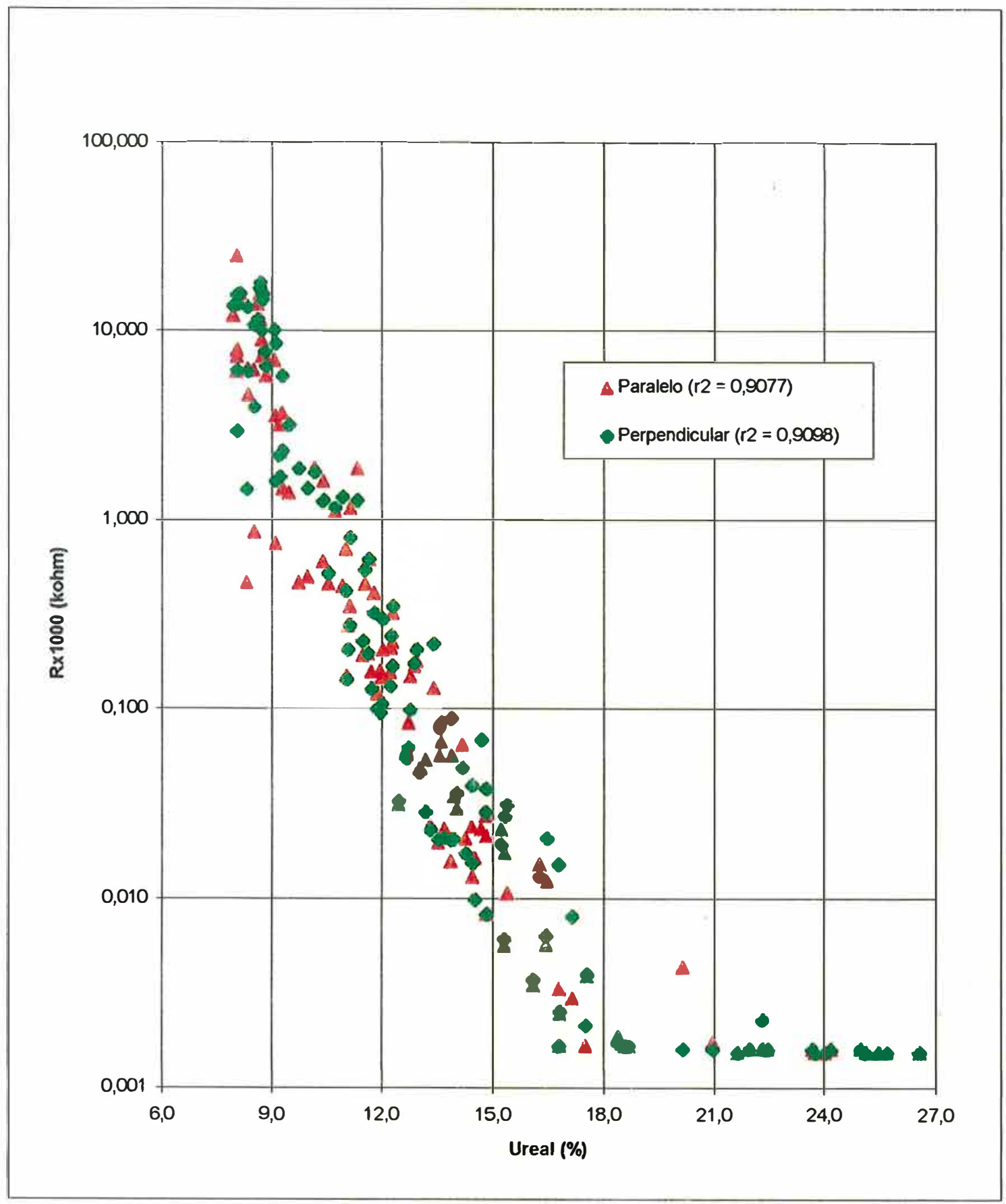

Anexo 27: Variação da resistência elétrica, no sentido paralelo e perpendicular em relação a umidade para a madeira de Quarubarana. 


\section{REFERÊNCIAS BIBLIOGRÁFICAS}

BITTNER, T. ; VANICEK, T. Continuous wood moisture measuring in frequency technology. In: IUFRO INTERNATIONAL WOOD DRYING CONFERENCE, 3., Vienna, 1992. Proceedings. Vienna: IUFRO Wood Drying Working Party, 1992. p. 338-343.

BURGER, L. M. ; RICHTER, H. G. Anatomia da madeira. São Paulo: Nobel, 1991. 154p.

CHEN, Z.; WENGERT, E. M. ; LAMB, F. M. A technique to electrically measure the moisture content of wood above fiber saturation. Forest Products Journal, v.44, n.9, p. 54-62, Sept.1994.

CONCHA, J. Medição do conteúdo de umidade pelo método de resistência elétrica. Revista da Madeira, v.24, n. 285, p. 32-34, Sept.1975.

DEAN, A. R. A pratical comparison of moisture determination by means of the oven drying method and the use of eletrical moisture meters. In: Building Research Estabilishment. Report of a seminar on moisture content determination of wood. s.e., 1972. p. 21-25. (Timberlab Papers, 24 - 1970).

DREINER, K. ; WELLING, J. Selftuning controllers for the kiln drying process. In: IUFRO INTERNATIONAL WOOD DRYING CONFERENCE, 3., Vienna, 1992. Proceedings. Vienna : IUFRO Wood Drying Working Party, 1992. p. 205-210.

GALVÃO, A. P. M. ; JANKOWSKY, I. P. Secagem racional da madeira. São Paulo: Nobel, 1985. 111p. 
HUY, V. R. Measurement of moisture content in resinous wood. In: SYMPOSIUM ON FOREST PRODUCTS RESEARCH INTERNATIONAL, Pretoria, 1985. Proceedings. Pretoria : Republic of South African, 1985. v.1, p. $16-20$.

JAMES, W. L. Eletrical moisture meters for wood. Madison : USDA, Forest Service, FPL, 1958. 18p.

JAMES, W. L. Calibration of eletric moisture meters for some wood species grown in Hawaii. Madison : USDA, Forest Service, FPL, $1964.26 p$. (Research Note).

JAMES, W. L. Eletric moisture meters for wood. Madison : USDA, Forest Service, FPL, 1975. 27p.

JAMES, W. L. The interaction of eletrode design and moisture gradients in dieletric measurements of wood. Wood and Fiber Science v.18, n.2, p. 264-275, 1986.

JAMES, W. L. Eletric moisture meters for wood. Madison : USDA, Forest Service, FPL, 1988. 17p. (USDA. General Technical Report FPL-GTR,6).

JAMES, W. L. Fundamentals of hand held moisture meters : an outline. In: ASTM WORKSHOP ON HAND - HELD MOISTURE METERS, Madison, 1993. Papers compiled by S.R.Warren. Madison, USDA, Forest Products Service, 1994. p. 13-16.

JANKOWSKY, I. P. Possibilidades de automação no controle do processo de secagem. Indústria Moveleira, n.91., p. 30-31,1989.

JANKOWSKY, I. P. Secagem de madeira de reflorestamento : técnicas e equipamentos. In: SEMINÁRIO SOBRE PROCESSAMENTO E UTILIZAÇÃO DE MADEIRAS PARA REFLORESTAMENTO, Curitiba. 1996. Anais. Curitiba: ABPM, 1996. p. 107-117.

JANKOWSKY, I. P. ; BRIENZA Jr., S. Determinação da umidade da madeira com medidores elétricos. Revista da Madeira n.344, p.12-16, Ago. 1980. 
JANKOWSKY, I. P. ; GALINA, I.C.M. Improving accuracy of resistance type moisture meter to improve drying control. In: IUFRO INTERNATIONAL WOOD DRYING CONFERENCE, 5., Quebec City, 1996. Proceedings. Quebec City : Forintek Canada Corp, 1996. p. 545-550.

JOHNSTON, D. D. Gravimetric and distillation methods of moisture content determination. In: Building Research Establishment. Report of a seminar on moisture content determination of wood. s.e., 1972. p. 1-3. (Timberlab Papers, 24 - 1970).

KOLLMANN, F. F. P. ; CÓTÉ Jr., W. A. Principles of wood science and technology. Berlin: Springer - Verlag, 1968. v.1, 592p.

KYTE, C. T. Resistance type moisture meters. In: Building Research Establishment. Report of a seminar on moisture content determination of wood. s.e., 1972. p. 5-7. (Timberlab Papers, 24 - 1970).

LIN, R. T. A study on the eletrical conduction in wood. Forest Products Journal, v.15 n.11, p. 506-514, Nov.1965.

LITTLE, R. L. ; MOSCHLER, W. W. ; TOENNISSON, R. L. Design of a computer based controller-recorder for an experimental dry kiln. Forest Products Journal, v.36, n.11/12, p 72-74, Nov./Dec.1986.

MALLQUE, M. A.; YOZA YOZA, L. ; GARCIA, A. Q. Determinacion de las propiedades electricas en seis maderas tropicales. Revista Forestal del Perú, v.18, n.1, p. 5-21, 1991.

MILOTA, M. R. Specific gravity as a predictor of species correction factors for a capacitance - type moisture meter. Forest Products Journal, v. 44 , n.3, p. 6368, Mar.1994.

MILOTA, M. R. Calibration os moisture meters for Western hardwood species. Forest Products Journal, v.46, n.1, p. 39-42, Jan.1996.

MILOTA, M. R. ; GUPTA, R. Moisture meter correction factors for Dahurian larch from the Russian Far East. Forest Products Journal, v.46, n.6, p. 91 93, June.1996. 
MORAES, R. M. de S. Determinação de curvas de correção para medidores elétricos de umidade para madeiras da Amazônia. Acta Amazonica, v.18 ,n.3/4 , p. 255-268, July.Dec.1988.

Norma ABCP : Associação Técnica Brasileira de Celulose e Papel. Densidade básica da madeira M14/70.

OLIVEIRA, L. C. ; WENGERT, E. M. High temperature drying of Southern Pine - Some theorical aspects toward better process control. In: NORTH AMERICAN WOOD DRYING SYMPOSIUM, Mississippi, 1984. Mississipi : Mississippi Forest Products Utilization Laboratory,1984. p 49-53.

PANSHIN, A. J. ; DE ZEEUW, C. Textbook of wood technology. 3. ed. New York: Mcgraw - Hill, 1970. v.1,705p.

PFAFF, F. ; GARRAHAN, P. New temperature correction factors for the portable resistance - type moisture meter. Forest Products Journal, v.36, n.3, p. 28-30, Mar.1986.

PONCE, R. H. ; WATAI, L. T. Manual de secagem da madeira. Brasília : STI/IPT, 1985. 70p.

QUARLES, S. L. ; MILOTA, M. R. Influence of kiln temperature and density on the performance of in - line moisture meters. Forest Products Journal, v.41, n.5, p. 61-65, May. 1991.

RASMUSSEN, E. F. Dry kiln operator's manual. Madison : USDA, 1961. Cap. 6, p. 99-111, kiln samples: USDA. Agriculture Handbook, 188.

SALAMON, M. Continuous moisture content determination during kiln., using eletric resistance techinique. Quebec: Forest Products Research Branch: Departament of Forest, 1964. 21p. (Department of Forestry Publication, 1091)

SAMUELSSON, A. Calibration curves for resistance - type moisture meters. In: IUFRO INTERNATIONAL WOOD DRYING CONFERENCE, 3., Vienna, 1992. Proceedings. Vienna : IUFRO Wood Drying Working Party, 1992. p. 405-408. 
SANTINI, E. J. Alternativas para o monitoramento e controle do processo de secagem de madeira serrada em estufa. Curitiba. 1996. 197p. Tese (Doutorado) - Universidade Federal do Paraná.

SIAU, J. F. Flow in wood. Syracuse: Syracuse University, 1971. 131p.

SIAU, J. F. Transport process in wood. Berlin : Springler - Verlag, 1984. 255p.

SIMPSON, W. T. Resistance moisture meter correction factors for tropical wood species. Madison: USDA, Forest Service, FPL, 1994. 6 p. (USDA. Research Note, FPL-RN-0260).

SIMPSON, W. T. ; BAAH, C. K. Grouping tropical wood species for kiln drying. Madison: USDA, Forest Service, FPL, 1989. 14p.

SKAAR, C. Water in wood. Syracuse: Syracuse University Press, 1972. 218p.

SKAAR, C. Wood : water relations. Berlin : Springler - Verlag, 1988. 293p.

STAMM, A. J. An eletrical conductivity method for determining the moisture content of wood. Industrial and Engineering Chemistry Analytical, v.2, n.3, p. 240-244, July. 1930.

VERMAAS, H. F. D.C. Resistance moisture meters for wood : part I - review of some fundamental considerations. South African Forestry Journal v.121, p. 88-92, June.1982a.

VERMAAS, H. F. D.C. Resistance moisture meters for wood : part II - the influence of temperature and moisture content on the resistance of two South African Pines. South African Forestry Journal, v.122, p. 70-81, Sept.1982b.

VERMAAS, H. F. D.C. Resistance moisture meters for wood : part III temperature correction of moisture meter readings for a proposed new moisture meter (calibrated for $20^{\circ} \mathrm{C}$ ) for $P$. pinaster e $P$. radiata and calibration equations for a commercial moisture meter. South African Forestry Journal, v.123, p. 63-71, Dec.1982c.

WENGERT, G. ; DENIG, J. Lumber drying : today and tomorrow. Forest Products Journal, v.45, n.5, p 22-30, May 1995. 
ZELENIUC, O. Dry kiln control system. In: IUFRO INTERNATIONAL WOOD DRYING CONFERENCE, 3., Vienna, 1992. Proceedings. Vienna : IUFRO Wood Drying Working Party, 1992. p. 317-322. 